\title{
Problematizing the photographic images of pedagogical documentation: A Foucauldian Analysis
}

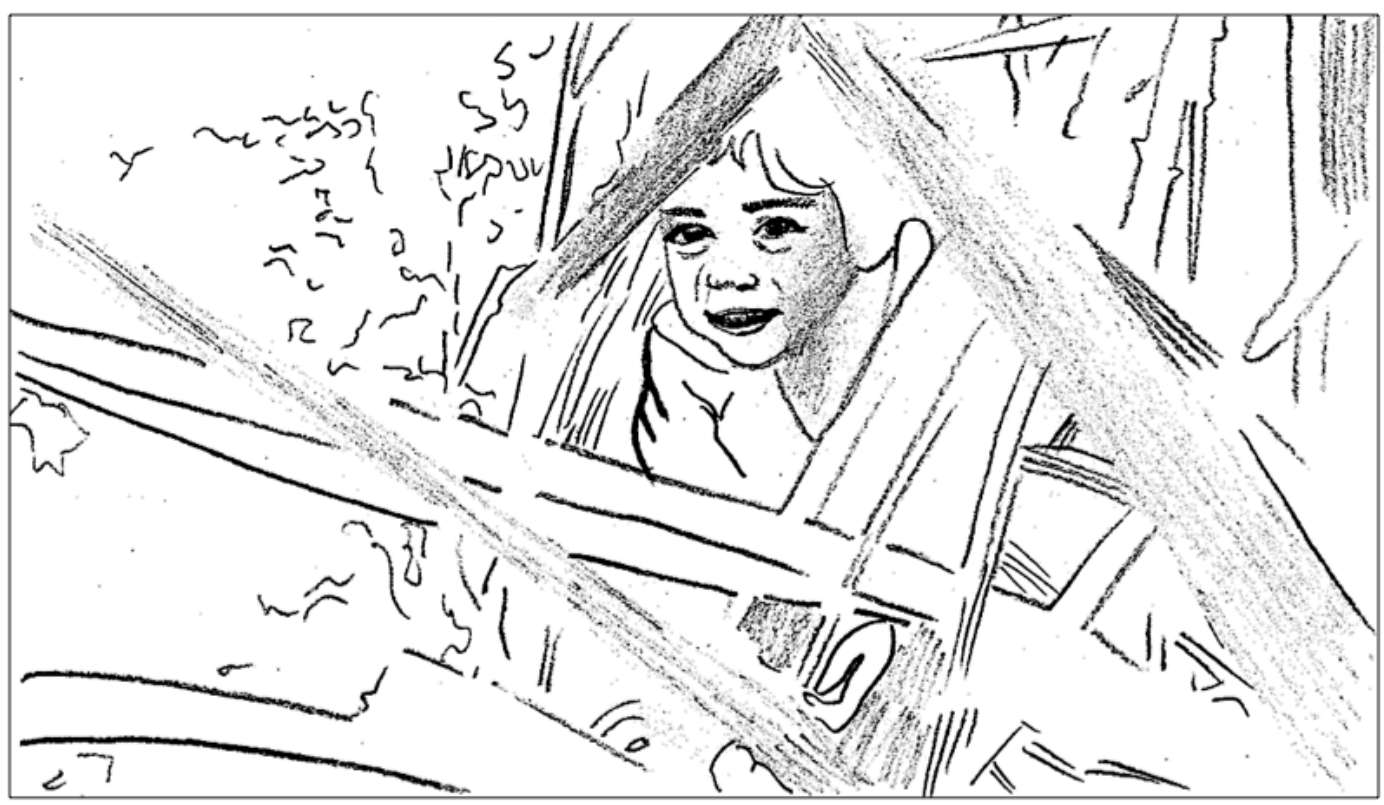

This is not a child.

\section{Daniel Patrick Whitaker}

A thesis submitted in partial fulfillment of the requirements for the degree of Master of Education

Victoria University of Wellington

February 2018 


\begin{abstract}
Photographic practices and the images they generate play a dominant role in documenting and assessing children's learning and development in the early childhood education environments of Aotearoa-New Zealand. In the context of pedagogical documentation these visual practices are predominantly enacted through the medium of digital photography, utilized both locally (through assessment documentation) and nationally (through various policy documents). My concerns are in regards to the normalizing and regulatory effects of such visual practices, and how the photographic image is implicated in the construction of particular subjectivities in diverse populations of young children. The revised Aotearoa-New Zealand early childhood curriculum, Te Whāriki (2017a) is the first iteration of the national document to include photographic images and thus presents a timely opportunity to engage with questions concerning this contemporary visual politic.
\end{abstract}

By means of addressing these concerns I work within a post-structural epistemological framework, drawing methodological insights from the philosophy of Michel Foucault and Gilles Deleuze/Félix Guattari. This Rhizomatic epistemology, inspired by both Deleuzio-Guattarian and Foucauldian scholarship, is an experimental mode of inquiry that acts to illuminate, resist and transgress dominant discursive constructs and the subjectivities they produce. Each chapter of this thesis takes the diffuse realm of photographic practices and processes of subjectivity in the context of education as their impetus, making linkages between texts, concepts and the child subject.

This thesis suggests that an entanglement of both neoliberal and 'psy' rationalities are constitutive of particular visual-discursive practices, which mutually serve individualizing ends and construct particular subjectivities at this point in history. These predominant discourses and the subjectivities they are productive of are perceived to be problematic on the grounds that they place burdensome levels of responsibility on the young citizen and act to erode other educational values such as collective responsibility and community. It is further 
suggested that these predominant discourses are problematic in the sense that they act to foreclose other ways of thinking and being in educational settings to the effect of limiting other possible subject-positions (thought or unthought) that both child and teacher might come to inhabit within these spaces. 


\section{Acknowledgements}

Firstly I would like to thank my supervisors, Maggie Haggerty and Judith Loveridge. I am particularly appreciative of their enthusiasm and openness towards this topic and the space they allowed for uncertainty as we grappled with the possible directions of this work. The insights gleaned from numerous lengthy conversations with both Judith and Maggie and their patience and kindness around my various ramblings were fundamental to what this work eventually became. I would also like to thank my partner, Emma, both for her ceaseless support of my academic pursuits and for her artistry in the context of this work. Thanks to her deft, empathetic renderings of various photographic images this work was able to proceed, allowing me to circumvent arbitrary copyright constraints and achieve what I set out to do. I would also like to thank the many children I have had the privilege of working with over the past few years. I am particularly grateful for the way in which these children have encouraged me to think, be and act differently as a teacher and post-graduate student within the frame of early childhood education. 


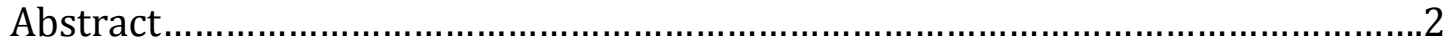

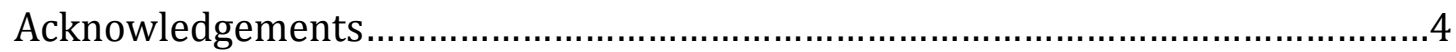

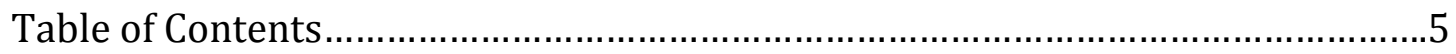

Terminological clarifications........................................................................

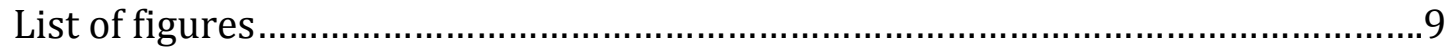

Chapter 1: Introduction ..........................................................................1

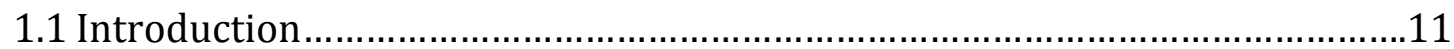

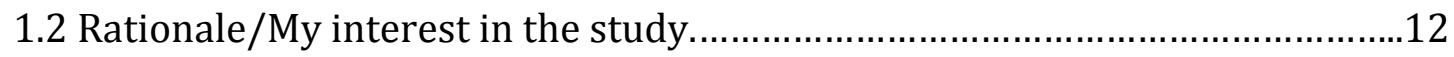

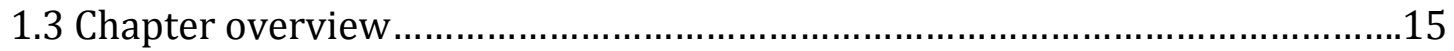

1.4 The sanctity of the photographic image/Copyright hurdles...........................18

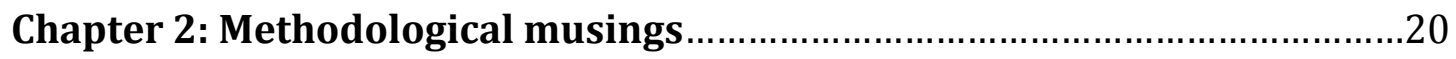

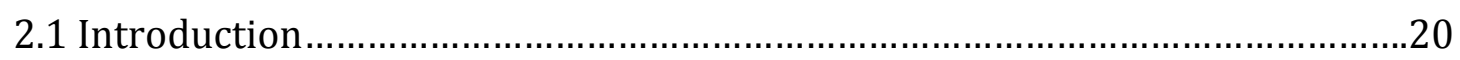

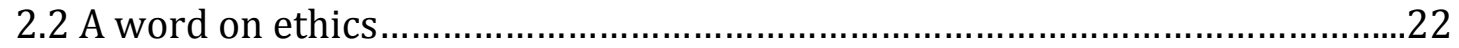

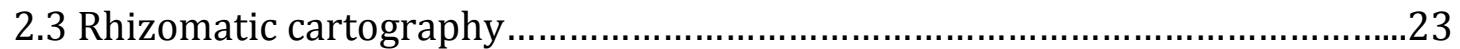

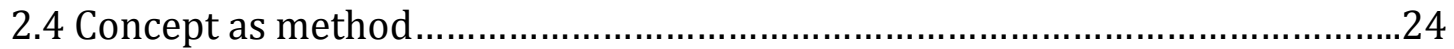

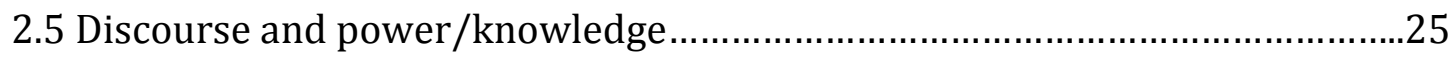

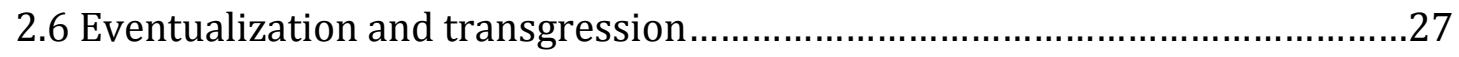

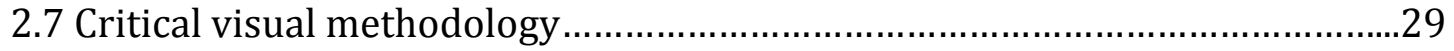

2.8 Visual discourse analysis.........................................................................

2.9 Putting the concept to work: contextualizing methodological nuances across

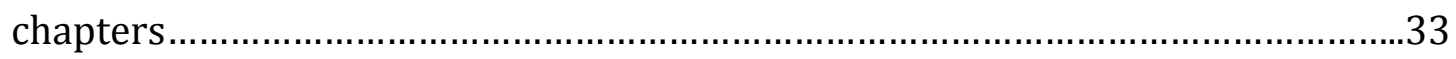

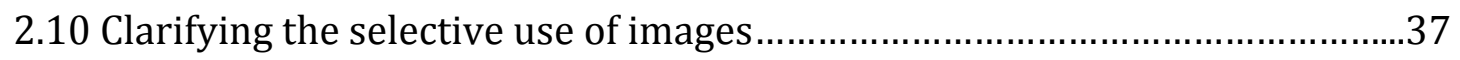

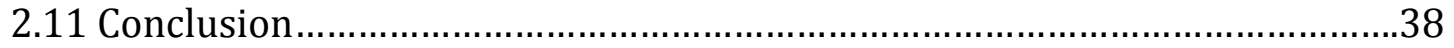

Chapter 3: Visual culture and the 'myth of photographic truth' .....................39

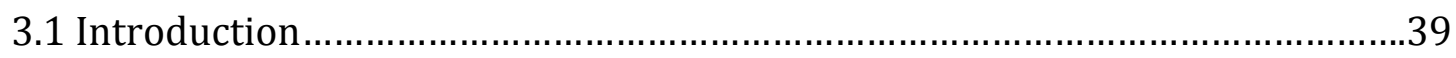

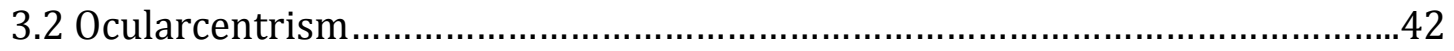

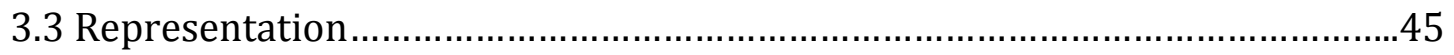




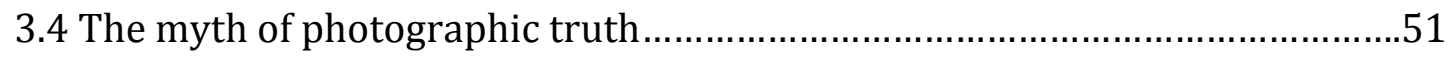

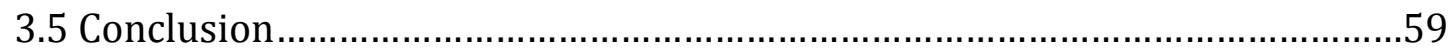

Chapter 4: Producing governable subjects through visual discourse: the child as an isolated, autonomous and competent individual......................61

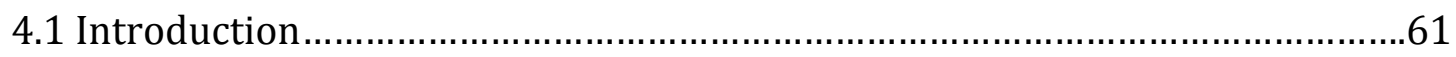

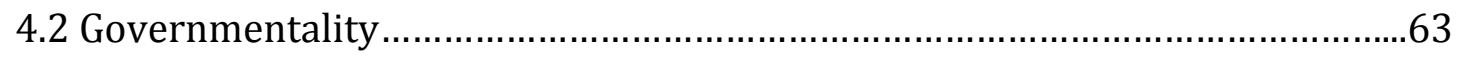

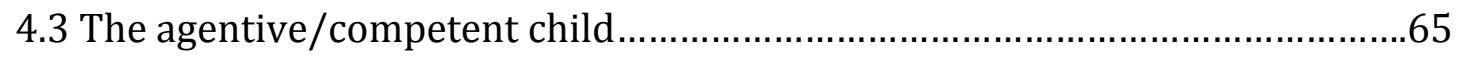

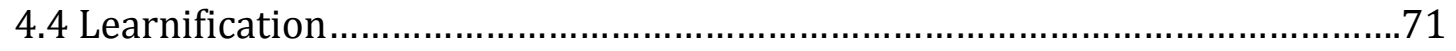

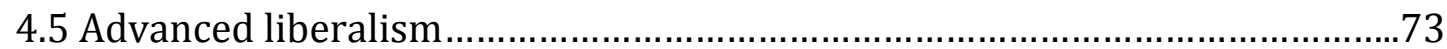

4.6 Consumption and Psychotherapeutics......................................................

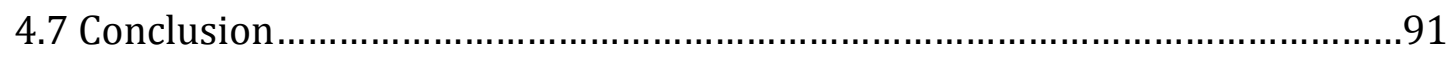

Chapter 5: Disciplining human difference: the child inscribed in 'psy' visual

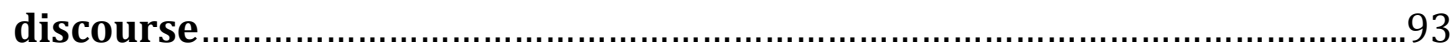

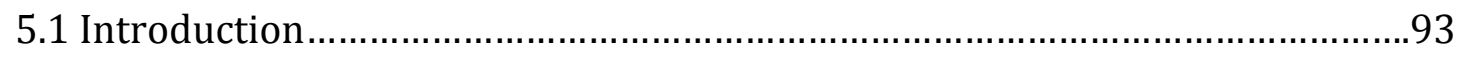

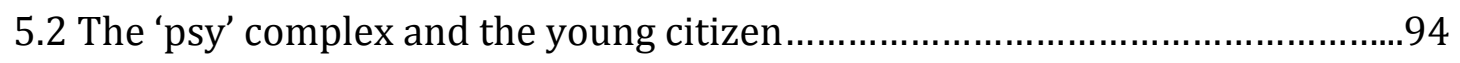

5.3 'Psy' discourse and the child conceptualized as a human 'becoming' ...........109

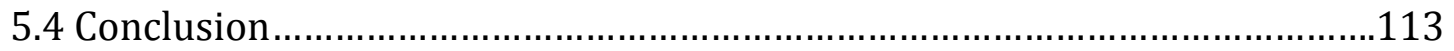

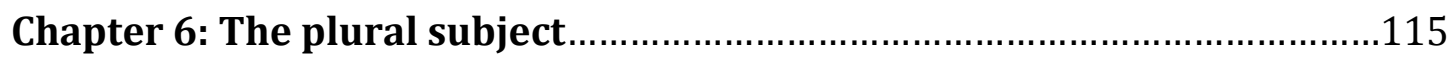

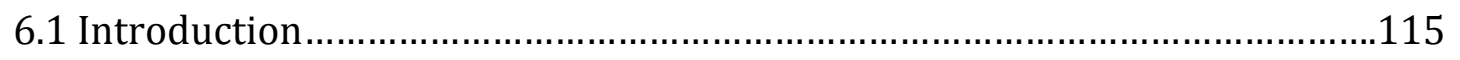

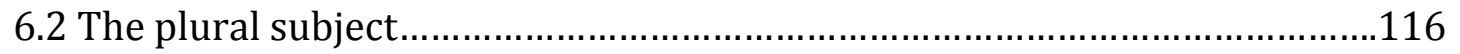

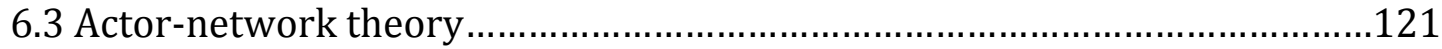

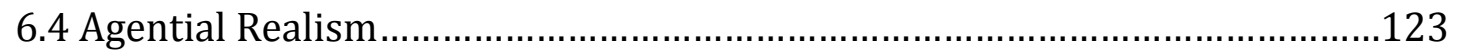

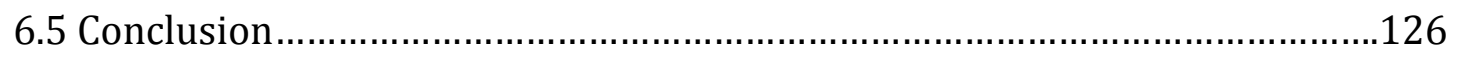

6.6 Final thoughts: towards the ethical task of re-imaging being ......................127

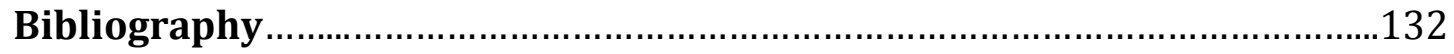




\section{Terminological clarifications}

\section{Rationalities:}

In the context of this thesis I employ the term rationalities as conceptualized in the work of Nikolas Rose (1999) and Michel Foucault (1991b). Foucault (1991b) discussed rationalities as both instrumental and relative to particular historical circumstances. For example, Foucault (1991b) states that the ceremony of public torture is not in itself "more irrational than imprisonment in a cell; but it's irrational in terms of a type of penal practice which involves new ways of envisioning the effects to be produced by the penalty imposed, new ways of calculating its utility, justifying it, graduating it" (p. 79). Significantly, this conceptualization of rationality is not about assessing phenomenon against some predetermined absolute/truth, "but rather examining how forms of rationality inscribe themselves in practices or systems of practices, and what role they play within them, because it's true that 'practices' don't exist without a certain regime of rationality" (Foucault, 1991b, p. 79).

\section{Assemblage:}

I use the term assemblage as conceptualized by Deleuze and Guattari (1988; 1994). The English word assemblage is the common translation of the French word agencement, which Deleuze and Guattari employ in their work. Nail (2017) points out the problems inherent in this translation on the grounds that each term comes from different etymological roots: "agencement comes from the verb agencer, to arrange, lay out, to piece together... The meaning of the English word assemblage is the joining or union of two things or a bringing or coming together" (p. 22). It is important to consider the dissonances in this translation as an arrangement or laying out is significantly different than a unity or coming together. Nail (2017) suggests that the important philosophical point to take away from this problematic translation is that English readers of Deleuze and Guattari should disassociate their understanding of the English word assemblage from the concept of agencement. In this sense I employ the concept of assemblage as a tool for thinking about arrangements and layouts of 
heterogeneous elements in relation to the questions and problems I foreground in my work. I cannot do justice to the complexities of this concept within the scope of this work due to space restraints (see Nail, 2017 for a comprehensive discussion of the concept of assemblage), however I have found an engagement with this conceptual framework (however limited) to be useful and formative, which I believe is reflected within the frame of this thesis.

\section{Entanglement:}

I work with an understanding of entanglement as conceptualized by Karen Barad (2007). Haggerty and Loveridge (2017) explain that Barad (2007) "uses entanglement to refer to the way that phenomena, practices, events and individuals... not only become relationally intertwined but 'iteratively reconfigured through intra-action" (p. 3). Within the frame of this thesis I do not offer a comprehensive discussion of the concept of entanglement (see Barad, 2007 for this). Rather, I use the concept of entanglement as a tool to explore the ways in which various individualizing and normalizing discourses of the child are always in the process of becoming something new/different and thus should not be understood as distinct or siloed sets of statements and practices but, rather, as assemblages that fuse in messy ways and that intra-act and transform over time. 


\section{List of Figures}

Figure 1. René Magritte, The Treachery of Images, created circa 1928 (as cited in Sturken \& Cartwright, 2001, p. 15).

Figure 2. (Ministry of Education, 2017a, p. 6).

Figure 3. (Ministry of Education, 2017a, p. 6).

Figure 4. (Ministry of Education, 2017a, p. 31).

Figure 5. (Ministry of Education, 2017a, p. 46).

Figure 6. (Ministry of Education, 2017a, p. 46).

Figure 7. Screen shot taken from a 'Samsung' advert entitled 'The New Normal.

(n.d). Retrieved from

https://www.google.co.nz/search?q=samsung+the+new+normal\&rlz=1C 5ACMI_enNZ519NZ599\&oq=samsung+the+new+\&aqs=chrome.1.69i57j01

5.5711j0j7\&sourceid $=$ chrome \&ie $=$ UTF-8

Figure 8. (Ministry of Education, 2017a, p. 6).

Figure 9. (Ministry of Education, 2017a, p. 20).

Figure 10. (Ministry of Education, 2017a, p. 17).

Figure 11. (Ministry of Education, 2017a, p. 31).

Figure 12. (Ministry of Education, 2017a, p. 31).

Figure 13. (Ministry of Education, 2017a, p. 46).

Figure 14. (Ministry of Education, 2017a, p. 46).

Figure 15. (Ministry of Education, 2017a, pp. 28-29, 33-34, 38-39, 43-44, 48-49).

Figure 16. (Ministry of Education, 2017a, pp. 28-29, 33-34, 38-39, 43-44, 48-49).

Figure 17. (Ministry of Education, 2017a, pp. 28-29, 33-34, 38-39, 43-44, 48-49).

Figure 18. (Ministry of Education, 2017a, p. 20).

Figure 19. 'Children in advertising'. (n.d). Retrieved from

https://www.google.co.nz/search?q=children+in+advertising\&rlz=1C5AC MJ_enNZ519NZ599\&source=lnms\&tbm=isch\&sa=X\&ved=0ahUKEwj7vaK nsLDZAhWDi7wKHXWLBR8Q_AUICigB\&biw=1187\&bih=655

Figure 20. (Ministry of Education, 2017a, p. 46).

Figure 21. 'Children in advertising'. (n.d). Retrieved from 
https://www.google.co.nz/search?q=children+in+advertising\&rlz=1C5AC MI_enNZ519NZ599\&source=lnms\&tbm=isch\&sa=X\&ved=0ahUKEwj7vaK nsLDZAhWDi7wKHXWLBR8Q_AUICigB\&biw=1187\&bih $=655$

Figure 22. (Ministry of Education, 2017a, p. 17).

Figure 23. 'Children in advertising'. (n.d). Retrieved from

https://www.google.co.nz/search?q=children+in+advertising\&rlz=1C5AC MI_enNZ519NZ599\&source $=\operatorname{lnms\& tbm=isch\& sa=X\& ved=0ahUKEwj7vaK}$ nsLDZAhWDi7wKHXWLBR8Q_AUICigB\&biw=1187\&bih=655

Figure 24. (Ministry of Education, 2017a, p. 31).

Figure 25. 'Children in advertising'. (n.d). Retrieved from

https://www.google.co.nz/search?q=children+in+advertising\&rlz=1C5AC

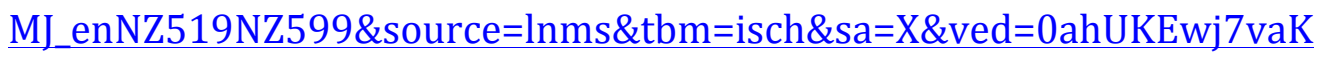
nsLDZAhWDi7wKHXWLBR8Q_AUICigB\&biw $=1187 \&$ bih $=655$

Figure 26. (Ministry of Education, 2017a, p. 46).

Figure 27. Arnold Gesell in his laboratory (as cited in Rose, 1990, p. 143).

Figure 28. Arnold Gesell, The first five years of life (as cited in Rose, 1990, p. 145).

Figure 29. (Ministry of Education, 2017a, p. 6).

Figure 30. (Ministry of Education, 2017a, pp. 28-29, 33-34, 38-39, 43-44, 48-49).

Figure 31. (Ministry of Education, 2017a, p. 31).

Figure 32. (Ministry of Education, 2017a, pp. 28-29, 33-34, 38-39, 43-44, 48-49).

Figure 33. (Ministry of Education, 2017a, p. 20).

Figure 34. (Ministry of Education, 2017a, pp. 28-29, 33-34, 38-39, 43-44, 48-49).

Figure 35. (Ministry of Education, 2017a, p. 31).

Figure 36. (Ministry of Education, 2017a, pp. 28-29, 33-34, 38-39, 43-44, 48-49).

Figure 37. (Ministry of Education, 2017a, pp. 28-29, 33-34, 38-39, 43-44, 48-49).

Figure 38. (Ministry of Education, 2017a, pp. 28-29, 33-34, 38-39, 43-44, 48-49).

Figure 39. (Ministry of Education, 2017a, pp. 28-29, 33-34, 38-39, 43-44, 48-49).

Figure 40. (Ministry of Education, 2017a, pp. 28-29, 33-34, 38-39, 43-44, 48-49).

Figure 41. (Ministry of Education, 2017a, pp. 28-29, 33-34, 38-39, 43-44, 48-49).

Figure 42. Girl and sand in sandbox (as cited in Hultman \& Lenz Taguchi, 2010, p. $528)$. 


\section{Chapter 1: INTRODUCTION}

\subsection{Introduction}

Photographic practices and the images they are generative of play a dominant role in documenting and assessing children's learning and development in the early childhood education environments of Aotearoa-New Zealand. In the context of pedagogical documentation these visual practices are predominantly enacted through the medium of digital photography, utilized on both a local level within early childhood education settings (through assessment documentation) and a national one (through various policy documents). My concerns are in regards to the normalizing and regulatory effects of such visual practices, and how the photographic image (understood as a visual-discursive statement/practice) is implicated in the construction of particular subjectivities in diverse populations of young children.

By means of addressing these concerns I work with a Foucauldian conceptualization of discourse and power. In the context of this work discourse is understood as both a set of statements that structure the way in which a thing can be thought (Rose, 2001) and specific practices that systematically form the objects of which they speak (Foucault, 1977, as cited in Barad, 1998). Power is understood, not in negative terms, such that it 'represses', 'censors', or 'conceals', but rather in terms of its productive capacity and function: power "produces reality; it produces domains of objects and rituals of truth" (Foucault, 1977, p. 194). I augment Michel Foucault's theoretical and methodological perspectives with insights gleaned from a discipline loosely categorized as 'visual culture studies' and broader philosophical literature concerned with questions of representation. I also put to work the philosophical perspectives of Gilles Deleuze/Félix Guattari and methodological insights assembled from the emergent body of literature loosely categorized as 'New Empiricism' (Lenz Taguchi, 2016; Lather, 2013). The revised Aotearoa-New Zealand curriculum, Te Whāriki (2017a), is the first iteration of the document to include photographic 
images and presents a timely opportunity to engage with the complexities inherent in the visual politic of this reformed national syllabus. In this thesis I explore the notion that a significant number of visual representations of children present in the revised Te Whāriki (2017a) document resonate strongly with predominant (individualizing and normalizing) contemporary discourses of the child and thus might be understood to constitute a visual discourse in which competence and self-reliance is a dominant theme. The decision to include the particular series of photographic images that are present in the revised Te Whāriki (2017a) document is clearly a deliberate decision made by those responsible for its revision and therefore can be considered as a kind of visual politics.

In the context of this thesis visual politics can be understood as a discursive practice that plays a central role in forming our understanding of children within a particular institutional setting. Through an exercise that consists of exploring the parallels/resonances between the visual-discursive construction of the child and broader relations of power I suggest that the intensive focus on the individual child through the visual medium of photography can be understood in terms of its relationship to, and contribution towards, wider governance practices of the late modern neoliberal disciplinary state. It is further suggested that the advanced liberal rationalities and the individualizing discourses they instantiate coalesce powerfully with those of the 'psy' sciences, which can be observed in particular photographic techniques present in the revised Te Whāriki (2017a) document. In this respect I conclude that the entanglement of both 'psy'-based and advanced liberal associated discourses of the child are, at least in part, productive of a particular kind of educated subject, and that the photographic image making practices of pedagogical documentation are implicated in the assemblage of rationalities that inform these diffuse discursive practices in significant ways.

\subsection{Rationale/My interest in the study}

As a student of education, and now an early childhood teacher in my third year of practice, I find myself engaged with what might be described as an 'ethic of 
resistance' towards the photographic practices of pedagogical documentation, an ethic which now informs the direction of my post-graduate study. Lenz Taguchi (2009) describes an ethic of resistance in the following way:

An ethic of resistance refers to the conscious act of thinking deeply about the assumptions we bring with us (often without awareness) as we engage in our daily work with children. As we practice an ethic of resistance we deconstruct, or take apart, what we "know to be true," to reflect on it, analyze it, criticize it, and resist its seductive powers arising from its familiarity (p. 259).

My skepticism towards the photographic practices of early childhood education environments began over the course of my practicum experiences as a student of education in 2015. I was moved by what I observed as the centrality of both camera and photographic image to the daily practices of the early childhood teacher. I felt inundated with visual representations of children and the pervasiveness of these practices would often strike me as somewhat surreal. I often observed teachers removing themselves from seemingly meaningful and connected encounters with children to find a camera and document the moment. At times the direction of children's play seemed to sway in response to the presence of the camera. The event or episode being documented then seemed to take on a performative element. In this way I started to consider in what ways photographic practices were productive of particular behaviors/subjectivities in young children, which opened up a philosophical space in which to consider the unacknowledged effects of this particular mode of visual representation and what it demands of bodies in space.

I also started to have concerns around what I perceived to be the reductive nature of photographic image making practices in the context of pedagogical documentation. That is to say I often observed individual children being imaged in a way that isolated them from the complexities of the wider environment, framing them, as I perceived it at least, as individual units whose individual actions would later be made sense of in relation to the various learning outcomes of the national syllabus. In this sense I started to have concerns around how 
photographic practices might be entangled within the broader political programs of a free market orientated society. Of particular concern was how rarely I observed teachers being 'captured' in the photographic images of pedagogical documentation (an obvious effect of the fact that the teacher is often the photographer in this context). In this respect I wondered how educational values such as interconnectedness and collective responsibility were being represented through these visual practices and how the individualizing/objectifying gaze of the pedagogue might be operating in such a way as to erode such values.

My interest in this area of inquiry is also informed by my undergraduate study in the field of cultural anthropology, specifically the subject matter of a visual anthropology paper I was engaged with in my final year (see Barthes, 1981; Sturken and Cartwright, 2001; Benjamin, 2008). As I started to elaborate on the above concerns through short pieces of writing I found myself returning to the course reader of this particular paper, which gave shape to an emerging ethical concern related to what I had started to consider as the othering of children through the photographic practices of pedagogical documentation. Through my previous engagement with the field of visual anthropology I had a sense of the troubled, often violent, history of photographic practices. For example, photography has been employed to explore the 'otherness' of particular groups of people, "to classify body types of criminals, document race types, categorize pathology and deviance in human subjects, and has been used for regulation, categorization and surveillance" (Kind, 2013, p. 427; Sturken \& Cartwright, 2009). Navab (2001) comments upon the inherent violence built into the language of photography - we take photos, capture and expose images, embark on a photo shoot, utilize point and shoot cameras. Susan Sontag (1978) provocatively associates the act of photographing another with murder when she writes:

There is something predatory in the act of taking a picture. To photograph people is to violate them, by seeing them as they never see themselves, by having knowledge of them they can never have; it turns people into objects that can be symbolically possessed. Just as the camera is a sublimation of the gun, to photograph someone is 
a sublimated murder - a soft murder, appropriate to a sad, frightened time (p. 10).

Meditating on these ideas I felt, as a recently graduated early childhood teacher, that there was much being taken-for-granted and assumed concerning the way in which we image children within the context of pedagogical documentation and the diffuse sphere of early childhood in general. In this spirit I set out to breach some of these assumptions and worked towards bringing attention to the unacknowledged power of photographic practices at this particular point in history.

An initial question that formed around these concerns and which acted to loosely direct the movements of my research was: what is being produced, constructed or articulated through the photographic practices of pedagogical documentation that, with some consistency (but not exclusively), frames the child through the medium of digital photography as an isolated individual?

\subsection{Chapter overview}

In chapter two (methodological musings) I draw attention to the tension and curiosity that emerged for myself as a researcher as I engaged with both poststructural and what has been termed 'New Empirical' (Lather, 2013) perspectives in relation to my topic. I foreground the central concepts and methodological nodes that formed in response to my unease around working with a systematic or procedural methodological approach to the visual material of interest. A further aim of this chapter is to orientate the reader around the spirit in which this kind of empiricism (New Empirical/post-qualitative) is practiced and to contextualize the methodological nuances of each chapter in relation to this empirical mode.

In chapter three (visual culture and the myth of photographic truth) I engage with the question: why does a study concerned with the critical examination of photographic images matter? In seeking an answer to this question I explore a body of literature loosely categorized as 'visual culture studies' (Rose, 2014) and 
broader philosophical perspectives concerning representation that surround this particular area of inquiry. The central aim of this chapter is to problematize the assumption that photographic images represent reality in a benign or objective manner, stressing the idea that photographic inscriptions should instead be considered as mediated representations of reality. I suggest that if we come to understand photographic images as mediated representations of reality we can begin to consider how visual mediums can be used to both exert and act as instruments of power. In this sense I propose that an examination of the unacknowledged power of the photographic image can be activated through an engagement with the Foucauldian conceptualizations of discourse and power.

In chapter four (producing governable subjects through visual discourse) I employ the thinking of Michel Foucault and Nikolas Rose to explore the links/resonances between the visual-discursive construction of the child and broader relations of power. Most significantly, the competent/agentive visualdiscursive construction of the child is discussed in relation to what Nikolas Rose (1999) terms advanced liberalism and, more specifically, the entrepreneurial selfhood that this assemblage of rationalities demands of the (post) modern individual. Various iterative contemporary discourses of the child are outlined including the competent child, learnification, priority learner, performativity and broader rights-based discourses. It is suggested that particular visual representations of children present in the revised Te Whāriki (2017a) document resonate strongly with these contemporary discourses of the child and thus constitute a visual discourse in which competence and agency is a dominant theme. It is further suggested that this assemblage of contemporary multi-modal discourses can be understood to resonate strongly with the interests of a free market orientated/neoliberal society and the subsequent entrepreneurial subjectivities such a system of governance demands of the social subject. These discourses are perceived to be problematic in the sense that they place burdensome levels of responsibility on young children and act to erode other educational values such as interconnectedness and collective responsibility. It is concluded that the intensive focus on individual children through the visual medium of photography is related to (and contributes towards) wider 
governance practices of the late modern neoliberal disciplinary state. In the context of this work I use the terms neoliberalism and advanced liberalism interchangeably and synonymously to demarcate an identifiable but heterogeneous form of modern governance (Dean, 2014) under which "the 'social state' gives way to the 'enabling state'” (Rose, 1999, p. 42).

In chapter five (disciplining human difference) the central aim remains the same as chapter four: to explore the links/resonances between the visualdiscursive construction of the child and broader relations of power. However, the rationalities of interest shift from those of neo/advanced liberal forms of government to those of the 'psy' sciences. In this chapter I consider how the psysciences (specifically developmental psychology) and the visual discourse this body of knowledge instantiates is caught up in the assemblage of rationalities that construct the young educated subject at this particular point in history. It is suggested that mainstream 'psy'-based discourses coalesce powerfully with the neo/advanced liberal discourses explored in chapter four as they both construct a concept of the child as a bounded, autonomous and individualized agent. I suggest that particular photographic conventions present in the revised Te Whāriki (2017a) document resonate strongly with those established through the discipline of developmental psychology and can be understood as normalizing visual discourse that disciplines human difference in particular ways. It is suggested that these visual-discursive statements attain their (taken-forgranted) authority to speak for the other by relying on some fundamental philosophical assumptions, which are informed by the individualizing metaphysics of the 'psy' sciences. These visual practices are perceived to be problematic and reductive on the grounds that they act to foreclose other ways of thinking and being in a contemporary early education setting and limit the possibilities of embodying alternative subject-positions that exist outside of those prescribed through these individualizing discourses.

It is in response to this concern that the last chapter of this work takes form. In chapter six (the plural subject) I outline some theoretical positions produced through the work of Gilles Deleuze and Fèlix Guattari, Bruno Latour and Karen 
Barad that might be understood as useful tools or 'travel guides' for the exploration of subject-positions that reside beyond those foregrounded and critiqued in chapters four and five. In this sense the final chapter of this thesis can be understood to serve a 'where to from here' or 'direction for future research' function that at once problematizes and strives to move beyond the narrow and reductive discursive construction of the child as an economic unit, or bounded individual. This is not about generating advice, or arguing that children should be conceptualized as 'plural' in any kind of totalizing way. Rather, the final chapter of this work is concerned with foregrounding the importance of experimentation in thought, specifically in relation to how we conceptualize children in an ontological sense. Something akin to what Nikolas Rose (2007) might term "writing the history of possible futures" (p. 7), or what Deleuze and Guattari (1987) might articulate as the surveying and mapping of "realms yet to come" (p. 4).

It is important to note at this point that my work is not a visual discourse analysis of Te Whāriki (2017a) in its entirety. Rather, I work with a relatively small selection of photographic images and elaborate upon their significance in relation to predominant contemporary discourses of the child and relations of power that might be understood to construct those discourses. This is an entirely intentional move aimed at illuminating the way in which photographic images/practices are both entangled with linguistic discourses and implicated in the assemblage of rationalities that construct the educated subject at this particular point in history. The selective use of images will be discussed in more detail below (section, 2.10) and contextualized in relation to the empirical mode this thesis subscribes to.

\subsection{The sanctity of the photographic image/copyright hurdles}

The reader will notice that there are in fact no photographic images of the revised Te Whāriki (2017a) document included in this thesis. Rather, there are illustrated copies of these photographic images. This came about in response to copyright restrictions imposed on these photographic images from the Ministry of Education. Through a series of emails with the Ministry of Education's 
copyright permissions department I outlined the aims and concerns of my research and sent through the series of images I was interested in utilizing within my analysis. After several emails I was informed that... "The permissions we have over those images include only use by the Ministry of Education for its publications, so unfortunately we are not able to grant permission for your use “ (personal communication, June 6, 2017). This response struck me as problematic. I was troubled by the way such restrictions acted to stifle intellectual engagement with the dynamic (multi-modal) nature of this particular policy document. The fact that the Ministry is the sole agency with the authority to (re)present these images is concerning. It is my view that published policy material (regardless of which system of representation/medium said material includes) should be open to unrestricted intellectual engagement (regardless of the concerns that inform that engagement). In chapter three (visual culture and the myth of photographic truth) I draw attention to the "ocularcentric" (Rose, 2001, p. 7) nature of contemporary western life in which the proliferation and circulation of visual images is understood as central to (post) modern societies (Baudrillard, 1988). I hope that this chapter is able to elaborate upon the significance of these concerns regarding the copyright restrictions imposed on the photographic images of Te Whāriki (2017a). If we come to understand the central role of visual representations to contemporary life then the freedom to interrogate the grammars and ethics of our masters' gaze is of great importance. 


\section{Chapter 2: METHODOLOGICAL MUSINGS}

\subsection{Introduction}

As the title to this chapter might suggest the question of method has proven to be a consistent point of tension and curiosity throughout the course of this work. Through an engagement with both post-structural (Rose, 1999; 2007; Foucault, 1972; 1991a) and what has been termed 'New Empirical' or 'post-qualitative' (Lather, 2013; Lather \& St. Pierre, 2013; St. Pierre, 2004; Lenz Taguchi, 2016) literature/research I became reluctant to construct a systematic or procedural methodology in relation to my concerns around the normalizing and regulatory effects of the photographic practices of pedagogical documentation. The aim of this chapter then is to foreground the central concepts and methodological nodes that took form in response to this unease around working with a systematic or procedural methodological approach to the visual material that this thesis is concerned with. A further aim is to orientate the reader around the spirit in which this kind of empiricism is practiced and contextualize the methodological nuances of each chapter in relation to this empirical mode. To this end a brief word on ethics is also necessary and follows this introductory section.

Lenz Taguchi (2016) suggests that "New Empirical research needs to be preoccupied with reconfigurations of established concepts and norms and the creation of new possible ways of thinking and doing to produce events that might produce social change" (p. 215). Considering the context of this empirical shift Lather (2013) draws attention to the various methodological movements within the social sciences and aims to capture such movements through constructing the schema Qual 1.0; Qual 2.0; Qual 3.0 and Qual 4.0. Within this schema Lather (2013) explains that:

QUAL 3.0 begins to use postmodern theories to open up concepts associated with qualitative inquiry: validity, voice, data, empathy, authenticity, experience, interviewing, the field, reflexivity, clarity, etc... The field continues to be structured, and a kind of interpretive mixed methods enters the picture and begins to be 
normalized. QUAL 4.0 is becoming in the Deleuzian sense as researchers... imagine and accomplish an inquiry that might produce different knowledge and produce knowledge differently (p. 635).

Lather (2013) goes on to explain that QUAL 4.0 research cannot be neatly described and extrapolated upon in text books or handbooks: "There is no methodological instrumentality to be unproblematically learned... In this methodology to come, we begin to do it differently wherever we are in our projects... Here the term "post-qualitative" begins to make a certain kind of sense" (p. 635). If I were to position my work in relation to this methodological schema I would say that it moves between both QUAL 3.0 and QUAL 4.0, which is reflected in the concepts (and their methodological implications) explored in detail below.

The methodological musings and nodes mapped out in this chapter are done so under the premise that methodological approaches to visual material should not be subjected to any one logic or set of philosophical assumptions, inscribed in the 'how to' manuals of research handbooks and dutifully enacted by the postgraduate student. Rather, I am interested in the notion of what Deleuze and Guattari (1987), in resonance with Foucault (1991b), might call 'a thousand tiny methodologies' (Grosz, 1993) that hold the potential to open up seemingly static research material to new questions and concerns. How can visual material be opened up, played with, alternative methods put into conversation with each other, broken down and put back together in interesting, non-totalizing ways? How can a methodology be aligned with the ethical charge of this work, which, as I perceive it, is about questioning the assumptions that keep us from thinking and living differently, transgressing the self-evident by means of illuminating the possibilities of other subject positions. What does a post-modern ethics look and feel like? An ethics positioned in the wake of the "dissolution of the rational, judging subject or contract-based, liberal accounts of the individual's allegiance to the social community" (Grosz, 1993, p. 172). 


\subsection{A word on ethics}

Deleuze and Guattari (1988) work with a Spinozist (1982) understanding of ethics. For Spinoza ethics is not considered in terms of an abstract system of moral rules and obligations, habits of mind inherited through the moral instructions and prescriptions of Christian morality (Grosz, 1993). Rather, the question of ethics, through a Spinozist lens, comes to the fore "whenever the question of a being's, or assemblage's, capacity and ability is raised" (Grosz, 1993, p. 172). In this sense ethics is about attending to perceived increases and decreases in one's strengths, abilities and capacities, rather than measuring one's actions (past or future) against the abstract system of moral rules and inherited obligations. Deleuze (1990) captures the essence of this ethics concisely in the following statement: "Either ethics makes no sense at all, or this is what it means and has nothing else to say: not to be unworthy of what happens to us" (as cited in St. Pierre, 2004, p. 291). This is an ethics that calls upon an affirmative "belief in the world" and the possibility of worlds we have not yet thought into existence (Deleuze \& Guattari, 1994, p. 75).

Taking this Spinozist inspired ethic seriously opens up a space for a particular kind of empiricism to be practiced. In the introductory chapter to Nikolas Rose's work Powers of Freedom (1999) he situates his empirical approach to the contemporary problem of governmentality in relation to Deleuze's (1994) articulation around the function of his philosophy. Deleuze (1994) compares the graft of his philosophy, in a sense, to a detective novel,

in that concepts, with their zones of presence, should intervene to resolve local situations. They themselves change along with the problems. They have spheres of influence where, as we shall see, they operate in relation to "dramas" and by means of a certain "cruelty"... This is the secret of empiricism (Deleuze, 1994, as cited in Rose, 1999, p. 12).

In this sense empiricism is understood as a method of creation and inventivity, "the invention of concepts as objects of an encounter, a here-andnow encounter which produces ever new, ever different 'heres' and 'nows" 
(Rose, 1999, p. 12). Through such a method attention is paid to those occasions when minuscule modifications enter the realm of possibility, a point at which difference can be made. As Rose (1999) suggests:

it is this concern with drawing small differences and weak generalities from a respect for the particularities of specific cases that seems to me to be more likely to produce what Deleuze terms, after Nietzsche, an untimely attitude to our present, one that is capable of acting counter to our time and thereby on our time, and, let us hope, for the benefit of a time to come (p. 13).

\subsection{Rhizomatic cartography}

Deleuze and Guattari's (1988) concept of the rhizome offers both a method and objective in light of this empirical mode and understanding of ethics. In the introductory 'plateau' of $A$ Thousand Plateaus, titled 'Rhizome' Deleuze and Guattari (1988) are clear that their work has no relation to conventional modes of explanation, interpretation and analysis. As Grosz (1993) points out: "they [Deleuze and Guattari] refuse the domination of linguistic/literary/semiological models, which all seek some kind of hidden depth underneath a manifest surface" (p. 173). What Delueze and Guattari (1988) are interested in are connections and interrelations, not between a text and its meaning, but between a text and other objects, "a text and its outside" (Grosz, 1993, p. 173). In this sense writing is not a process of signifying, but one of surveying and mapping. To become Deleuzian then is not to ask what a text means, but what it does and how it connects with other things.

Rhizomatics stands in oppositions to other dominant epistemological metaphors/models such as the tree or root metaphor. Grosz (1993) explains that the tree metaphor "is an emblem of linear, progressive ordered systems", while the "root metaphor also presumes a unity, but like the root itself, this unity is hidden or latent, and thus may present itself as if it were decentered or nonunified" (p. 173). Alternatively, the rhizome metaphor employed by Deleuze and Guattari (1988) creates the image of an underground network of multiple roots that branch off in all directions with no central axis or cohesive point of origin - 
"a proliferating, somewhat chaotic and diversified system of growths" (Grosz, 1993, p. 173). A central feature of the rhizomatic method then is that it is premised on cartography, "not a reproduction or tracing, model making, or paradigm-construction but map-making or experimentation" (Grosz, 1993, p. 174). Rhizomatics is concerned with how subjects, concepts and texts can be put to work in the process of forming new connections. Putting concepts to work within this empirical mode has been articulated by Lenz Taguchi (2016), following the Deleuzio-Guattarian inspired scholarship of Colebrook (2010; 2014), as 'concept as method.'

\subsection{Concept as method}

Lenz Taguchi (2016) suggests that to work with the concept as method is a practice of rethinking qualitative inquiry in light of what has been described above as New Empiricism in the humanities and social sciences (Lather \& St. Pierre, 2013). Lenz Taguchi (2016) distinguishes New Empirical and DeleuzioGuattarian research from the critical and post-structural epistemological frameworks from which they evolved through conceptualizing the former in terms of "a doubled and entangled action or movement of tracing-and-mapping (p. 214). On the one hand, Lenz Taguchi explains, this movement is concerned with extracting concepts "from the chaos of multiple realities" (p. 214). Through the process of tracing-and-mapping a concept (Deleuze \& Guattari, 1987) we may learn something about how the concept has been utilized to "apprehend" a specific problem (Deleuze \& Guattari, 1994, p. 158). On the other hand, the function of this double movement is concerned with the construction or creation of entirely new events, concepts, possibilities and problems for a reality yet to come (Deleuze \& Guattari, 1994, as cited in Lenz Taguchi, 2016). Lenz Taguchi (2016) explains that the "mapping aspect of tracing-and-mapping involves connecting a concept to other concepts in other territories on the map" (p. 214). Deleuze and Guattari (1987) use the term asignifiying ruptures to encapsulate this kind of empirical performance. Lenz Taguchi (2016) suggests that within this movement of tracing-and-mapping differences can be produced which might act in such a way that deterritorializes the concept and "accomplish reconfigurations with the purpose of resisting normalizing practices" (p. 214). In 
this sense concept as method is a method that can be defined as "affirmative micro-political resistance" (Lenz Taguchi, 2016. 214) that aims to create the unthought and thus unknown potentialities (Deleuze and Guattari, 1987).

It is this preoccupation with resisting and transgressing normalizing practices that interests me most about the tracing-and-mapping of concepts in the context of this thesis. It is important to note that I cannot claim to have implemented this method comprehensively in the context of this thesis and in many ways the complexity of this methodological approach exceeds the scope of my work. However, I have found an engagement with these ideas influential and formative as I put to work various sets of concepts within the frame of each chapter, which all take the diffuse realm of photographic practice and processes of subjectification in the context of education as their impetus. The 'concept as method' then can be understood as one of the many methodological tools or nodes that formed around the central concerns of this thesis and its resistance to empirical modes that seek to stratify methodological movements. Michel Foucault's concepts of discourse, power/knowledge and eventualization are also implicated in this methodological assemblage and can be understood to be the most vividly represented ideas throughout the following chapters.

\subsection{Discourse and power/knowledge}

Michel Foucault's (1972; 1991a) notions of discourse and 'power/knowledge' are central to both the theoretical arguments of this thesis and its methodology. Gillian Rose (2001) explains that discourse, in Foucauldian terms, refers to "groups of statements which structure the way a thing is thought, and the way we can act on the basis of that thinking" (p. 136). In this way discourse refers to a set of statements that function in such a way as to "define, regulate, and limit the object of knowledge" (Nguyen \& Mitchell, 2012, p. 481). Foucault urges us to consider discourse not merely as "groups of signs" but also as "practices that systematically form the objects of which they speak" (Foucault, 1977, as cited in Barad, 1998, p. 103). 'Practices' are understood by Foucault (1991b) as “places where what is said and what is done, rules imposed and reasons given, the planned and the taken for granted meet and interconnect" (p. 75). From a 
Foucauldian perspective a subject is constituted through discourse (Foucault, 1972). In this respect there is no pre-discursive subject (Ahl, 2008). A person comes to know him or herself as a particular kind of subject through the discourses that are made available to them in a particular time and place. In this way discourses both restrict and enable subject-positions (Ahl, 2008), and thus the need for critical interrogation of predominant discourses and the subjectivities they are productive of arises.

In the context of this thesis I work with a consciously selected series of photographic images that, on the one hand, might be considered as visual statements that structure the way in which a child can be thought of. However, these images, on the other hand, might also be considered as discursive practices that systematically form the objects of which they speak. Foucault suggests that the various elements of discourse, including particular statements (statements interpreted here in a multi-modal sense), are interconnected with systems of knowledge which can be observed as effects of specific relations of power (Foucault, 1972). In this respect Foucault urges us to consider power and knowledge, not as separate 'entities', where knowledge is understood (through the Manichean foundations of the Enlightenment) to 'combat' power (Biesta, 2008). Rather, Foucault (1977) suggests that power and knowledge always come together - a point articulated in his notion 'power/knowledge' (Biesta, 2008). Significantly, this philosophical position signifies the end of the perception that knowledge is somehow 'innocent', "the end of the idea that knowledge is 'pure', 'simple', and uncontaminated by power and thus can be used to reveal how power operates" (Biesta, 2008, p. 199). In this sense there is no 'victory' of knowledge over power, or power over knowledge, but instead a recognition that we are always operating from within particular fields of power/knowledge. This point is an important one to consider in relation to a Foucauldian inspired analysis because it draws attention to the idea that analysis (and any claims to truth said analysis makes) does not sit outside of the workings of power. In this way I have come to understand a Foucauldian inspired analysis as necessarily modest, experimental and incomplete, a kind of live practice that seeks to multiply intelligibility of an event and thus move beyond the inside-outside 
thinking of enlightenment logic. Foucault referred to this methodological approach at points in his work as 'eventualization' (Foucault, 1991b).

\subsection{Eventualization and transgression}

For Foucault (1991b) the notion of 'eventualization' can be understood as a method concerned with breaching that which appears to be self-evident. Eventualization is concerned with "making visible a singularity at places where there is a temptation to invoke a historical constant, an immediate anthropological trait, or an obviousness which imposes itself uniformly on all" (Foucault, 1991b, p. 76). To Foucault's (1991b) mind...

it wasn't as a matter of course that mad people came to be regarded as mentally ill; it wasn't self-evident that the only thing to be done with a criminal was to lock him up; it wasn't self-evident that the causes of illness were to be sought through the individual examination of bodies...A breach of self-evidence, of those self-evidences on which our knowledges, acquiescences and practices rest: this is the first theoretico-political function of 'eventualization'.

In this sense Foucault was not interested in searching for a single explanation of particular 'facts' or 'events'. Rather, through the methodological approach of eventualization, he worked to construct a "polyhedron" of intelligibility around a single event, "the number of whose faces is not given in advance and can never properly be taken as finite" (Foucault, 1991b, p. 76). In this way Biesta (2008) explains that eventualization means "to complicate and pluralize our understanding of events, their elements, their relations and their domains of reference" (p. 200). Working with the methodology of eventualization one is not concerned with attaining a 'deeper' understanding of essential 'causes' or 'structures' and thus does not seek to produce emancipatory knowledge that will release us from the oppressive workings of those causes or structures (Biesta, 2008). As Deleuze (1995) notes: “Foucault's method was always opposed to any interpretive method... Never interpret; experience, experiment" (p. 87). 
Some have critiqued this approach on the grounds that it has an anesthetizing effect from which point there is nothing left to 'do', no tools left with which one can 'act' or proceed (see Biesta, 2008 for a discussion of this). However, Foucault has been insistent that such a mode of analysis is not without significant effects, that such an approach is, contrary to the aforementioned critique, mobilizing in all sorts of interesting ways (Foucault, 1991b). Foucault is clear when he articulates that eventualization is not concerned with generating guidelines or instructions pertaining to what is to be done (Foucault, 1991b). Nonetheless, what it can mobilize, produce or create is a situation in which people "no longer know what they do, so that the acts, gestures, discourses, which up until then had seemed to go without saying become problematic, difficult, dangerous" (Foucault, 1991b, p. 84). It is important to note that, for Foucault, this destabilizing effect is totally intentional. Thus a Foucauldian inspired analysis should not be preoccupied with trying to articulate an objective or 'true' understanding of how power actually works, nor should it aim to create particular recipes deigned to inform action (Biesta, 2008; Foucault, 1991b). Rather, its primary function is to disturb that which is taken-for-granted. With this in mind we can come to understand how a Foucauldian analysis does not serve the function of 'solving' problems or producing ideas in the heads of the many soldiers of social reform who aim to make the world 'better.' Rather, Foucault (1991b) was interested in directing this kind of analysis towards a different 'audience' - subjects who wish to act, those who are struggling to bring into existence different ways of being and doing, different ontological and ethical textures to our humdrum (and highly orchestrated) socio-political experience. In the words of Foucault (1991b):

Critique doesn't have to be the premise of a deduction which concludes: this then is what needs to be done. It should be an instrument for those who fight, those who resist and refuse what is. Its use should be in processes of conflict and confrontation, essays in refusal. It doesn't have to lay down the law for the law. It isn't a stage of programming. It is a challenge directed to what is (p. 84). 
Biesta (2008) suggests that this mode of critique lies behind Foucault's (1991b) claim that in a sense the "only important problem is what happens on the ground" (p. 45). Significantly, what this process of conflict and confrontation consists of is a "practical critique that takes the form of possible transgression" (Foucault, 1984, as cited in Biesta, 2008, p. 200). When we enact a critical practice of transgression we do not set out to overcome limits, rather we aim to illuminate these limits through a kind of practical experimentation (Biesta, 2008). With this in mind we can gain a sense around how Foucault's methodological perspectives resonate with Deleuze and Guattari's (1988) mode of empiricism and the emergent 'paradigm' of New Empiricism (Lather, 2013) that I have outlined above.

As mentioned in the introductory chapter my work augments the theoretical and methodological aspects of Michel Foucault's philosophy with insights gleaned from the discipline of 'visual culture studies' (Rose, 2014). In this sense my analysis also borrows strategies/ways of thinking from critical visual methodologies and, more specifically, Gillian Rose's (2001) elaboration on Foucauldian ideas in relation to working with visual materials.

\subsection{Critical visual methodology}

Gillian Rose (2001) outlines three criteria that she suggests is productive for a critical approach to working with/interpreting visual images. Gillian Rose defines 'critical' as

an approach that thinks about the visual in terms of the cultural significance, social practices and power relations in which it is embedded; and that means thinking about the power relations that produce, are articulated through, and can be challenged by, ways of seeing and imaging (p. 3).

The three criteria Rose (2001) maps out in relation to a critical approach concerned with interpreting visual images are as follows: 
1. takes images seriously... Social scientist tend to assume that images are simply reflections of their social 'contexts'. In contrast, I argue that it is necessary to look very carefully at visual images, and it is necessary to do so because they are not entirely reducible to their context. Visual representations have their own effects.

2. thinks about the social conditions and effects of visual objects... Cultural practices like visual representations both depend on and produce social inclusions and exclusions, and a critical account needs to address both those practices and their cultural meanings.

3. considers your own way of looking at images... If ways of seeing are historically, geographically, culturally and social specific, then how you look is not natural or innocent. So it is necessary to reflect on how you as a critic of visual images are looking. As Haraway (1991: 190) says, by thinking carefully about where we see from, 'we might become answerable for what we learn how to see.' (Rose, 2001, pp. 15-16).

To my mind the concerns I have foregrounded in the previous chapter regarding the photographic practices of pedagogical documentation resonate with the concerns expressed by this particular mode of critical inquiry. Through an engagement with visual culture studies literature and broader philosophical perspectives concerning photography and photographic practices I have (in chapter three) worked towards a particular consciousness that takes images seriously, breaching some fundamental assumptions and taken-for-granted notions that we bring with us in our work with visual representations. My feelings of unease around the normalizing and regulatory effects of the photographic practices of pedagogical documentation have moved me to think about the social conditions and effects of visual objects (explored in depth in chapters four and five). Finally, my concerns regarding the contingent nature of image making practices and the epistemological and ontological assumptions that inform/construct this contingency have challenged me to consider my own way of looking at images, sparking a curiosity around alternative ways of seeing and analyzing visual data (evidenced in the content of chapter six). I see this as a 
process through which I may become answerable for what and how I have learnt to see.

\subsection{Visual discourse analysis}

Rose (2001) makes the important distinction between vision and visuality. She explains that vision is what the human eye is capable of seeing in a physiological sense, while visuality refers to the way in which vision is constructed in multiple ways - how we are able, allowed, or made to see. In this way Rose (2001) draws attention to the resonances between visuality (as it is articulated within the discipline of visual culture studies) and the Foucauldian conceptualization of discourse elaborated upon above.

It is possible to think of visuality as a sort of discourse. A specific visuality will make certain things visible in particular ways, and other things unseeable, for example, and subjects will be produced and act within that field of vision (Rose, 2001, p. 137).

In this way Rose (2001) draws attention to the fact that discourses are articulated through various forms of visual and verbal images and texts. Rose (2001) suggests that the multiplicity of "forms through which a discourse can be articulated means that intertextuality is important to understanding discourse" (p. 136). By the notion of intertextuality Rose (2001) refers to the "way that the meanings of any one discursive image or text depend not only on that one text or image, but also on the meanings carried by other images and texts" (p. 136). This kind of intertextual approach can be observed throughout my analysis as I draw on various images and linguistic texts in relation to specific images presented in the revised Te Whāriki (2017a) document.

Rose (2001) brings attention to efforts made in the social sciences to render procedures of discourse analysis more explicit. Drawing on the work of Tonkiss (1998) Rose suggests that these efforts have been directed towards two main areas: analysis of the structure of discursive statements, and the analysis of the social context of those statements (who is saying them, and in what 
circumstances are they being said). Rose (2001) labels these approaches discourse analysis I and discourse analysis II. However, she also explains that this distinction is not clear cut and that it is common to come across scholarly works that investigate visual images, linguistic text, institutions and social practices together (see Green, 1990). In the context of my work I have not found this distinction to be particularly useful and have drawn insight from both perceived categories of discourse analysis. I have also avoided subscribing to a preconceived program of analytical steps or procedures in relation to a Foucauldian inspired analysis of visual material (see Clarke, 2005 for an example of this procedural approach). Jonathan Potter (1996) describes discourse analysis in terms of a "craft skill" (p. 140), and suggests that the only way to learn it is to get stuck in and do it. Through the process of this work I have come to identify more closely with the latter conceptualization of discourse analysis. My approach to analysis unfolded in an open and experimental way (inspired by the philosophy of Michel Foucault, Deleuze/Guattari and the emergent New Empirical literature foregrounded above) as I meditated on a consciously selected set of photographic images present in the revised Te Whāriki (2017a) document in relation to broader discourses of the child and the relations of power that might be understood to construct those discourses. This fluid approach to analysis opened up a necessary space within which the 'event' (in this case photographic images/practices) was complicated and pluralized, the taken-for-granted disturbed and the self-evident breached.

Each chapter of this thesis works with various sets of concepts in approaching a set of problems or concerns that shifted and morphed as the work progressed. This movement is evident in the nuanced formulation of 'research questions' posed and the analytical tack taken within the frame of each chapter, which all took the diffuse realm of photographic practices and processes of subjectivity in the context of education as their impetus. Within this mode of inquiry linkages are made between texts (linguistic and visual), concepts and the child subject, which act to illuminate, resist and transgress dominant discursive constructs and the subjectivities they produce. In this sense I have come to think of this particular methodological approach to visual materials as a kind of 
rhizomatic cartography (Deleuze \& Guattari, 1987; Grosz, 1993; Lenz Taguchi, 2016), an experimental and creative exercise that embraced a kind of "messy conceptual labor" as a positive norm (Lather, 2013, p. 642).

Through the process of this thesis I have come to realize that to experiment with qualitative methodology is to be alive to the reality that method is deeply political (Lather, 2013). Through reading Martin and Kamberelis (2013) I have come to consider this empirical project as a post-structural work that, to some extent, eschews the traditional thesis format in favor of foregrounding (implicitly and explicitly) "the constitutive connections between and among researcher... data, theory, and method" (p. 675). To experiment in this space is to resist the codifying and disciplinary forces that plug-up the possible futures such research might create, working towards a more democratic intellectual atmosphere that celebrates the expanse of thought as apposed to its reduction. In what remains of this chapter I aim to contextualize the methodological substance of each of the following chapters in relation to the particular empirical mode I have outlined above.

\subsection{Putting the concept to work: contextualizing methodological nuances across chapters}

The following section necessarily covers some of the same ground as the chapter overview section (1.3) above. However, the main intention behind what follows is to draw out/foreground the conceptual labor, in the Deleuzio-Guattarian/New Empirical spirit, implicit in the chapters that follow. In doing this I hope to communicate to the reader how I have used 'the concept' as a methodological tool throughout my work in relation to the empirical mode I have foregrounded in this chapter. If the reader should need something solid or consistent to hold on to over the trajectory of this experimental work I would offer the following statement to be held in the mind (or the body): each chapter experiments with making links between texts (linguistic and visual), concepts and the child subject in relation to the problem of photographic practices and processes of subjectification. 
In chapter three I aim to problematize the assumption that photographic inscriptions represent reality in a benign or objective manner (the myth of photographic truth), stressing the idea that photographic inscriptions should instead be considered as mediated representations of reality. I foreground various philosophical perspectives concerning the nature of representation, which open up a space in which Roland Barthes' concepts of myth and connotation can be put to work as tools for exploring perspectives around photographic truth. Within this mode of inquiry linkages are made between texts/discourses (linguistic and visual), concepts and the child subject, which act in such a way as to reveal how photographic images might be used to both exert power and act as instruments of power within processes of subjectification. This assemblage of ideas then opened me up to Michel Foucault's conceptualizations of discourse and power.

In chapter four Michel Foucault's (2007) notion of governmentality is employed as a conceptual tool to observe and examine the visual-discursive construction of the child and broader relations of power. Most significantly, the competent/agentive visual-discursive construction of the child is discussed in relation to what Nikolas Rose (1999) terms advanced liberalism and, more specifically, the entrepreneurial selfhood that this assemblage of rationalities demands of the (post) modern individual. Various iterative contemporary discourses of the child are outlined including the competent child, learnification, priority learners, performativity and broader rights-based discourses. The idea that the visual-discursive construction of the child involves multiple translations (Rose, 1999) between government rationalities and particular (visual) practices of educational institutions is also explored. Here the concept of translation (as conceptualized by Nikolas Rose) enables an exploration concerning how general and wide-ranging political rationalities might link up with specific programmes for "the government of this or that problematic zone of life" (Rose, 1999, p. 50). In the context of this thesis the specific programme of interest can be understood as Aotearoa-New Zealand early childhood care and education centres. In this sense I utilize/analyze the revised curriculum Te Whāriki (2017a) under the assumption that this document is a widely adopted and informative piece of 
policy literature in the context of this programme. The advanced liberal rationalities elaborated upon in chapter four can be understood as the wideranging political rationalities (Rose, 1999) of concern. In this sense chapter four explores how the entrepreneurial subjectivities that are produced through advanced liberal rationalities link up with a particular practice that operates within a specific programme on a local level. In this way the concept of translation intervenes with a local situation (Deleuze, 1994) and aims to disrupt and problematize a discursive practice that makes particular forms of modern government possible (Rose, 1999). This empirical performance then opens up the possibilities of the question: how does an advanced liberal programme of government render itself consonant with the photographic image making practices exemplified in the revised Te Whāriki (2017a) document?

In chapter five I continue to explore the links between the visual-discursive construction of the child and broader relations of power through the lens of governmentality. I foreground an aspect of Michel Foucault's thought that concentrated on how the psychological sciences became entangled with modern forms of government concerned with the diffuse project of 'sovereignty over the self' (Rose, 1999). A central aim of this chapter, generated through an engagement with Foucault's thinking in relation to the psychological sciences and modern forms of governance, is to penetrate the taken-for-granted nature of 'psy' based knowledge and practices and foreground the way in which particular photographic images/practices may be understood as 'psy' visual discourse that disciplines human difference in particular ways. The conceptual labor that crystalized around this aim can be understood to be located within the new sociology of childhood literature (Prout, 2005), specifically the being/becoming dichotomy and its concurrent intellectual debates. Certain visual assemblages/discursive statements in the revised Te Whāriki (2017a) are problematized through bringing them in relation to these hegemonic conceptualizations of children/childhood and by foregrounding the productive capacity of these assemblages to construct particular subjectivities. In this way further links are made between discursive texts, concepts and the child subject. This conceptual labor can be understood to construct an awareness that 
concepts can come together in such a way as to regulate and stratify institutionalized educational practices "in a machinic fashion that will have very concrete and material consequences for the agents involved in those realities" (Lenz Taguchi, 2016, p. 215). Transgressing the self-evidence of the 'psy' sciences and its associated discourses here functions in such a way as to both illuminate the limits of these dominant discourses and show that other subjectpositions are indeed possible, subject-positions which cannot be apprehended or articulated within these existing discursive constructs. This empirical exercise then woke me up as a researcher to concerns related to how these predominant material-discursive practices foreclose other ways of thinking and being in contemporary early education settings. In this sense I felt the urge to explore other possible subject-positions that are potentially asphyxiated by these dominant discourses, or perhaps even yet to manifest in the realities we 'know'. Following this concern and curiosity the last chapter takes form.

In chapter six I lay out some conceptual frameworks that might be understood as useful tools, or 'travel guides' (Latour, 2005), for an exploration of subject positions (existing or yet to come) beyond those foregrounded and critiqued within the main body of my work. Deleuze and Guattari's $(1987 / 1988)$ heterogeneous conception of subjectivity (haeccities) is foregrounded as a possible alternative to the individualizing subjectivities produced through the iterative discourses and rationalities of neo/advanced liberalism and the 'psy' sciences. I suggest that the Deleuzio-Guattarian subject is obscured by these predominant entangled discourses that collectively serve identity-fixing and normalizing ends. Considering heterogeneous conceptualizations of the subject problematizes certain photographic techniques in the revised Te Whāriki (2017a) document that are illustrative of a compulsion, or habit of mind, to fix the identity of children in particular ways (infant, toddler, young child) and arrange pedagogical practices around these normalizing categorizations, which have very real material consequences for the children involved. This consideration then opened me up to theoretical constructs (namely actornetwork theory and agential realism) that may be understood as useful 
frameworks in relation to the investigation (tracing and mapping) of modes of individuation beyond those of the individualized Cartesian knowing subject.

\subsection{Clarifying the selective use of photographic images}

As stated above this work is not a visual discourse analysis of Te Whāriki (2017a) in its entirety. Rather, I work with a relatively small (and consciously selected) set of photographic images and elaborate upon their significance in relation to predominant contemporary discourses of the child and relations of power that might be understood to construct those discourses. At various points in the following chapters I refer to this assemblage of photographic images generally as individualizing on the grounds that they all focus sharply on individual children with the effect of cutting off (to varying degrees) other bodies (both human and non-human) and the wider material environment. There are of course a number of photographic images within this document that image children in relation to other bodies and materials and so it must be reiterated that my varied analyses and the tentative conclusions they are generative of should not be understood in totalizing or generalizable terms. Simply put, I am not at all interested in totalizing, positivist empirical accounts and their stratified relationships to data.

As I hope this methods chapter has established, I am interested in producing connections between texts (linguistic and visual), concepts and the child subject, which might act to illuminate, resist and transgress dominant discursive constructs and the subjectivities they produce. As Martin and Kamberelis (2013) explain: "Such research does not "represent" reality but rather indexes the various ways reality might be produced and how different ways of producing reality have different social, economic and political effects... This kind of research is critical and has political teeth" (p. 673). These images have been intentionally 'drawn' or 'singled-out', purposely utilized to animate thought (MacLure, 2013), worked upon by means of illuminating the ways in which photographic images/practices are both entangled with linguistic discourses and implicated in the assemblage of rationalities that construct the educated subject at this particular point in history. 


\subsection{Conclusion}

The concepts explored in this chapter exceed me in all sorts of ways as a thinker and researcher within the discipline of education. Through a perpetual grappling (conceptual laboring) with these various concepts and their methodological implications in the context of this thesis I cannot claim to have enacted an 'in depth' or 'comprehensive' analysis of the data of interest. It is my understanding that to take the concepts and philosophical perspectives explored above seriously is to not so much be concerned with 'depth' but, rather, to prioritize 'width'/experimentation and a conception of thought as a process of transformation and change. Deleuze and Guattari's (1987) concept of "molecular-girl" is illustrative of this understanding of thinking as a process of transformation and change (pp. 277-278). For Deleuze and Guattari "the molecular-girl" is a state of becoming, "a process of being in a constant movement of thinking: a state of in-between fixed positions and away from coagulated stratifications" (Deleuze and Guattari, 1987, p. 277, as cited in Lenz Taguchi, 2013, pp. 1103-1104). Within the scope of this empirical project I hope to have aligned myself with this conceptualization of thought. The varied methodological musings and nodes foregrounded and explored above are illustrative of this conceptualization of thought and how it might manifest in an empirical project within the discipline of education. 


\section{Chapter 3: VISUAL CULTURE AND ‘THE MYTH OF PHOTOGRAPHIC}

TRUTH'

\subsection{Introduction}

Every image embodies a way of seeing. Even a photograph. For photographs are not, as is often assumed, a mechanical record. Every time we look at a photograph, we are aware, however slightly, of the photographer selecting that sight from an infinity of other possible sights (Berger, 2008, pp. 2-3).

As I started to engage with the complexity of visual representations present in the revised Te Whāriki (2017a) document one of the first questions I had to ask myself was: why does a study concerned with the critical examination of photographic images matter? In seeking an answer to this question I began to engage with a body of literature loosely categorized as 'visual culture studies' (Rose, 2014). Gillian Rose (2014) explains how this discipline has emerged over the past two decades, producing a growing number of journals and handbooks that are all concerned with exploring the effects of the visual/'hyper-visuality' in contemporary life.

The history of visual studies can be traced back to the late nineteenth century and were predominantly enacted by anthropologists studying nonwestern cultures (Nguyen \& Mitchell, 2012). This early work in visual studies was often conducted through the objectifying gaze of the western colonizer (Stuken \& Cartwright, 2001; Rose, 2001). In more recent times this objectifying approach to visual material has been widely criticized and rejected by researchers that are interested in adopting critical approaches to visual representations (Nguyen \& Mitchell, 2012). These scholars prioritize multidisciplinary research that utilizes a subjective lens, employing interpretive frameworks to question dominant discourses and knowledge production (Burke, 2001; Pink, 2006; Rose, 2001).

Scholarly works addressing the effects of the visual/'hyper-visuality' (Rose, 2001) in contemporary life understand visual experience as entrenched in social 
and cultural practices (Sturken \& Cartwright, 2009; Evans \& Hall, 1999; Mirzoeff, 2009; Smith, 2008). Sturken and Cartwright's (2009) book, Practices of Looking: an introduction to visual culture, is considered one of the field's most influential works (Rose, 2014) and employs the following definition of visual culture as: "the shared practices of a group, community, or society through which meanings are made out of the visual, aural, and textual world of representations and the ways that looking practices are engaged in symbolic and communicative activities" (Sturken \& Cartwright, 2009, as cited in Rose, 2014, p. 26).

Rose (2014) explains that the above definition of visual culture has been worked upon by various theoretical elaborations. Some scholars in this field (see Jay, 2008) take the approach of an art historian, focusing on images as the representational site of meaning making. Other scholarly perspectives in this field are concerned with understanding the "social practices through which specific visual objects become meaningful" (Rose, 2014, p. 26), influenced by a range of social science disciplines such as postcolonial anthropology, audience studies and social semiotics (Rose, 2001; 2012). The latter theoretical orientation towards the study of visual objects treats visual representations as “compressed performances" (Pinney, 2004, p. 8), rather than a "screen onto which meaning is projected" (Rose, 2014, p. 26).

The central insight produced by the theoretical orientation outlined above is that meaning does not lay dormant within images, awaiting a 'decoding process', but rather is "produced at the moment that they are consumed by and circulate among viewers" (Sturken \& Cartwright, 2001, p. 7). This understanding of visual objects allows us to consider the ways in which visual material can be used to service institutional power, particular discourses and processes of normalization and categorization. It is through this understanding of visual culture that I utilize a Foucauldian conceptualization of discourse in the context of this thesis. With a definition of visual culture established I would like to explore the question posed above: why does a study concerned with the critical examination of photographic images matter? 
In this chapter I address this question through drawing attention to the “oculacentric" (Rose, 2001, p. 7) nature of contemporary 'western' life in which the proliferation and circulation of visual images is understood as central to (post) modernity (Baudrillard, 1988; Mirzoeff, 1999; Rose, 2001). I suggest that a research project preoccupied with visual representations has particular relevance in relation to pedagogical documentation practices of early childhood education institutions, precisely because these practices are highly visual. In this respect contemporary practices of pedagogical documentation are representative of the ocularcentrism of contemporary western societies to which Rose (2001) draws attention.

With the centrality of the visual to contemporary life in mind I then move on to a discussion of how we can understand photographic images as a system of representation through which we create meaning about the world that surrounds us, drawing attention to how photographic image making practices hinge on particular epistemological and ontological assumptions (namely representationalism). I aim here to problematize the assumption that photographic inscriptions represent reality in a benign or objective manner, stressing the idea that photographic inscriptions should instead be considered as mediated representations of reality. I employ Roland Barthes concepts of myth and connotation as tools for exploring ideas around photographic truth and offer an example of how this might play out in relation to images of young children in the context of pedagogical documentation.

If we come to understand photographic images as mediated representations of reality we can begin to consider how visual mediums can be used to both exert power and act as instruments of power. In this sense an examination of the unacknowledged power of the photographic image can be activated through an engagement with the Foucauldian notion of discourse. Sturken and Cartwright (2001) suggest that Foucault's concept of discourse is useful to understand how systems of power "work to define how things are understood and spoken about (and, by implication represented in images) in a given society" (p. 93). In this 
way the end of this chapter galvanizes the methodological approach utilized in the chapters that follow.

The focus and discussion of this chapter is heavily influenced by two key texts: Sturken and Cartwright's (2001/2009) Practices of Looking: an introduction to visual culture, and Gillian Rose's (2001) Visual Methodologies: an introduction to the interpretation of visual materials.

\subsection{Oculacentrism}

Martin Jay (1993) employs the term ocularcentrism to describe what he understands to be the centrality of the visual to contemporary western life. For John Berger (2008) the visual is the most fundamental of all the senses through which we come to know the world as it really is for us: "Seeing comes before words. The child looks and recognizes before it can speak" (p. 1). Clearly Berger pays little attention to those of the human species that are born blind, however for the majority of us such a statement may certainly ring true. Reflecting on my work as an early childhood teacher also leads me to find a certain resonance in Berger's statement. For example, when one sits with a young child before an illustrated book the images, to my mind at least, seem to affect that child to a much greater extent than the linguistic text that accompany those images. It is quite something to observe the way in which an image can animate a child. Illustrations of food are snatched for and brought to the child's mouth in symbolic gesture; oceans are swum in and skies are flown through; monsters are hidden from and heroes are followed. Children seem to enter the fold of narrative through visual mediums. In this sense it feels to me in such moments that what a child has recognized (come to know?) has a fundamentally visual origin.

Rose (2001) suggests that the narrative of ocularcentrism in western societies fits within a wider analysis concerned with the shift from premodernity to modernity; and from modernity to postmodernity. Mirzoeff (1999) draws attention to the way in which the production and dissemination of visual images proliferated with the onset of modernity. Jenks (1995) contends that this 
proliferation constituted new modern forms of knowledge that depended on a 'scopic regime' that associates seeing with knowledge (I will elaborate on the term scopic regime in more detail below). Jenks (1995) suggests that "looking, seeing and knowing have become perilously intertwined so that the modern world is very much a seen phenomenon" (Jenks, 1995, as cited in Rose, 2001, p. 7).

We daily experience and perpetuate the conflation of the 'seen' with the 'known' in conversation through the linguistic appendage of 'do you see?' or 'see what I mean?' to utterances that seem to require confirmation, or, when seeking opinion, by inquiring after people's 'views' (Jenks, 1995, p. 3).

In this respect it has been argued that modernity is ocularcentric. Rose (2001) also brings attention to the way in which the visual can be understood as equally important to post modernity. Mirzoeff (2002) contends that the postmodern is fundamentally a visual culture that breaks the aforementioned modern relationship between seeing and true knowing. In this respect we can consider postmodernity ocularcentric...

not simply because visual images are more and more common, nor because knowledges about the world are increasingly articulated visually, but because we interact more and more with totally constructed visual experiences. Thus the modern connection between seeing and knowledge is stretched to breaking point in postmodernity (Rose, 2001, p. 8).

This dislocation between seeing and knowing is what Jean Baudrillard (1988) termed the simulacrum. For Baudrillard it was no longer possible to make clear or coherent distinctions between the real and the unreal in postmodern societies. In other words, mediated images had permeated our social world to such a great extent "that we now live in a scopic regime dominated by simulations, or simulacrum" (Baudrillard, 1988, as cited in Rose, 2001 , p. 8). I think this point is interesting to consider in relation to the photographic practices of pedagogical documentation in the context of early childhood education. The inclusion of photographic images in the revised Te 
Whāriki (2017a) document may be understood as reflective of the proliferation of photographic practice both within the institutional setting of early childhood environments and wider society. An obvious effect of this proliferation is that we (as teachers, researches and policy makers) may well be spending more time looking at mediated representations of children, and thus less time engaging with actual children (in the world beyond the frame) themselves. This is a visual documentation of life that takes as long as life itself. I contend that such institutionalized oculacentric phenomena is quite significant and worthy of critical discussion and analysis.

The centrality of the visual to contemporary western life discussed in this section is also reflected in the New Zealand Ministry of Education (2017b) document that reports on the engagement process of the draft Te Whāriki update. Firstly, I found it interesting that the discussion of photographs was framed under the section Layout and design while... "The inclusion of photographs was one of the most commented upon aspects of the draft document" (MoE, 2017a, p. 16). To my mind, the relegation of the discussion of the photographic images included in the draft to the Layout and design section communicates that those producing the document primarily considered images as an aesthetic appendage, rather than a pedagogical significant system of representation. This point is reflected in the following statement:

Many people loved the colours [of the photographs] and said it helped draw the reader into the document and made it "lighter". The photographs were praised for reflecting cultural diversity and helping with navigation by using repeated photographs as visual signposts" (MoE, 2017, p. 16).

Those that did not support the use of photographs in the document at all stated that the photographs in the draft curriculum:

- distracted too much from the text

- made the curriculum seem like a brochure or magazine 
- were not relevant to a curriculum as it is an academic or "serious" document (MoE, 2017, p. 16).

Here it is interesting to note how photographic images are positioned as not academic or "serious" while this visual medium obviously plays a significant role in the day-to-day pedagogical practices of early childhood teachers. If the work of early childhood teachers relies so heavily on the medium of digital photography in the construction of pedagogical documentation then positioning images as not serious or academically significant seems problematic. The notion that the images "distracted too much from the text" suggests a lack of recognition of the visual as a predominant form of representation in contemporary society. I find the second bullet point above especially interesting given that this comment conflates pedagogical documentation with broader visual practices that manifest in "magazines and brochures." As a whole I think these comments reflect the commonly held assumption that photographic images function solely as aesthetic appendages to service or illustrate linguistic text, rather than significant visual representations that have become central to our ways of knowing in (post) modern society. To my mind the inclusion and prominence of discussion concerning photography in the engagement process document reflects the ocularcentric condition of (post) modernity discussed above. However, the positioning of the discussion in the document itself (Layout and design) and the content of the comments (both for and against the inclusion of photographs) are reflective of assumptions that fail to recognize the significance of such a condition and the ways in which this might permeate our work with children and the policy documents we utilize to inform our pedagogical practices. In what follows I aim to confront and problematize such assumptions.

\subsection{Representation}

Representation refers to the way in which we employ language and images to create meaning about the world. We go about describing, defining and understanding the world through utilizing words, and we also engage images in this process (Sturken \& Cartwright, 2001). This process unfolds through particular systems of representation that include a range of visual mediums such 
as painting, photography, television and cinema. Sturken and Cartwright (2001) explain that historical debates concerning representation have "considered whether these systems of representation reflect the world as it is, such that they mirror it back to us as a form of mimesis or imitation, or whether in fact we construct the world and its meaning through the systems of representation we deploy" (p. 12). The latter view can be understood as a social constructivist approach to understanding systems of representation in that the specific cultural context determines the meaning we make from the material world, which takes place through the system of representation we utilize (Sturken \& Cartwright, 2001). In this respect systems of representation do not reflect or imitate a preexisting reality in an objective or benign manner, but rather construct and mediate our understanding of reality in profound ways. As Prout (2005) explains:

Representation, in language and by other means, is a form of mediation. Mediations are never just transparent, they also add to and take away from that being represented. They are slippery and create effects not always intended or even apparent to those who do the representing (p. 85).

My concerns in this thesis are around the ways in which particular photographic images of young children present within the revised Te Whāriki (2017a) document construct and mediate that which is being represented (the child) in significant ways. A further concern is related to how these photographic images/visual statements resonate with broader dominant contemporary discourses of child/educated subject (explored in depth in chapters four and five of this work). As discussed above, I understand a Foucauldian inspired analysis to be a particularly apt analytical tool for exploring the effects of this system of representation, effects not always intended or apparent to those doing the representing. In the context of this thesis I work with a series of photographic images that can be considered as visual statements that structure the way in which a child can be thought of. As outlined earlier my interest in this topic is predicated on a concern around the effects of a constellation of visual statements that take young children as their subjects. Latour (2002) defines this uncertainty 
around the production and dissemination of mediated visual representations as an iconoclash. For Latour (2002) the

critical mind is one that shows the hands of humans at work everywhere so as to slaughter the sanctity of religion, the belief in fetishes, the worship of transcendent, heaven-sent icons, the strength of ideologies. The more the human hand can be seen as having worked on an image, the weaker is the image's claim to offer truth (pp. 67).

Echoing the above social constructivist understanding of representation Rose (2001) draws a distinction between vision and visuality. She explains that vision is what the human eye is capable of seeing in a physiological sense, while visuality refers to the way in which vision is constructed in multiple ways - how we are able, allowed, or made to see (Rose, 2001). Rose (2001) explains that the term scopic regime is often used synonymously with visuality, both terms referring to the "ways in which what is seen and how it is seen is culturally constructed" (Rose, 2001, p. 6). Rose's distinction between vision and visuality resonates with Sturken and Cartwright's (2001) distinction between seeing and looking. These authors have argued that seeing is an egalitarian practice, an arbitrary process of our everyday lives enabled by the physiological capability of sight. Looking on the other hand is often emergent through commands and productive of acts of choice:

Looking is a practice much like speaking, writing, or signing. Looking involves learning to interpret and, like other practices, looking involves relationships of power. To willfully look or not is to exercise choice and influence (Sturken \& Cartwright, 2001, p. 10).

Thus, I want to suggest that when we (as early childhood teachers, researchers and policy makers) produce, analyze and disseminate photographic images of young children we are engaging in a profound and politically charged process that we should not take for granted or assume to be benign or natural. The way in which we work with photographic images is a learnt, constructed (mediated) process that augments and distorts the subjects/objects of our gaze 
in significant ways. Practices of looking therefore involve particular relationships of power and thus their production and circulation necessitates a kind of ethics. As Susan Sontag (1978) observes:

In teaching us a new visual code, photographs alter and enlarge our notion of what is worth looking at and what we have the right to observe. They are a grammar and, even more importantly, an ethics of seeing (p. 1).

The ethic most prevalent/advocated for in the context of this thesis is one of experimentation, skepticism and resistance. The Surrealist painter Rene Magritte commented on the process of representation and practiced such an ethic of resistance by challenging the notion that visual representations possess inherent qualities of stability and authenticity through their claims to realism (Foucault, 1982). Magritte's famous painting of a pipe that has written across the bottom in French "This is not a pipe" (The Treachery of Images, created circa 1928) is often referred to by means of concisely illuminating this point. Here Magritte draws attention to the complex relationship (or relational space) between words and things, foregrounding the obvious but important point that representations are not in fact the material objects that they (however realistically) represent. As Foucault (1983) puts it in a short text on Magritte's work: "Magritte names his paintings in order to focus attention upon the very act of naming" (p.36). 


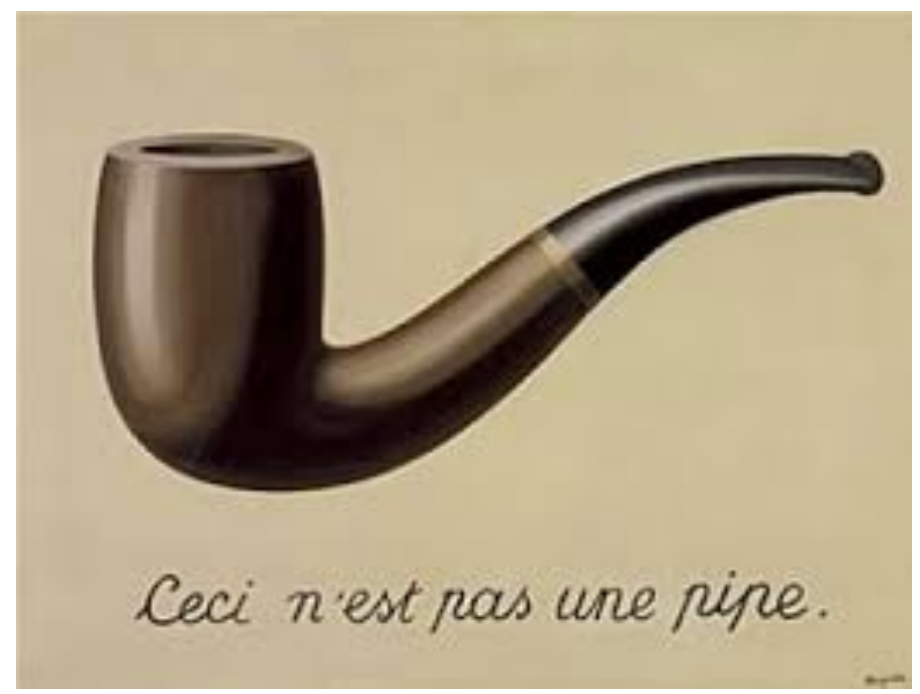

Figure 1.

Sturken and Cartwright (2001) explain that Magritte (obviously but importantly) is reminding us that a picture of a pipe is not the real thing. In this way Magritte provides us with the space to consider that the sea of images that floods our daily lives (including those images of each other) are fundamentally surreal and in desperate need of critical analysis.

The work of Karen Barad $(2003 ; 2007)$ is another point of access to an engagement with the problematic nature of representation. As a feminist physicist Barad contends that language, culture and discourse have been granted too much power in scientific inquiry and calls for a recognition of matter that moves beyond the confines of representational logic (Barad, 2003). Barad is critical of social constructivism on that grounds that such approaches "get caught up in the geometric optics of reflection where, much like the infinite play of images between two facing mirrors, the epistemological gets bounced back and forth, but nothing more is seen" (Barad, 2003, pp. 802-803). Expressing a similar critical thrust to that of Magritte and Foucault above regarding representation Barad (2007) concisely explains: "conviction about what to see is thus a precondition for seeing in the representational paradigm" (p. 51). Barad (2007) suggests that the representational paradigm has a contingent history, bringing attention to philosophical assumptions that underpin the belief that representations offer a transparent view into an objective reality, rather than a 
constructed mediation of worldly phenomenon. Drawing on the work of Rouse (1996), Barad (2003) elaborates on how we might understand the origins of representationalist logic: "the asymmetrical faith in our access to representations over things is a contingent fact of history and not a logical necessity; that is, it is simply a Cartesian habit of mind" (p. 806). I will return to Barad's work in the final chapter of this thesis and discuss some of the further implications of this thinking in relation to the analysis of photographic images of children. For now I am interested in foregrounding the way in which Barad's thinking on representation resonates with the perspectives I have foregrounded so far, offering further support to the central aim of this chapter: to problematize the assumption that photographic inscriptions represent reality in a benign or objective manner by drawing attention to literature and broader philosophical perspectives that act as resources for understanding photographic inscriptions as mediated representations of reality.

With the above discussion in mind I suggest that an engagement with critical literature concerned with the process of representation (a process which we normally take for granted) can deepen one's sense around the complexity of how images and words produce meaning in our world (Sturken \& Cartwright, 2001; Rose, 2001). With this in mind, the following appropriation of/play on Magritte's Treachery of Images might be considered as an apt point of departure for this thesis that stands in the place of a conventional research question and illuminates the significance of the photographic image in relation to critical inquiry within the discipline of early childhood education. 


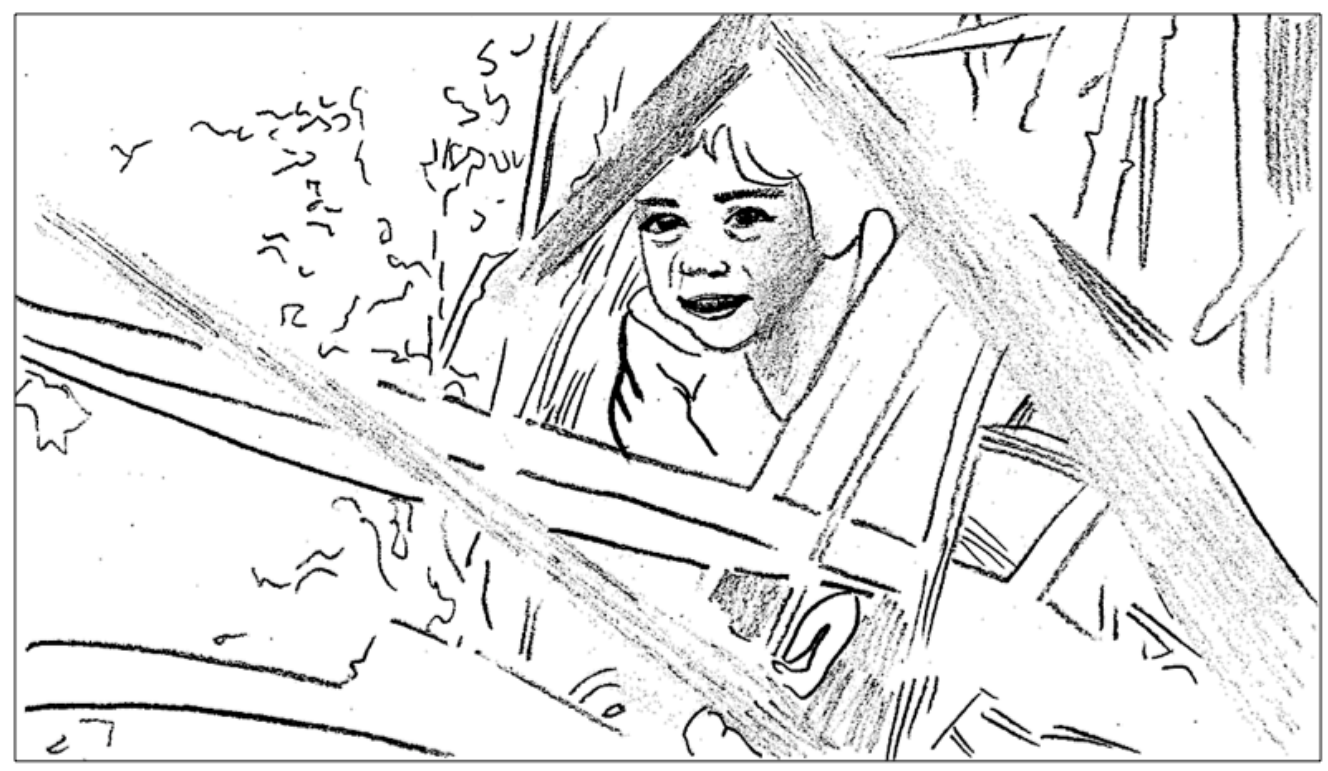

This is not a child

Figure 2.

\subsection{The myth of photographic truth}

Above I have broadly discussed the concept of representation and brought attention to the complexity that often goes unexamined as we utilize particular systems of representation to produce meaning. This section focuses specifically on the photographic image as a system of representation that, perhaps more the any other visual medium (such as painting or drawing), is assumed to unproblematically represent reality in an objective manner. As Sturken and Cartwright (2001) explain: "A photograph is often perceived to be an unmediated copy of the real world, a trace of reality skimmed off the very surface of life" (p. 17). This pervasive assumption is what Sturken and Cartwright (2001) conceptualize as the myth of photographic truth. Thus the function of this section is to elaborate on this myth and establish further support towards an understanding of photographic images as subjectively constructed mediations. As the quote from John Berger (2008) featured at the start of this chapter suggests even photographs cannot be considered objective mechanical records. The frame of a photograph that the mechanism of the camera produces is inherently limited and reductive, thus the photographer makes a subjective decision, selecting one particular sight "from an infinity of other possible sights" (Berger, 2008, pp. 2-3) and, in doing so, constructs the ocular landscape we 
inhabit. In this respect I understand an engagement with this tension between the subjective and objective as central to a critical examination of cameragenerated images. The images present in the revised Te Whāriki (2017a) document are clearly a deliberate choice by those responsible for the production/revision of the document. My contention is that this is significant and can be understood as a kind of visual politics (Nguyen \& Mitchell, 2012).

In the context of this thesis visual politics can be understood a discursive practice that plays a central role in constructing our understanding of childhood within a particular institutional setting. In this sense visual analysis is a useful tool in that it enables us to "examine how childhood is governed through a regime of practices that shape the modern subject" (Nguyen \& Mitchell, 2012, p. 490). It may be the case that the authors of a specific policy document employ photographic images as an illustrative tool that is intended simply to serve the linguistic text. However, this level of engagement (regardless of intentionality) and consciousness around visual images ignores the meaning and ideological implications that particular images may convey to those that consume (and those that are subject to) the document. In this regard it is important to consider the ways in which the meanings constructed by visual representations may be reflective of particular institutional discourses that imply specific relations of power.

I hope to show in the fourth and fifth chapters of this work the way in which photographic images (understood as visual-discursive statements) both play an instrumental role in producing and shaping our understanding of childhood within a specific institutional context and contribute to the constellation of practices that shape the modern educated subject. Exploring the myth of photographic truth here might be understood as a way to foreground/breach a fundamental assumption that opens up a space in which the photographic image can operate as a discursive statement. That is to say the assumption that photographic images are objective renderings of the real world means that images have a particular kind of authority or power within a specific text or document (in this case the Aotearoa-New Zealand early childhood curriculum) to 
structure "the way in which a thing is thought, and the way we can act on the basis of that thinking" (Rose, 2001, p. 136). My intention here is to foreground how photographic images have a unique authority/power to speak for the other.

Considering the myth of photographic truth necessitates a brief articulation of the historical context in which photography was developed. Mirzoeff (1999) explains that the invention of photography was the result of a culmination of decades of experimentation with visual media in an effort to find a more efficient means of representation than those available through traditional visual mediums such as painting or drawing. Various techniques of "writing light", the literal meaning of photography, were invented in Europe from the 1820s onwards (Mirzoeff, 1999, p. 63). Sturken and Cartwright (2001) explain how photography emerged at a time in which positivist science dominated. Positivism can be understood as the belief that empirical truths can be proven through reference to visual evidence (Sturken \& Cartwright, 2001). Significantly, positivist science viewed the subjectivity of the scientist as a liability in the empirical process of producing and reproducing experiments, as this subjectivity would risk sullying the objectivity of the experiment being conducted (Sturken \& Cartwright, 2001). In this respect the machine responsible for producing the results of a scientific experiment were regarded as more reliable than human beings conducting said experiment (Latour, 1987). In a similar way,

photography is a method of producing images that involves a mechanical recording device (the camera) rather than hand recording (pencil and paper). In the context of positivism, the photographic camera was taken to be a scientific tool for registering reality and was regarded by its early advocates as a means of representing the world more accurately than hand-rendered images (Sturken \& Cartwright, 2001, p. 17).

Roland Barthes (1981) described photography as "the impossible science of the unique being" (p. 71). Mirzoeff (1999) suggests that this description communicates the idea that photography seeks to record the individuality of a subject with the most refined level of realism, but, paradoxically, it is this sense 
of an individual that cannot be photographed. In this respect photography is a past-tense medium - it says "that was there" not what is there (Mirzoeff, 1999, p. 74). Mirzoeff (1999) suggests that the photograph is "Death's point of entry into everyday life" in secular societies (p. 74). For Barthes (1981): "With the Photograph, we enter into flat death", for the past that the photograph presents cannot be returned to (p.92). Susan Sontag (1978) echoes this meditation on the photographic image: "to take a photograph is to participate in another person (or thing's) mortality, vulnerability, mutability. Precisely by slicing this moment and freezing it, all photographs testify to time's relentless melt" (p. 11).

For Barthes $(1981 ; 1982)$ a photographic image holds two distinct levels of meaning - denotative and connotative. Barthes (1982) suggested that an image can denote apparent truths, providing documentary evidence of a particular circumstance. In this respect the denotative meaning of an image refers to its literal, descriptive meaning (Sturken \& Cartwright, 2001), what Barthes (1982) refers to as reality's "perfect analogon" (p.196). The connotative meaning on the other hand refers to the culturally constructed nature of our interpretation of the same image. On the level of connotation the meaning we make from an image relies on "the cultural and historical context of the image and its viewers' lived, felt knowledge of those circumstances" (Sturken \& Cartwright, 2001, p. 19). Barthes (1982) reflects on the difficulty in distinguishing between these two levels (subjective/objective) of meaning when confronted with a photographic image:

In front of a photograph, the feeling of "denotation", or, if one prefers, of analogical plentitude, is so great that the description of a photograph is literally impossible; to describe consists precisely in joining to the denoted message a relay or secondorder message derived from a code which is that of language and constituting in relation to the photographic analogue, however much care one takes to be exact, a connotation: to describe is thus not simply to be imprecise or incomplete, it is to change structures, to signify something different from what is shown (pp. 197-198). 
In Mythologies (1993) Roland Barthes examines the tendency of contemporary society to create modern myths. The term myth is employed by Barthes to refer to the specific cultural values and beliefs that are expressed at the level of connotation discussed above (Sturken \& Cartwright, 2001). In this way Barthes understands a myth to constitute the socially and culturally specific conventions through which subjective (socio-culturally and historically contingent) meanings are constructed as universal 'truths.' Thus, myth opens up a space in which the connotative meaning of a certain thing (a photographic image for example) appears to be denotative and, by extension, an exact or natural rendering of an objective reality. To illustrate this point Barthes (1977) examines an advertisement for Italian sauce and pasta and suggests that such an ad is not simply presenting a consumable product but rather actively producing a myth about Italian culture, what Barthes terms "Italianicity" (p. 34). For Barthes then this advertisement signified a specific French concept of Italian culture and not the universal or natural representation of Italian culture that is implied or assumed at the level of denotation. Sturken and Cartwright (2001) further illustrate this observation by drawing attention to the way in which contemporary concepts of beauty render specific cultural norms of appearance natural and universal in modern, image-saturated societies. Such constructed norms constitute a myth precisely because they are specific to a particular cultural and historical context, thus in no way 'natural'. In this respect Barthes' concepts of myth and connotation can be understood as useful tools for examining ideas of photographic truth (Sturken \& Cartwright, 2001). Thinking with Roland Barthes we can start to examine the cultural, social and historical meanings/assumptions that affect our work with and relationship to photographic images.

With the above conceptual landscape in mind we might ask to what extent myth governs our engagement with images of children/childhood. In a sense the very category of childhood can be understood through the lens of myth. Craw and Leonard (2004) draw attention to the way in which childhood is predominantly viewed and constructed retrospectively by 'adults' (illuminating the arbitrary distinction between child/adult) as a universal, biological fact. 
However, childhood (as it is currently understood) is for the most part a relatively recent cultural phenomenon (Craw \& Leonard, 2004). The work of the French social historian Philippe Aries (1962) is exemplary of this understanding of childhood as a cultural phenomenon. In Centuries of Childhood Aries (1962) traces the origin and dissemination of the modern (western) notion of childhood. For Aries the modern concept of childhood started as an elitist idea among the European upper classes of the $16^{\text {th }}$ and $17^{\text {th }}$ centuries; proliferating with the Romantics in the $18^{\text {th }}$ century and spreading through the middle classes in the $19^{\text {th }}$; finally being inscribed across all classes in the $20^{\text {th }}$ century (Aries, 1962, as cited in Craw and Leonard, 2004). In this sense...

childhood is not a natural occurrence. There was a time when children were treated like small adults. Childhood is an invention, a social construct, made possible by society as it increased in sophistication and resource (Craw and Leonard, 2004, p. 129).

Craw and Leonard (2004) explain that the $18^{\text {th }}$ century was a significant turning point in the construction of childhood as the Romantics refined their ideology of the natural child. A significant text associated with this Romantic invention is Jean-Jacques Rousseau's (1911) book Emile in which Rousseau argues that if children experience a 'natural childhood' (that is, being allowed to interact with nature while being guided and protected by adults) then their inherent goodness will naturally unfold. Central to Rousseau's thesis is that children are born with intrinsic virtues such as innocence, freedom and a capacity for reason, and thus the child's mind should not be forcefully molded but allowed to grow like a plant. As Craw and Leonard (2004) put it in their analysis of Rousseau's work: "Like noble savages, children exist in a state of nature and must be protected from social corruption" (p. 129). It is interesting to consider the way in which this specific kind of othering of the child, galvanized through the ideology of the Romantics, may manifests in the photographic images of the revised Te Whāriki (2017a) document. I use the term othering here in relation to criticisms of early work in the discipline of (visual) anthropology that functioned in such a way as to "represent codes of dominance and 
subjugation, difference and otherness" between anthropologist and the 'native' subject (Sturken \& Cartwright, 2001, p. 100). Here I am interested in applying this notion of otherness/othering to the relationship between the child and the early childhood pedagogue. To my mind the images below provide an example of how the aforementioned concepts of myth and connotation may manifest in photographic images that represent young children. Here the mediated representations of children/childhood depict children through the myth/ connotation of the Romantics - the "noble savage", intrinsically good, inherently innocent and close to nature:

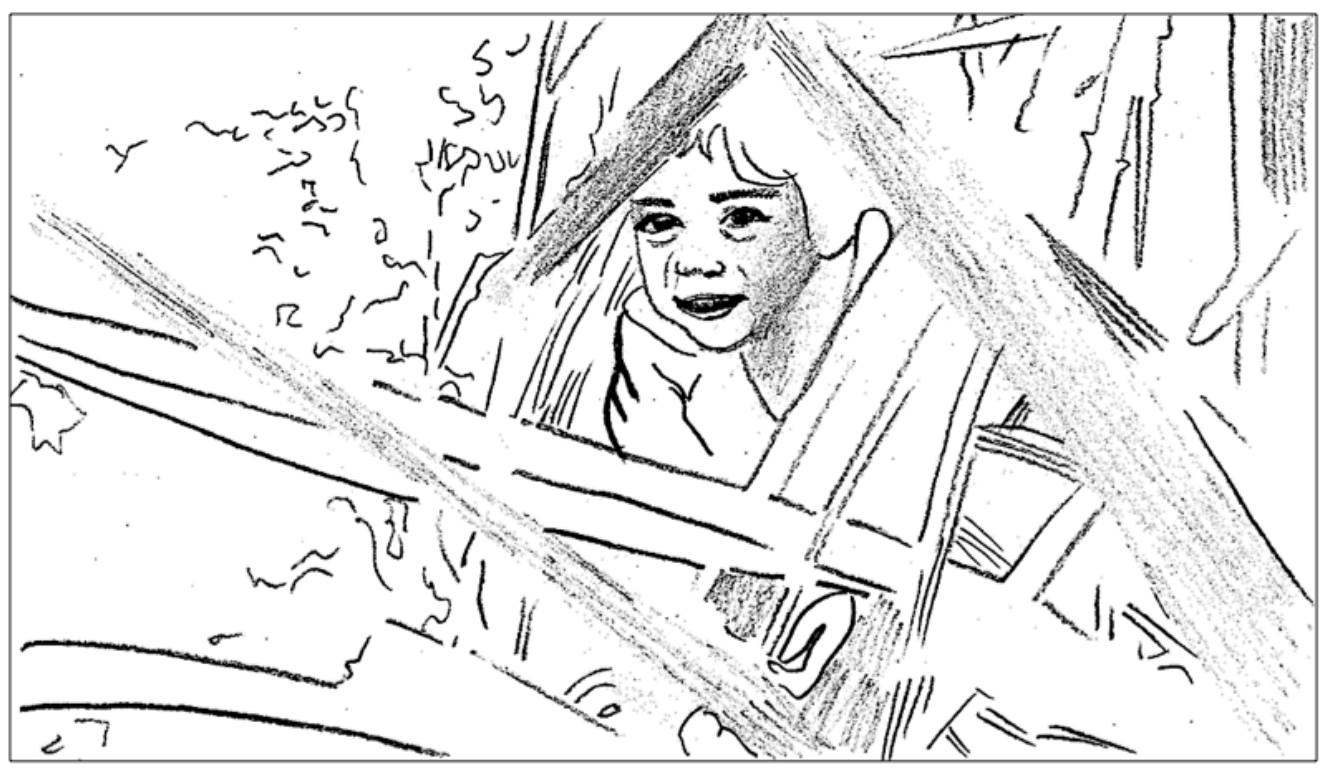

Figure 3. 


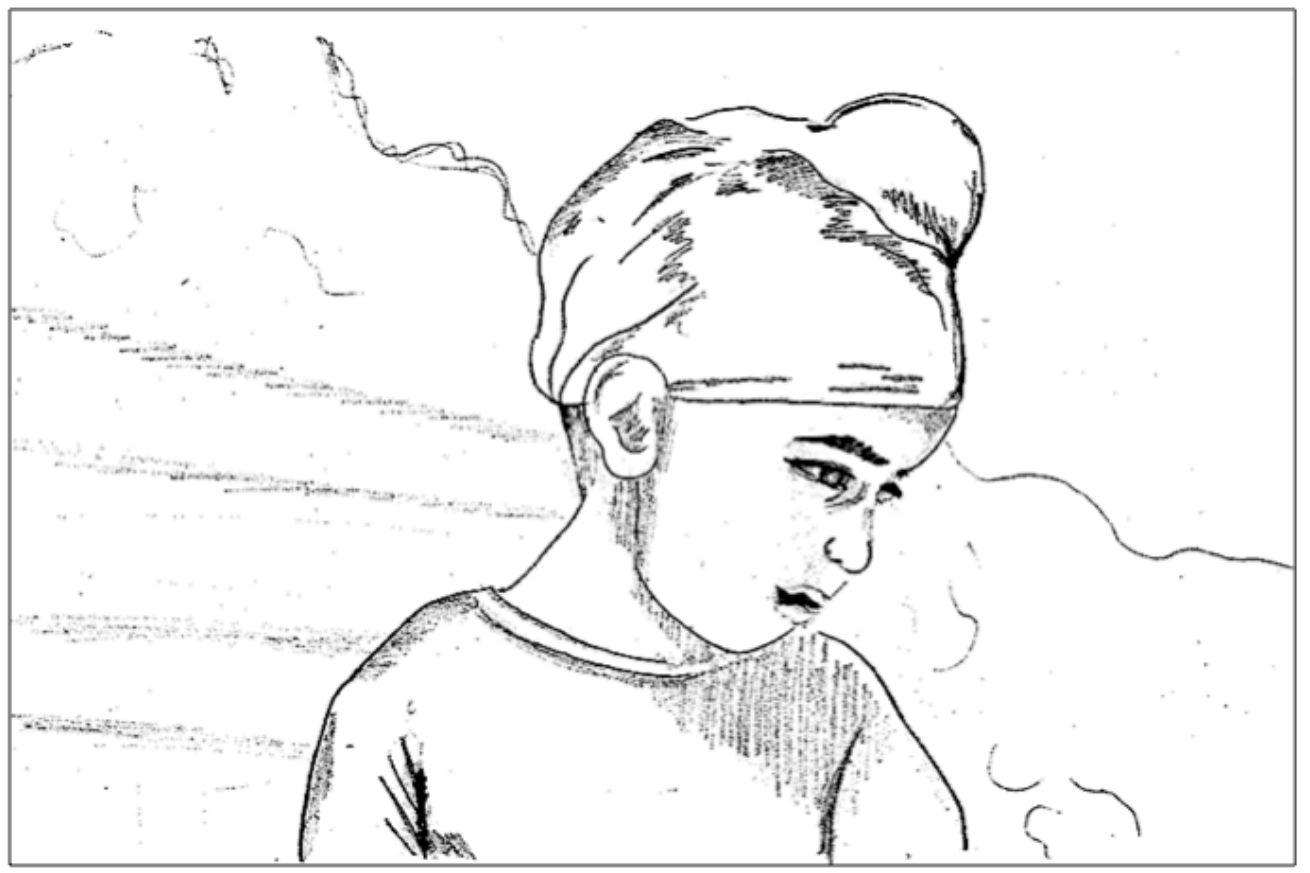

Figure 4.

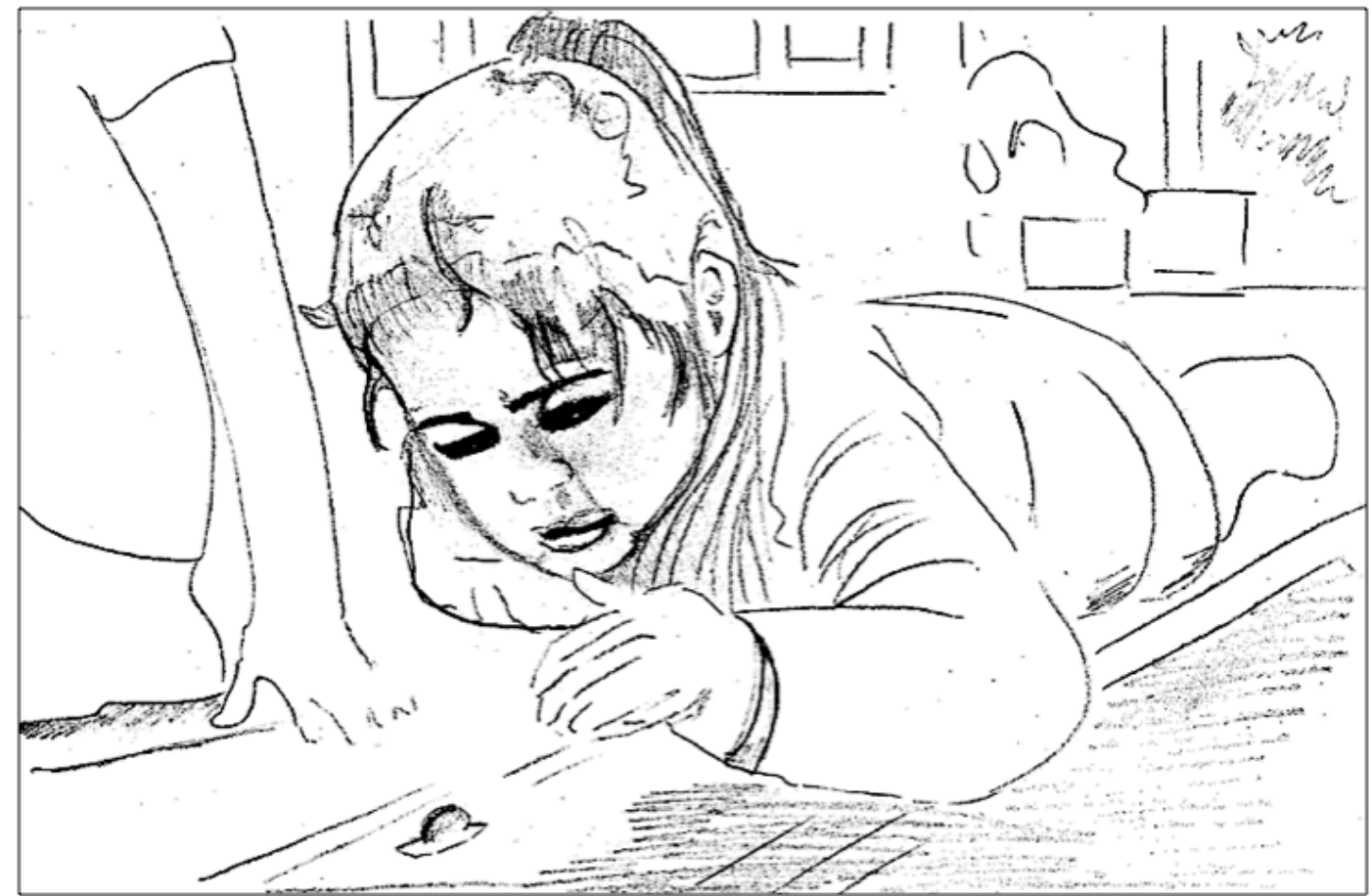

Figure 5. 


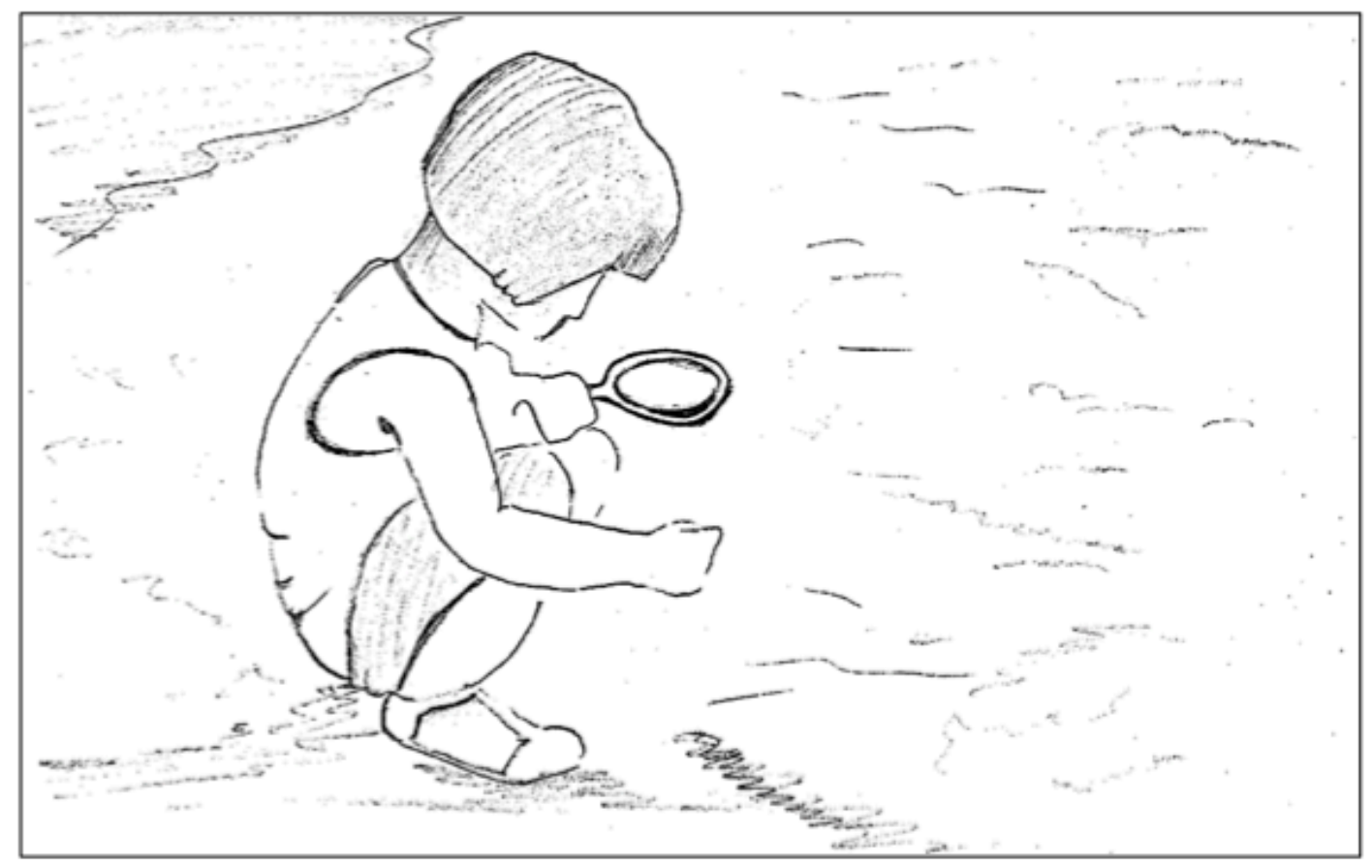

Figure 6.

\subsection{Conclusion}

Within the scope of this chapter I have drawn attention to the "ocularcentric" (Rose, 2001, p. 7) nature of contemporary 'western' life in which the proliferation and circulation of visual images is understood as central to (post) modernity. I have suggested that a research project concerned with visual representations has particular relevance in relation to the pedagogical documentation practices of early childhood institutions, precisely because these practices are highly visual. In this respect I have argued that contemporary practices of pedagogical documentation are representative of the ocularcentrism of contemporary western societies that Gillian Rose (2001) draws attention to. With the centrality of visual practices to contemporary life in mind I then moved on to a discussion concerning how we can understand visual images as a system of representation through which we create meaning about the world that surrounds us and I drew attention to how these representational practices hinge on particular ontological and epistemological assumptions. In this way I aimed to problematize the assumption that photographic inscriptions represent reality in a benign or objective manner, stressing the idea that photographic inscriptions should instead be considered as subjective, and thus significantly mediated, 
representations of reality. I employed Roland Barthes' conceptions of myth and connotation as tools for exploring these ideas around photographic truth and as a way of illustrating how this might play out in relation to images of young children in the context of pedagogical documentation. I have suggested that if we come to understand photographic images as mediated representations of reality then we can begin to consider how visual mediums can be used to both exert power and act as instruments of power. In this sense an examination of the unacknowledged power of the photographic image can be activated through an engagement with Michel Foucault's (1972; 1991a) conceptualization of discourse and power. 


\section{Chapter 4: PRODUCING GOVERNABLE SUBJECTS THROUGH VISUAL DISCOURSE: THE CHILD AS AN ISOLATED, AUTONOMOUS AND COMPETENT \\ INDIVIDUAL}

\subsection{Introduction}

The central aim of this chapter is to explore the resonances/links/parallels between the visual-discursive construction of the child and broader relations of power. Most significantly, the competent/agentive visual-discursive construction of the child is discussed in relation to what Nikolas Rose (1999) terms advanced liberalism and, more specifically, the entrepreneurial selfhood that this assemblage of rationalities demands of the (post) modern individual social subject. The idea that the visual-discursive construction of the child involves multiple translations (Rose, 1999) between government rationalities and particular (visual) practices of educational institutions is also explored. Various individualizing contemporary discourses of the child are outlined including the competent child, learnification, priority learner, performativity and broader rightsbased discourses. These discourses are understood as constituting sets of statements and practices that contribute towards the diffuse project of forming the young educated subject at this particular point in history. It is suggested that particular visual representations of children present in the revised Te Whāriki (2017a) document resonate strongly with these contemporary discourses of the child and thus constitute a visual discourse in which competence and agency is a dominant theme. The decision to include the particular series of photographic images that are present in the revised Te Whāriki (2017a) document is clearly a deliberate decision made by those responsible for its revision and therefore can be considered as a kind of visual politics (Nguyen \& Mitchell, 2012). As previously mentioned visual politics can be understood as a discursive practice that plays a central role in forming our understanding of children/childhood within a particular institutional setting.

My analysis aims to bring attention to the significance of underlying themes and perspectives that are inscribed in the visual discourse of the document. In 
this way photographic depictions of children within Te Whāriki (2017a) can be understood as a part of a particular discursive formation, which is productive of a certain kind of educated subject that an advanced liberal approach to government demands. In this sense I suggest that the intensive focus on the individual child through the visual medium of photography is related to (and contributes towards) wider governance practices of the late modern neoliberal disciplinary state. Michel Foucault's (2007) notion of governmentality is employed as a conceptual tool to observe and examine the visual-discursive construction of the child (agentive/competent) and broader relations of power (advanced liberalism). My concern is that such unrelenting focus on the individual places burdensome levels of responsibility on the young, ignoring and acting to erode consciousness around the inter/intra (see chapter six for a discussion of Barad's (2007) notion of 'intra' activity) connected nature of teaching and learning, which includes various bodies (both human and nonhuman) and materials beyond the individual 'learning' subject inscribed in predominant discourses.

It is important to note here that my work is not intended to be a comprehensive thesis, but rather a foray into how photographic practices are caught up in the assemblage of rationalities that constructs the child in particular ways. My analysis is limited and partial. In this sense I do not intend to convey that the agentive/competent child produced through visual discourse is totalizing or inevitable. I focus on one particular practice (photographic image making) present in a specific piece of policy documentation and seek to interrupt its taken-for-grantedness and unproblematized exercises of power. The analysis of this chapter has no intention of building an argument that can be generalized to the totality of photographic images present in the revised Te Whāriki (2017a) document. I work with a relatively small (and consciously selected) series of images and elaborate upon their significance in relation to predominant discourses of the child and broader relations of power that might be understood to construct those discourses. To reiterate what has been foregrounded above: this is an entirely intentional move aimed at illuminating the way in which photographic images/practices are both entangled with linguistic discourses and 
implicated in the assemblage of rationalities that construct the educated subject at this particular point in history.

\subsection{Governmentality}

It is not possible to offer a detailed account of Foucault's notion of governmentality (Foucault, 1991a) within the scope of this work. Central to the function of this thesis is the idea that governmentality studies are concerned with examining the problematics of modern governance (Ball, 1994; Foucault, 1991a, 2007; Rose, 1999). Foucault (2007) conceptualizes governmentality as the conduct of conduct or the art of government through which disciplinary power operates to push the social subject towards normative categories of existence. In this sense the modern individual is constructed through the normative judgments of particular institutions (Rose, 1999). Crucial to Foucault's thought then is the idea that modern government goes beyond the notion of centralized state politics and should be understood as "any strategy, tactic, process, procedure or programme for controlling, regulating, shaping, mastering or exercising authority over others in a nation, organization or locality" (Rose, 1999, p.15). This notion of government gestures towards a particular and subtle mode of exercising power (unique to the modern, liberal society) that seeks to shape rather than exclude human agency (Foucault, 2007). In this respect, the modern neo-liberal state is based "upon the willingness and capacity of autonomous individuals to choose to exercise responsible self-government" (Smith, 2011, p.25). This shaping, rather than exclusion, of human agency is associated with the technologies of self-government that operate in the local practices of institutions (Dean, 1999).

This form of modern power is conceptualized by Foucault (1990) as biopolitics/power: the set of disciplines and techniques employed by institutions to govern the social subjects behavior in particular ways. An example of this kind of power is the way in which modern states shape the behavior of populations through management technologies such as compulsory education (Rose, 2010; Foucault, 1991a). Key to Foucault's notion of bio-politics is the idea that modern power acts upon the body in indirect ways. As Foucault observes: "the body is 
also directly involved in a political field, power relations have an immediate hold upon it; they invest in it, mark it, train it, torture it, force it to carry out tasks, to perform ceremonies, to emit signs" (Foucault, 1977, p. 25). In this way Foucault argued that local institutions (such as schools and hospitals) operate to construct a particular kind of knowledge of the body, forcing it to signify its relationship to social norms (Foucault, 1977). In relation to Foucault's analysis of power Sturken and Cartwright (2001) note how the emergence of various social institutions in the nineteenth century coincided with the emergence of photography, which inscribed (visually) the normalized and regulated body Foucault was concerned with.

It strikes me, in the year 2018, that the relationship between photographic practices and the regulatory and normalizing effects of bio-power are reflected in the majority of social spaces we inhabit on a day-to-day basis (for myself this includes early childhood education environments). The 'selfie', which could be considered a global phenomenon specific to photographic practice, is a stark example of this. It could be argued that the diffuse power relations of social media (a particular institution in itself) construct a particular kind of knowledge of the body through training it to perform a kind of individualized, narcissistic ceremony that comes to signify the bodies relationship to social norms. I feel that we also need to consider how young children enter the fold or territory of such popular visual practices and foreground an ethics around young citizens' participation in/awareness of such practices. I came across an advert recently by the company Samsung (a screen shot from which is depicted below), which was entitled 'The New Normal'. I was struck by the realization that in hospitals all over the world in this moment new born babies are becoming photographic subjects for the first time, their parents faces obscured by smart phones, the photographic inscriptions of their bodies disseminated within the vast space of social media and (re)presented in multiple contexts. 


\section{This content is unavailable}

Please consult the print version for access

\section{Figure 7.}

I do not intend here to suggest that popular culture phenomenon has simply permeated the photographic practices of pedagogical documentation in any straightforward way. Rather, I am interested in these references in that they can help us think about the habitual ways in which we produce and disseminate photographic images in contemporary society and how this acts on the human body and mind in indirect but arguably profound ways. Thinking with Foucault (1977) we can start to consider how photographic practices of pedagogical documentation, enacted by trained early childhood pedagogues, might construct a particular kind of knowledge of the body of the child and come to signify its relationship to social norms. In this respect we can come to think of pedagogical documentation as a technology of governance (Dean, 2010) in which the photographic practices and the mediated representations they produce play a central role. In essence, Foucault's (1991a) conceptualization of government allows us to explore the relationship between discourse, knowledge and power by examining the constellation of practices that construct the modern individual through the normative judgments of particular institutions (Nguyen \& Mitchell, 2012).

\subsection{The agentive/competent child}

Poststructuralist researchers, for instance Tobin (1995) and Canella (1997), have claimed that the pedagogical focus on the autonomous child and its attentiveness to the self-expression of the individual subject are "typically linked 
to the liberal, free market orientated society in need of autonomous, entrepreneurial individuals" (Vandenbroeck \& Bouverne-De Bie, 2006, p. 134). Tobin, Wu and Davidson (1989) bring attention to the social and historical construction of the prioritization of individuality within educational agendas through cross-cultural ethnographic research in early childhood education. Such research problematizes notions of the agentive/competent child as a universal, emancipatory 'progression' in contemporary constructions of childhood. Studies that followed Tobin's Preschool in three countries research illuminate the way in which economic and political shifts affect constructions of childhood and that these shifts move in the direction of autonomous individuals, which work to erode other educational values such as interconnectedness (Hsueh \& Tobin, 2003; Tobin, Karasawa \& Hsueh, 2004).

One striking feature of the photographic images subject to analysis in this chapter is that the children are depicted as isolated (often partial) individuals, separate from other bodies (both human and non-human) and the wider material environment. This isolation of the individual child produced through the visual medium of photography is reflected in both the framing conventions (the space, materials and bodies that are actually imaged in the confines of the frame) and other techniques that the technological apparatus of the camera allow (what is of most interest to me in this regard is the function of focus). The selection of photographic images explored in this chapter feature adult figures for example teachers or parents - relatively rarely. In this respect we can begin to consider how the visual system of representation within this document directs our gaze in a particular way through repetitive framing and focus conventions intrinsic to the technological capacities of the camera. We can also consider how these images are reflective of certain assumptions/subjectivities of those taking the photographs and those responsible for selecting and curating the images within the process of revising the document (see chapter 3). In this way we can consider how these images may come to function as visual discourse and constitute a kind of visual politics. Depicted below is a series of images that exemplify this particular concern around the frequency with which children are depicted as isolated (often partial) individuals. 


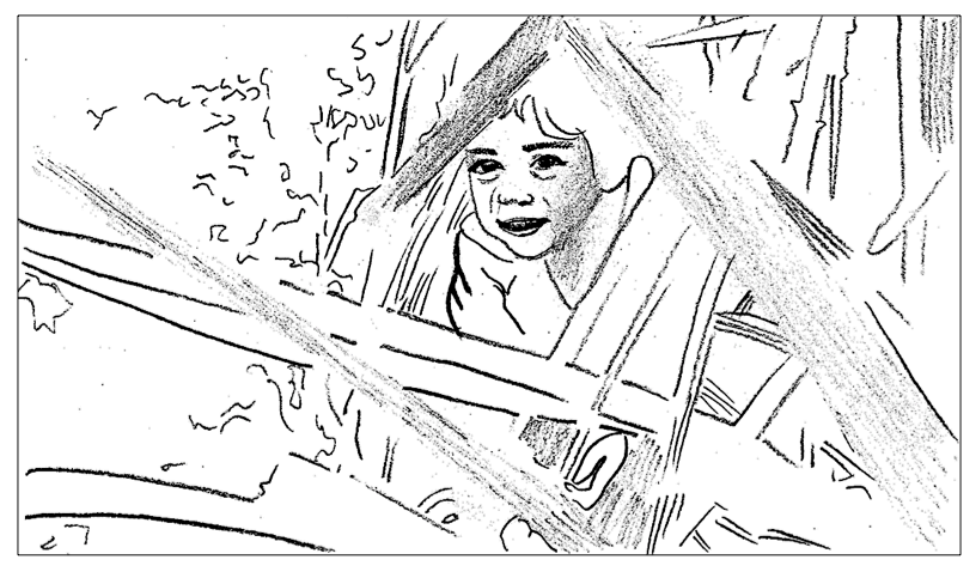

Figure 8.

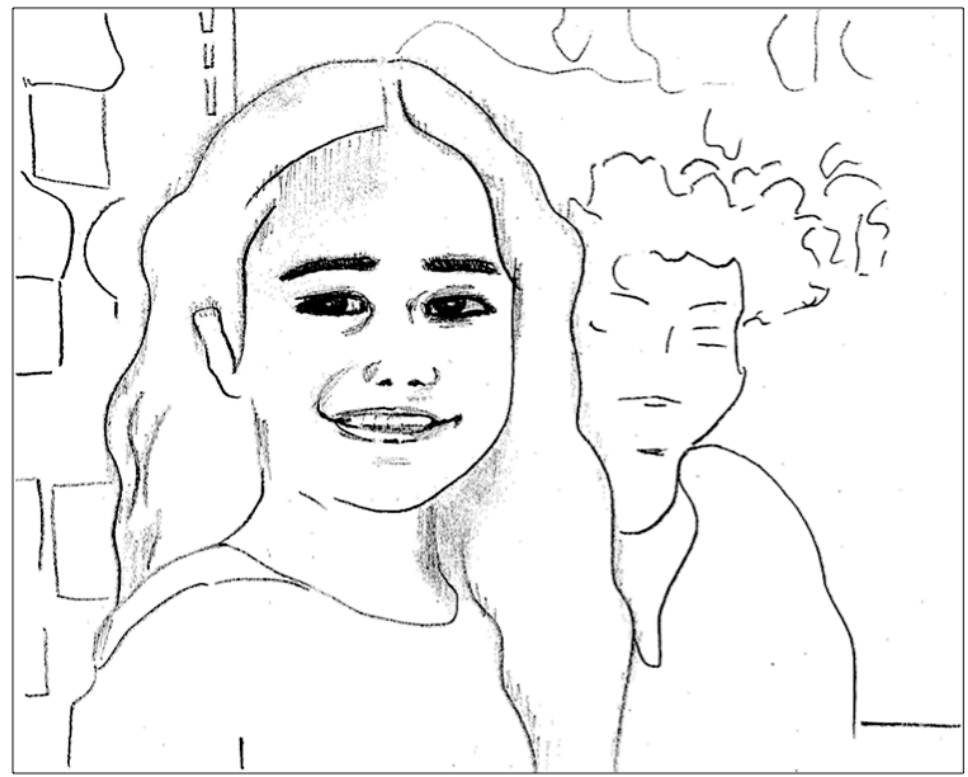

Figure 9.

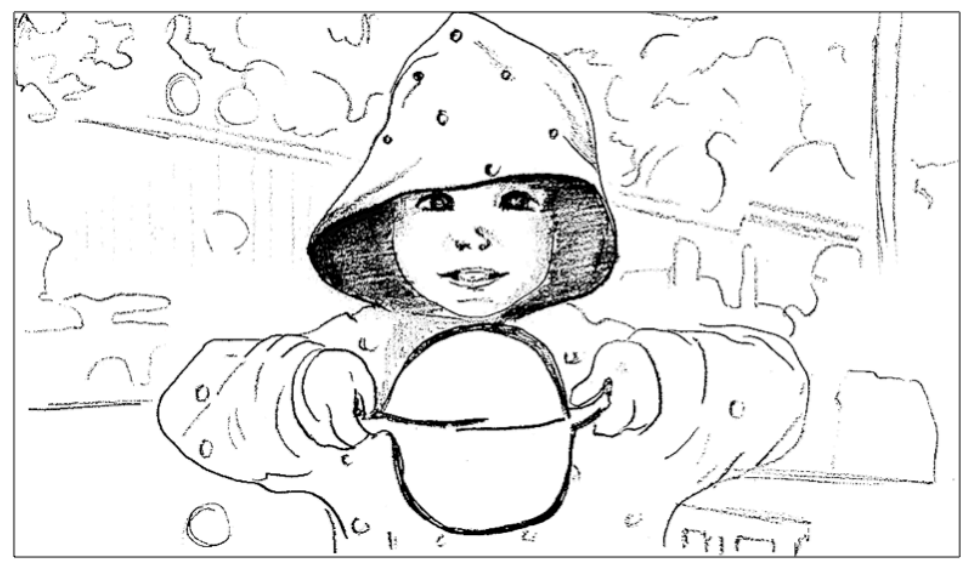

Figure 10. 


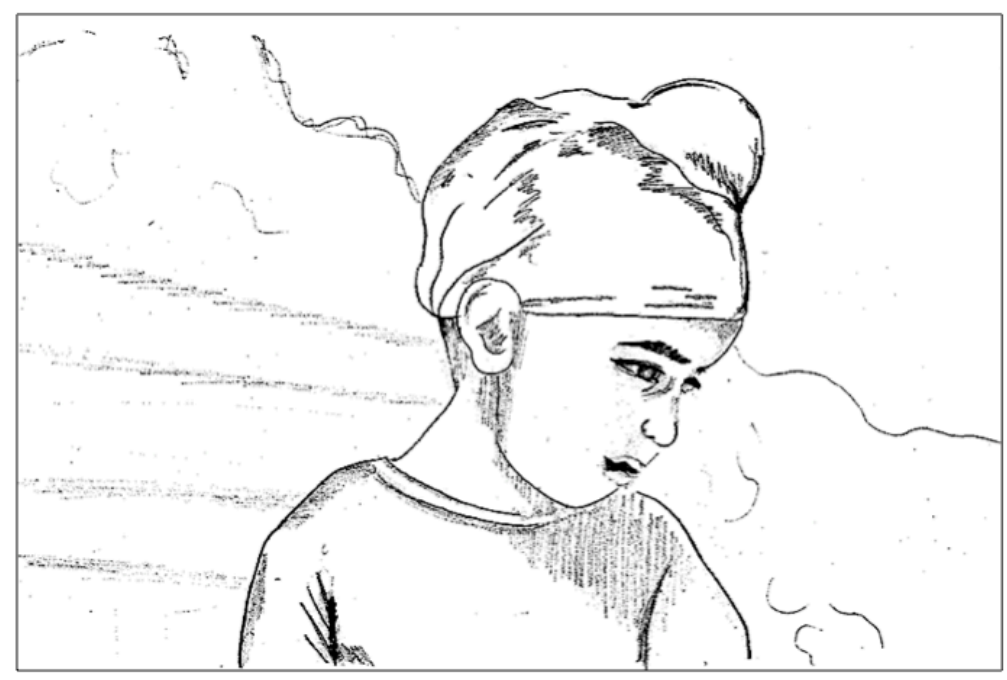

Figure 11.

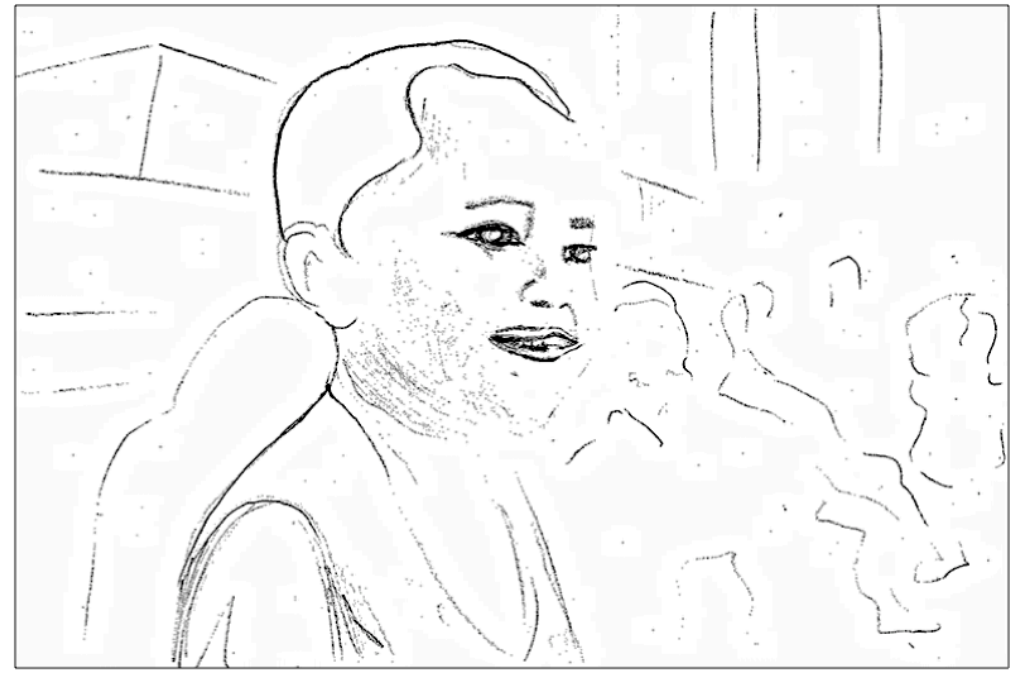

Figure 12.

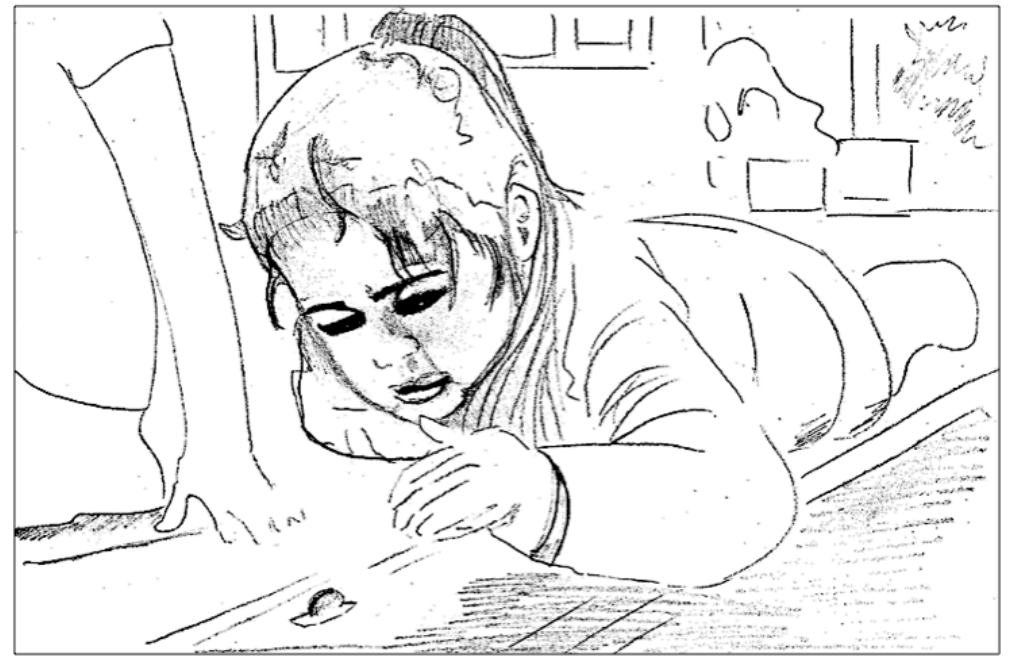

Figure 13. 


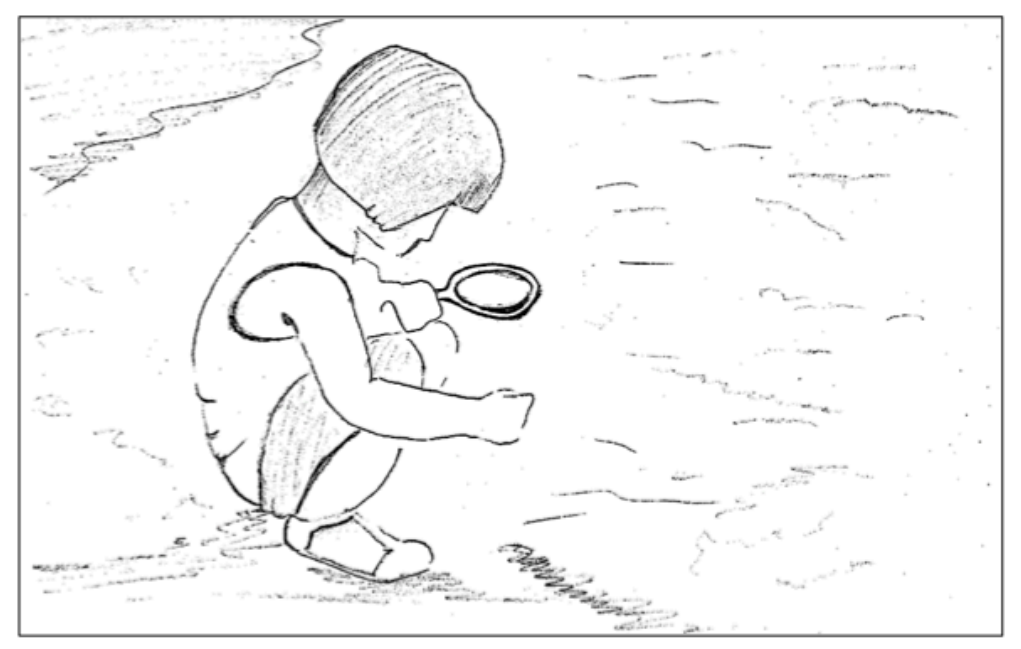

Figure 14.

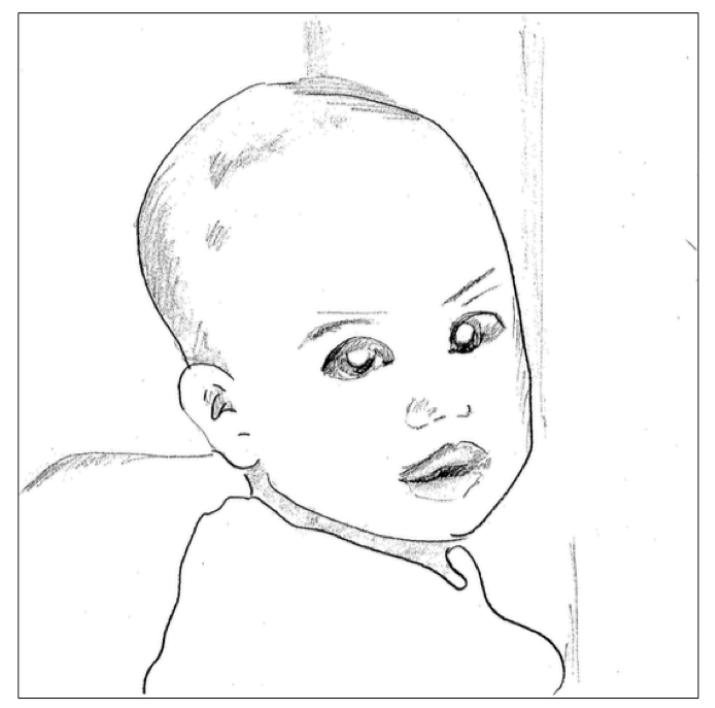

Figure 15.

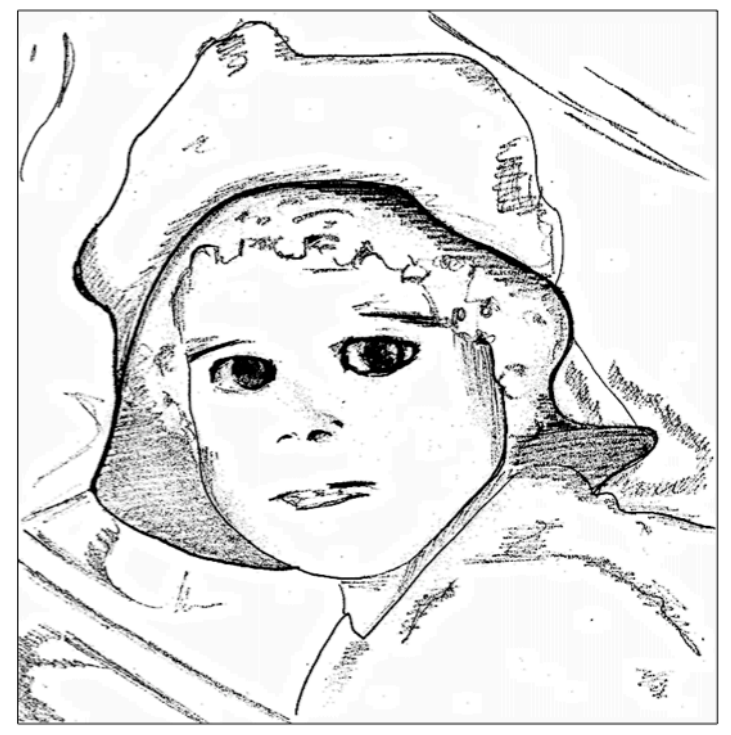

Figure 16.

69 


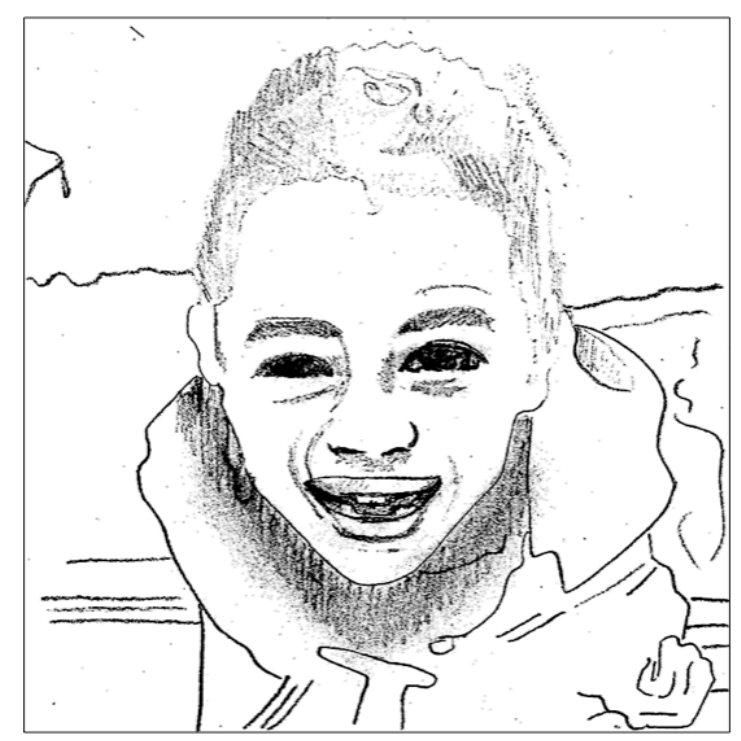

Figure 17.

Taking up a critical visual methodology in this work means that these rather obvious observations concerning the photographic images present in the revised Te Whāriki (2017a) document should not be taken for granted. To reiterate, Rose (2001) defines a critical visual methodology as

an approach that thinks about the visual in terms of the cultural significance, social practices and power relations in which it is embedded; and that means thinking about the power relations that produce, are articulated through, and can be challenged by, ways of seeing and imaging (p. 3).

In this respect pedagogical documentation, often laden with visual imagery of children, can be considered a particular social construction that foregrounds specific things and omits others (Dahlberg et al., 2006), as well as a discursive practice that constructs children in various ways (Alasuutari \& Karlia, 2010; Lenz Taguchi, 2010; Liljestrand \& Hammarberg, 2017). With this in mind the question here might become something like: what is being produced or articulated through the photographic practices of pedagogical documentation (in this case the Aotearoa-New Zealand early childhood curriculum) that, with some consistency (but not exclusively), frames the child through the medium of digital photography as an isolated individual? One way to explore this question might 
be to illuminate the parallels between the rise of the competent child, learnification, priority learner, performativity and broader rights-based discourses and the prioritization of responsibility and self-reliance within what Nikolas Rose (1999) terms advanced liberal approaches to government.

Liljestrand and Hammarberg (2017) suggest that... "the child as a competent citizen (in the broadest sense of the world) is an emergent international discourse in relation to the notion of the child as a unique individual demanding a child-centered pedagogy" (p.2). Vandenbroeck and Bouverne-De Bie (2006) point out the problematic nature of drawing a direct link between shifting conceptions of childhood and neoliberal policy. However, Smith (2011) points to research in the context of early years curricula (for example, Ailwood, 2004; Graham, 2007) that illuminates how ideas about children's competence and agency have been prioritized in contemporary discourse concerned with notions of childhood "in ways which resonate strongly with the idea of the selfmaximizing, entrepreneurial subject of neoliberal and advanced liberal thought" (Smith, 2011, p. 30).

\subsection{Learnification}

Biesta (2009) articulates that notion of learnification as a particular discourse concerned with "the translation of everything there is to say about education in terms of learning and learners" (p. 38). In distinguishing between notions of 'learning' and 'education', Biesta suggests that we can understand learning as a concept that promotes individualistic aims, whereas the concept of education implies and necessitates a procedural relationship of some sort in which the educator has a sense of purpose around his or her pedagogical activities (Biesta, 2009). Steeves (2012) suggests that the notion of learnification can be linked with what Biesta (2007) calls a democratic deficit within education. The concern here being that the discourse of learnification - the unrelenting focus on the individual/learner - may act to erode democratic values that inform teachers' work. Thus, learnification may be a discourse that "threatens to replace professional judgment and wider democratic deliberation about the aims, ends, and conduct of education" (Biesta, 2007, as cited in Steeves, 2012, p. 17). 
Biesta (2009) suggests that the notion of learnification and the learner centric language that unfolds around it - for instance, the word learner instead of pupil or student (and I would add child in the context of early childhood education); and the term life-long learning instead of permanent education - is a result of an assemblage of various, in some cases contradictory, trends and developments that transcend any one specific underlying agenda. Biesta (2009) explains that this assemblage includes:

(1) the rise of new theories of learning that have put emphasis on the active role of students [children] in the construction of knowledge and understanding and the more facilitating role of teachers in this; (2) the postmodern critique of the idea that educational processes can be controlled by teachers and ought to be controlled by them; (3) the so called 'silent explosion' of learning (Field, 2000) as evidenced in the huge rise of informal learning throughout people's lives; and (4) the erosion of the welfare state and the subsequent rise of neo-liberal education policies in which the individual is prioritized over and above other factors which has shifted the responsibility for (lifelong) learning from 'provider' to 'consumer', turning education from a right into a duty (p. 38).

In the context of this thesis I am not so much concerned with the 'language' of learnification/the competent child and how this manifests in the revised Te Whāriki (2017a) document - this would be an important work in and of itself, and I do not have the space here to explore the subtleties of a linguistically focused discourse analysis. Rather, I am interested in foregrounding a series of visual representations present in the revised Te Whāriki (2017a) document and drawing attention to the way in which they resonate with broader individualizing discourses of the child, which include that of the agentive/competent child and the discourse of learnification. As stated above, a significant feature of the photographic images subject to the analysis of this chapter is that children are depicted/framed as isolated individuals with adult figures featuring rarely. My contention is that such visual statements matter and hold a significant position in what we might consider the discursive formation of this particular curriculum, constituting a kind of visual politics. In the above two 
sections of this chapter I have foregrounded the discourses of the agentive/competent child and learnification, drawing attention to the ways in which these discourses can be understood as reflected in/proliferated through visual representations of children in the context of pedagogical documentation. In the next section I outline Nikolas Rose's (1999) thinking around advanced liberalism by means of examining the links/parallels between the discursive construction of the child explored so far and broader relations of power. It is important to reiterate that this process of analysis has no intention of producing a comprehensive or straight forwardly coherent argument, but rather exemplifies a foray into how photographic practices and the visual discourses they produce are entangled in the assemblage of rationalities that construct the young educated subject at this particular point in history.

\subsection{Advanced liberalism}

Rose (1999) suggests that a particular way of thinking about the "objects, targets, mechanisms and limits of government" (p. 139) formed over the last two decades of the twentieth century. This new mode of government involves the reconceptualization of...

the inherent rationality of different domains to which government must address itself - the market, the family, the community, the individual - and new ways of allocating the tasks of government between the political apparatus, 'intermediate associations', professionals, economic actors, communities and private citizens (Rose, 1999, pp. 139-140).

These assemblages of rationalities (or a new diagram of government) are what Rose (1999) terms an advanced liberal approach to government. Rose explains that the neoliberal notions of choice, competition and enterprise are central to this advanced liberal regime. These neoliberal notions form a particular conception of the social subject/human actor - shifting from the economic subject of interest in the nineteenth century, to the entrepreneurial self (Rose, 1999). Thus, Rose (1999) explains, "the idea of the 'social state' gives way to that of the 'enabling' state" (p. 142). With this in mind we might ask: to 
what extent has this reconceptualization of government (and by extension the social subject) permeated state institutions? And which details, or products derived from these institutions might we examine to understand this permeation? In the context of this work the state institution of interest is obviously early childhood institutions and the 'products' of concern here are photographic images.

Kampmann (2004) draws attention to how the notion of the competent child both creates new opportunities for children and introduces forms of control that hold the potential to place burdensome levels of responsibility on the young. We might consider this seemingly contradictory interconnection between freedom and control as a key insight that a Foucauldian conceptualization of governmentality offers us (Smith, 2011). Following this line of thought, individual freedom itself becomes a form of control - sovereignty over the self (Rose, 1999). Children have not always been 'free' in this sense. Smith (2011) states that

the extension of freedom (in the sense of citizenship rights) to the mass of the adult population in western states is associated with increasing external regulation of childhood. Children's 'rights' were understood in a narrow sense in terms of restriction on parental sovereignty designed to ensure compliance with childrearing norms (p. 31).

Rose (1999) brings attention to the ways in which this understanding of children's rights has broadened over the last few decades. Rose suggests that this broader notion of children's rights can be understood in relation to the shifting conceptions of freedom, which relates to the kinds of selves to be governed in an advanced liberal society (Rose, 1999). The United Nations Convention on the Rights of the Child (UNCROC) is exemplary in foregrounding the ways in which the rights of the child have been reconceptualized over the last few decades. The following passage is taken from the New Zealand Ministry of Social Development website: 


\section{In simple terms, what are the UNCROC rights?}

UNCROC gives children and young people up to the age of 18 the right to:

- Life, survival and development

- The Government making sure that the best interest of the child are taken into account when making decisions about the child

- Access to education and health care

- Grow up in an environment of happiness, love and understanding

- Protection from discrimination of any sort

- Develop their personalities, abilities and talents

- Protection from sexual exploitation, abuse and economic exploitation

- Special measure to protect those that are in conflict with the law

- An opinion and for the opinion to be heard

- Be informed about and participate in achieving their rights

- Special measures to protect those belonging to minority groups (New Zealand Ministry of Social Development, n.d., para. 4). Retrieved from https://www.msd.govt.nz/about-msd-and-our-work/publicationsresources/monitoring/uncroc/

The sentiments put forward by UNCROC clearly influence contemporary early childhood syllabus. The vision statement presented in the opening pages of the revised Te Whāriki (2017a) document is reflective of this influence or translation (Rose, 1999): Te Whāriki is underpinned by a vision for children who are "competent and confident learners and communicators, healthy in mind, body and spirit, secure in their sense of belonging and in the knowledge that they make a valued contribution to society" (Ministry of Education, 2017a, p. 5).

As discussed above, government and governance in Foucauldian terms includes "any strategy, tactic, process, procedure or programme for controlling, regulating, shaping, mastering or exercising authority over others in a nation, organization or locality" (Rose, 1999, p. 15). In this sense subjectivity (understood in this context as the mediated relationship of the individual to the self) is constructed through various forms of knowledge and expertise utilized in diffuse practices of government (Smith, 2011). Considering Foucault's notion of 
governmentality in relation to the above UNCROC passage and Te Whāriki (2017a) vision statement is not to suggest that these contemporary rights are 'bad' or 'wrong' in any totalizing way, or to dismiss the inequalities such articulations/initiatives aim to address. Rather, the insight we can draw from Foucault's thinking is that everything is dangerous (Foucault, 1997) and power is everywhere (Foucault, 1977), thus we should not assume that children's relatively recent status as rights bearing individuals is unproblematic or smoothly emancipatory. As Deleuze and Guattari (1994) concisely note: "Human rights say nothing about the immanent modes of existence of people provided with rights" (p. 107). Consider the logic of the second bullet point above for instance: "UNCROC gives children and young people up to the age of 18 the right to the Government making sure that the best interests of the child are taken into account when making decisions about the child" (New Zealand Ministry of Social Development, n.d., para. 4). In a sense this short quote encapsulates the core of the problem behind emancipatory discourses which governmentality literature concerns itself with: it asserts freedom and control in the same breath. By way of translating this thought, these words, into a visual medium I would ask the reader to muse over the following image:

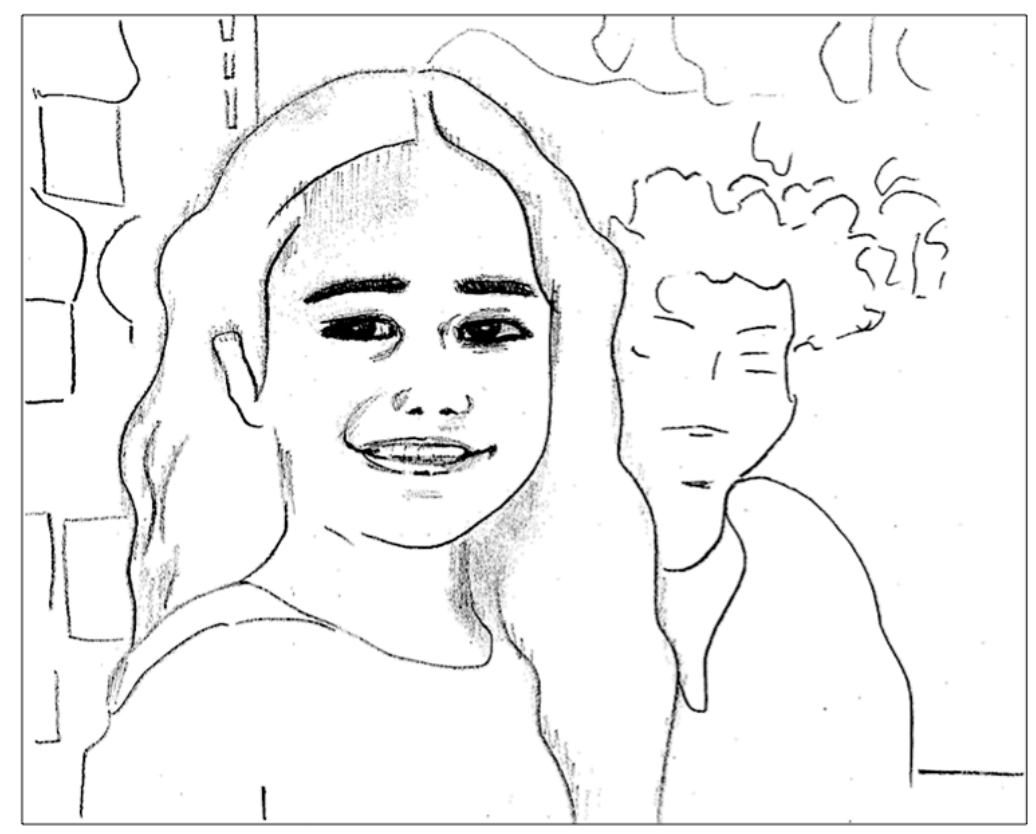

Figure 18. 
Considered against the backdrop of governmentality literature the complex and arguably insidious nature of such an image is brought to the fore. Much like the UNCROC utterance quoted above I would suggest that a visual statement such as this also asserts freedom and control in the same breath (or sight as the case may be). The adult figure lingers in the background, slightly out of focus, 'governing at a distance' (Rose, 1999). The child fills the majority of the frame. She is depicted smiling, directly addressing the camera. Her hair is neatly parted and her posture reads, to my mind, rigid and highly staged. In my experience such attentiveness and composure towards a camera is an extremely rare state of being to witness in young children; movement and messiness generally seem to be more accurate ways of describing young children's being. The child here is rendered 'womanly'/adult-like, ordered and still through the inscriptive practice of photography. The body of the girl here is forced to signify its relationship to social norms: the composure of an 'adult', the attentiveness and positive attitude of a 'learner'. In this sense, how we frame children and reflect these images back to them through the medium of photography is significant and laden with ontological assumptions. The most pressing of which, to my mind at least, are those assumptions that assert children/childhood as a transitory process of becoming 'adult', rather than a significant state of being in and of itself. Here an interesting tension/contradiction emerges between contemporary discourses of agency/competence and more historically situated (developmental psychology) discourses of the child conceptualized as a human becoming. I will take this point up further in the next chapter and draw on the new sociology of childhood literature (Prout \& James, 1997; Prout, 2005) to contextualize and examine this point in depth.

It is important to note here that the image above may represent or denote various meanings and perform various functions depending on the readers' socio-cultural, political and theoretical preoccupations. I recognize that different images/sets of statements are intended to do different 'work' and aim to service different ends. For example, we might consider the function of Figure 18 above in terms of how it addresses issues of cultural diversity and inclusivity through the visual representation of minority cultures in the context of Aotearoa-New 
Zealand early childhood education environments. Through offering a critical interpretation of the content and aesthetic properties of the image above I am not trying to construct a comprehensive argument aimed at discrediting the injustices such inclusive representational practices aim to address. Rather, to analyze such an image in relation to governmentality literature is simply to recognize that such representations are never unproblematically emancipatory and that power is always invested in representational practices. Visual representations of agentive/competent minority learners involve particular mechanisms of power and produce particular sets of discursive statements and practices, which construct particular 'learner' subjectivities. We might consider the discourse of 'priority learners' as a further example of how governmental power is invested in such visual representations and how these representations are entangled within and form part of wider official (linguistically-based) discourses.

The education review office (ERO) states that:

Research indicates that some of our most vulnerable children include Māori, Pacific, those from low-income families, and children with special learning needs. The government identifies these groups as priority learners... In early childhood education settings, priority learners will be the children the service has identified that require additional support to help them achieve equitable outcomes (Education Review Office, n.d., para. 4). Retrieved from http://www.ero.govt.nz/publications/he-pou-tataki-how-ero-reviews-earlychildhood-services/part-2-outcomes-for-children-in-early-childhood-education/

Through the lens of governmentality we might consider the discourse of 'priority learners' problematic on the grounds that it acts to stigmatize certain children and parents that, through a normative evaluation/judgment, are labeled 'irresponsible' or 'vulnerable'. Vandenbroeck and Bouverne-De Bie, (2006) suggest that the conceptualization of children as competent social actors and the concurrent autonomy this endows children with does not necessarily challenge social inequality but, rather, may act to reinforce the effects of existing structural inequalities. As Smith (2011) notes "children reared in low income families have 
frequently been regarded as inadequately socialized and consequently as potential liabilities to be contained" (p. 35). A further concern is related to the way in which the discourse of 'priority learners' operates in such a way that positions children reductively and dichotomously as potential assets or potential liabilities in relation to a broader social and political context (Smith, 2011). In this sense we can consider how visual representations depicting children as competent social actors who are identified as minority cultures, or 'vulnerable learners', are implicated in particular mechanisms of power and entangled with broader discourses that, contrary to their intended effect, may act to reinforce the social inequalities they intend to overcome. Such perspectives trouble the apparent emancipatory function of the 'priority learner' discourse foregrounded here and bring to the surface the importance of challenging the taken-forgranted function (and widely accepted denotation) of visual representations within educational syllabus.

Meditating on the above image (and the many like them depicted above), we might also consider the way in which such visual statements resonate with the discourse of performativity. Ball (2013) explains that performativity is a pervasive form of accountability discourse in the context of education and the "quintessential form of neoliberal governmentality, which encompasses subjectivity, institutional practices, economy and government... it is both individualizing and totalizing" (p. 31). Ball (2003) suggests that the translation of complex social processes and events into simple figures or categories of judgment is central to the functioning of performativity. Ball (2003) goes on to explain that:

What one wants to attempt here is to 'get behind' the objective façade of this aspect of public sector reform and its technical rationalities of reform to examine the subjectivities of change and changing subjectivities which are threatened or required or brought about by performativity (p. 217).

With the above insights offered by Ball $(2003 ; 2013)$ in mind we might start to consider particular photographic images within the context of the reformed 
Te Whāriki (2017a) document in terms of how they are representative or productive of this reduction of complex social processes and events into simple figures/categories (photographic images) essential to the functioning of the performativity discourse. Although I do not have the space within the scope of this work to thread notions of performativity throughout and expand on its nuances and complexities in depth, it is useful to foreground performativity and position these ideas in relation to the assemblage of diffuse individualizing discourses of concern here. It is useful in the sense that it is another significant line of sophisticated critical inquiry that can function in such a way that picks apart the taken-for-granted individualizing discourses addressed in this work and 'get behind' their objective façade as they manifest and are galvanized in diffuse policy networks.

It could be suggested that any reconceptualization of children/childhood (whether through the discourses of agentive/competent child, learnification, broader rights-based discourse, priority learner discourse, or the discourse of performativity) is a paternalistic and hegemonic one that soon settles and calcifies. Once settled the adult practices enacted in reaction to these new conceptions are those for children to endure alone. The practices of interest here are photographic in nature. I aim to offer a series of speculative threads within the scope of this chapter that speak to resonances between the visual-discursive construction of the child as manifest in the revised Te Whāriki (2017a) document and broader discourses around the agentive/competent child that are understood to construct particular subjectivities, which an advanced liberal regime demands of the child subject at this particular point in history. In other words, and as stated above, this approach can be considered as a series of attempts to draw speculative links and parallels between the visual-discursive construction of the child and broader relations of power.

One thread to follow, by means of elaborating upon the seemingly contradictory thesis that reconceptualizations of childhood that focus on the child as an autonomous agent may place potentially arduous responsibilities on the young, may be to consider the connected spheres of consumption and what 
Nikolas Rose (1999) terms psychotherapeutics (p. 84-93). What I hope to convey here is that the inscriptive process of photographic imaging making practices is a politically significant action/field of inquiry that exceeds the local context in which it is carried out. With this in mind I suggest that, as early childhood teachers, researchers, and policy makers it matters what we point the camera at and how we interpret theses mediated representations. This is so because representations are always a form of mediation, and mediations are never just transparent windows into an objective reality. Rather, they add to and subtract from that which is being represented in significant ways... "They are slippery and create effects not always intended or even apparent to those who do the representing" (Prout, 2004, p. 85).

\subsection{Consumption \& Psychotherapeutics}

Through an engagement with a Foucauldian conceptualization of governmentality we can consider the ways in which subjectivity (the relationship of the individual to the self) is constructed through various forms of knowledge and expertise deployed within practices of government, where government is understood as "any strategy, tactic, process, procedure or programme for controlling, regulating, shaping, mastering or exercising authority over others in a nation, organization or locality" (Rose, 1999, p. 15). Following this logic Rose (1999) asks how the personal practices of consumption can be linked with the political problem of the government of conduct. Rose (1999) brings attention to the ways in which technologies of mass consumption, taking shape over the course of the twentieth century, constructed a new relationship between the self and the world of goods.

For the first time, this power of goods to shape identities was utilized in a calculated form, according to rationalities worked out and established, not by politicians, but by salesman, market researchers, designers and advertisers who increasingly based their calculation upon psychological conceptions of humans and their desires... Consumption technologies... established not only a 'public habitat of images' for identification, but also a plurality of pedagogies for living a life that is both 
pleasurable and respectable, both personally unique and socially normal (Rose, 1999, p. 85-86).

By means of elaborating on what we can understand as psychotherapeutic Rose (1999) defines therapeutic broadly as "a certain rationality for rendering experience into thought in a way that makes it practicable, amendable to having things done to it" (p. 90). Thus, the psychotherapeutic landscape consists of

all those practices in which one problematizes one's existence in terms of an interpretation of its inner psychological and psychodynamic meanings and determinants, acts upon one's dilemmas in terms of psychological interpretations of their implications, and intervenes upon oneself (alone or with the assistance of others) in terms of psychological norms and techniques - through self-inspection, self-problematizing, self-monitoring and self-transformation (Rose, 1999, p. 90).

Following this line of thought Rose argues that the interconnected spheres of consumption and psychotherapeutics are fundamental components in providing the conceptual resources through which we have come to relate to ourselves under an advanced liberal regime. Key to Rose's (1999) argument is bringing attention to the intersecting ideas between popular psychology notions of individual fulfillment and self-actualization and consumerists notions of life-style choice, which, Rose suggests, was disseminated through the domain of purchasable goods and has come to permeate the most intimate spheres of human existence (Rose, 1999, as cited in Smith, 2011). In this regard Rose claims that the consequential regime of the self produced through the interrelated domains of consumption and psychotherapeutics has resulted in freedom becoming increasingly associated with individual autonomy, where autonomy is understood reductively as the 'right to choose' (Rose, 1998; 1999). Smith (2011) suggests such a right is increasingly afforded to children, drawing on the work of Cook (2004) to illustrate her point.

In The Commodification of Childhood Cook (2004) explains that the relationship between psychological expertise and marketing strategies has been fundamental in constructing the child as an autonomous choosing subject. Cook 
goes as far as to suggest that "children's participation in the world of goods as actors, as persons with desire, underpins their current emergent status as rightsbearing individuals" (Cook, 2004, as cited in Smith, 2011, p. 32). Representations of agentive children/childhood are mediated in particular ways through advertising and media, calling upon adults (parents, educators and policy makers) to relate to children in particular ways and effecting the way in which children relate to themselves (Smith, 2011). Rose (1999) employs the term translation to account for this kind of diffuse and fluid discursive formation: "In the dynamics of translation, alignments are forged between the objectives of authorities wishing to govern and the personal projects of those organizations, groups and individuals who are the subjects of government" (Rose, 1999, p. 48). My work here is concerned with drawing attention to the significance of visual representations of children within this diffuse and fluid discursive formation that makes government possible.

Rose (1999) articulates his concept of translation in relation to the work of Michel Callon and Bruno Latour. Callon and Latour employ conceptions of translation and conquest to explain the relationship between governmental problematizations and the standards/ideals of what we perceive to be rigorous science (Callon, 1986; Latour, 1983; 1986, as cited in Saari \& Harni, 2016). These authors define translation in the broadest sense of the word through drawing on the Latin translatio, meaning to transfer, transport or carry something over from one thing to another. "Translation thus gathers elements (concepts, subjects, materials and practices) into a part of the same network that fixes their positions and interrelations within it" (Latour, 2005, as cited in Saari \& Harni, 2016, p. 95). The translation process that Rose (1999) is interested in are those which "link up the concerns elaborated within rather general and wide-ranging political rationalities with specific programmes for government of this or that problematic zone of life" (p. 50). In this way translation

links the general to the particular, links one place to another, shifts a way of thinking, from a political centre - a cabinet office, a government department - to a multitude of workplaces, hospital wards, classrooms, child guidance centres or 
homes. Thus national programmes of government can render themselves consonant with the proliferation of procedures for the conduct of conduct at a molecular level across a territory (Rose, 1999, p. 51).

In the context of this thesis the specific programme of interest could be understood as Aotearoa-New Zealand early childhood care and education centres. In this sense I utilize the revised curriculum Te Whāriki (2017a) under the assumption that this document is a widely adopted and informative piece of policy literature in the context of this programme. The advanced liberal rationalities discussed above can be understood as the wide-ranging political rationalities (Rose, 1999) of concern in this work. In this respect I am interested in exploring how the entrepreneurial subjectivities that are produced through advanced liberal rationalities link up with a particular practice (or procedure for the conduct of conduct) that operates within a specific programme at a molecular or local level. In other words, how does an advanced liberal programme of government render itself consonant with the photographic image making practices exemplified in the revised Te Whāriki (2017a) document? Through an engagement with this question we can begin to explore the fluid and diffuse visual-discursive formation that makes government possible. I anticipate a critique by imagining that some may consider this approach to analysis incoherent in that it explores links or relations between (visual) statements in a non-systematic, non-linear way the lacks scientific or empirical 'integrity.' I think Foucault (1972) discussion of discursive formations (and by extension his approach to analysis) in The Archaeology of Knowledge addresses such a concern beautifully by foregrounding what such an analysis is not trying to do. Speaking on his approach to confronting the relations between a number of statements (discursive formation) Foucault (1972) explains that:

Such an analysis would not try to isolate small islands of coherence in order to describe their internal structure; it would not try to suspect and to reveal latent conflicts; it would study forms of division. Or again: instead of reconstituting chains of inference (as one often does in the history of science or of philosophy), instead of drawing up tables of differences (as the linguists do), it would describe systems of dispersion (p. 37). 
In this respect the analytical approach in this section brings attention to the way in which photographic images of young children are dispersed within particular systems and aims to illuminate the thematic resonances between these systems. Again, it is important to reiterate that this analysis is limited and partial. In this sense I do not intend to convey that the agentive/competent child produced through visual discourse is totalizing or inevitable, or that the entrepreneurial subjectivities produced through advanced liberal rationalities link up with these local discursive practices in any straightforward way. As foregrounded above this is a modest and experimental attempt to create a slightly more nuanced view of the relationship between (photographic) educational practices and the subjectivities they produce (knowingly or unknowingly) in service of broader relations of power. Gilles Deleuze (1995), speaking on Foucault's conceptualization of subjectivity/subjectification explains that

processes of subjectification are nothing to do with "private lives" but characterize the way individuals and communities are constituted as subjects on the margins of established forms of knowledge and institutional power, even if they thereby open the way for new forms of knowledge and power. Subjectification thus appears as a middle term between knowledge and power, a perpetual "dislocation," a sort of fold, a folding or enfolding... Foucault was fascinated by the movements of subjectification taking shape in our present-day societies: what modern processes are currently at work producing subjectivity (p. 151)?

As I hope to have shown in the opening chapters of this thesis visual systems of representation/visual culture can be understood as central to the construction of social life in contemporary western societies. I have suggested that the centrality of the visual (ocularcentrism) is obviously reflected in the revised Te Whāriki (2017a) document given that this is the first iteration of the curriculum that has included photographic images. I have also suggested that the prominence of discussion around the inclusion of photographic images (manifest in the engagement process document) is reflective of both the status of the visual in contemporary society and the lack of critical thought around those visual practices, specifically those of pedagogical documentation. This chapter has 
attempted to problematize the assumed objectivity/unproblematic nature of the photographic image and offer a critical perspective in relation to the inclusion of this visual medium in the Aotearoa-New Zealand early childhood curriculum. My intention here is to advocate for a healthy skepticism around the unacknowledged power of the photographic image to form or construct the young educated subject. In this way (inspired by Foucault's fascination with movements of subjectification) I examine a particular (post) modern process that is currently at work producing subjectivity in a particular institutional context. It is suggested that particular visual representations of children can be understood to resonate with broader contemporary individualizing discourses of the child (agentive/competent, learnification, priority learner and performativity discourses) and that these conceptualizations resonate strongly with the entrepreneurial subject of neo/advanced liberal thought. In this way photographic depictions of children within Te Whāriki (2017a) can be understood as a part of a discursive formation that produces a particular kind of educated subject that an advanced liberal approach to government demands.

With the above conceptual landscape in mind, a critical examination of the photographic image making practices of pedagogical documentation would necessitate the opening of a space to contrast and discuss the visual-discursive statements of pedagogical documentation with those images produced through broader networks of (advanced liberal) power. I am interested here in thinking about agentive representations of children in advertising images as a mediating force or kind of representational agent for what Rose (1999) terms the enabling state that advanced liberal approaches to government aim to produce. Such an examination brings to the fore visual parallels between agentive representations of children within the framework of pedagogical documentation and those that operate in a wider social context through media and advertising images. In this way we can start to speculate/experiment around how advanced liberal rationalities link up with the locally situated discursive practices of pedagogical documentation. In this regard I offer another attempt at drawing links/parallels between the visual-discursive construction of the child (as manifest in a selection of images utilized within Te Whāriki) and broader relations of power (manifest 
in generic advertising images that represent children as agentive consumers, which operate in a wider social context to service the ends of an advanced liberal regime). My contention is that the landscapes of mediated photographic images of young children that permeate contemporary western society (considered through Rose's notion of translation) play a significant role in constituting the child as an autonomous, agentive and entrepreneurial subject that neo/advanced liberal rationalities demand of the individual. Consider the following series of images in relation to each other. Figures 19, 21, 23 and 25 derive from a broad Google images search: 'Children in advertising and media'. Figures 20, 22, 24 and 26 derive from the revised Te Whāriki (2017a) document.

This content is unavailable

Please consult the print version for access

Figure 19.

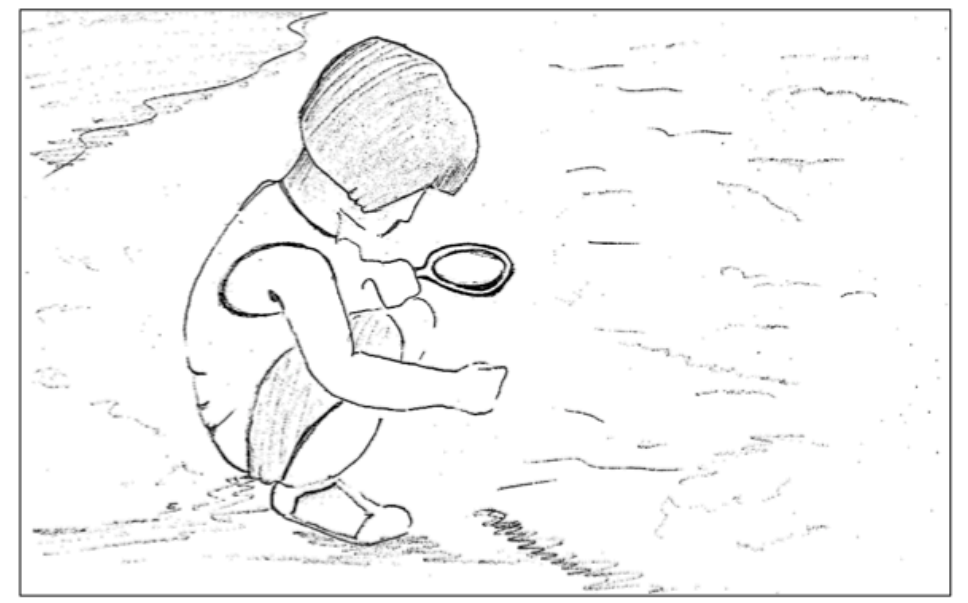

Figure 20. 


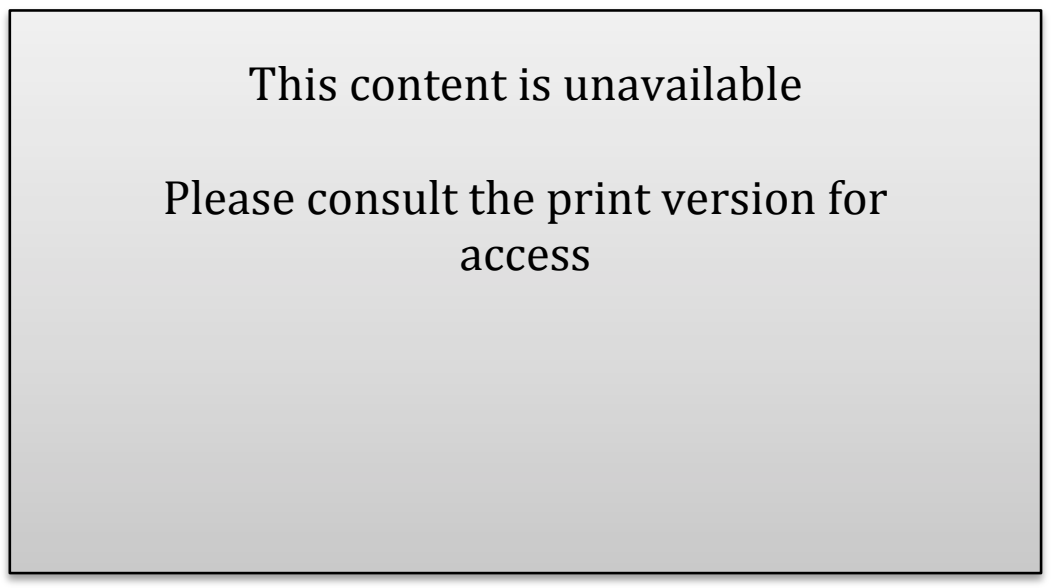

Figure 21.

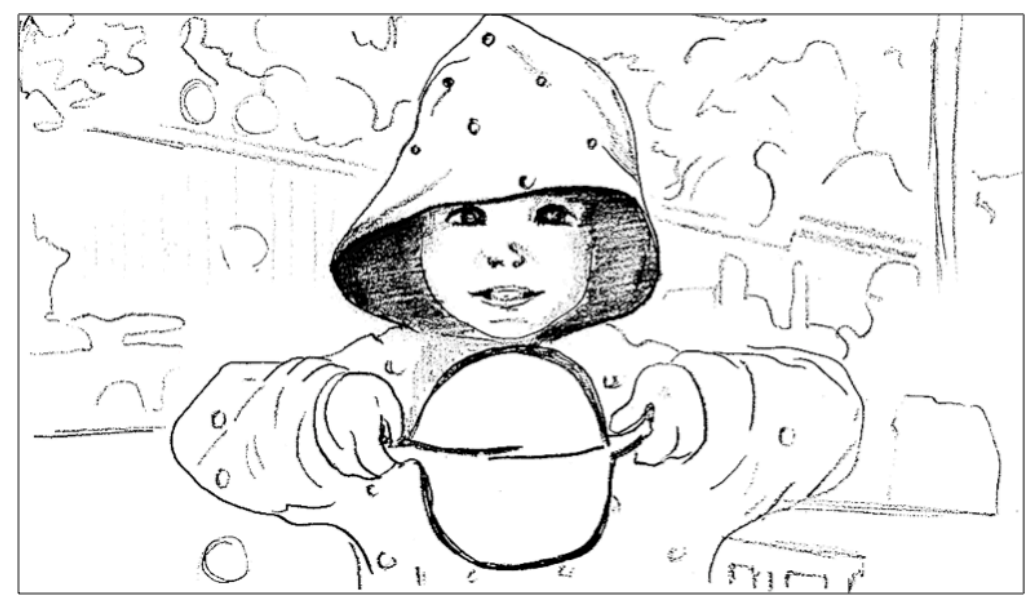

Figure 22.

\section{This content is unavailable}

Please consult print version for access

Figure 23. 


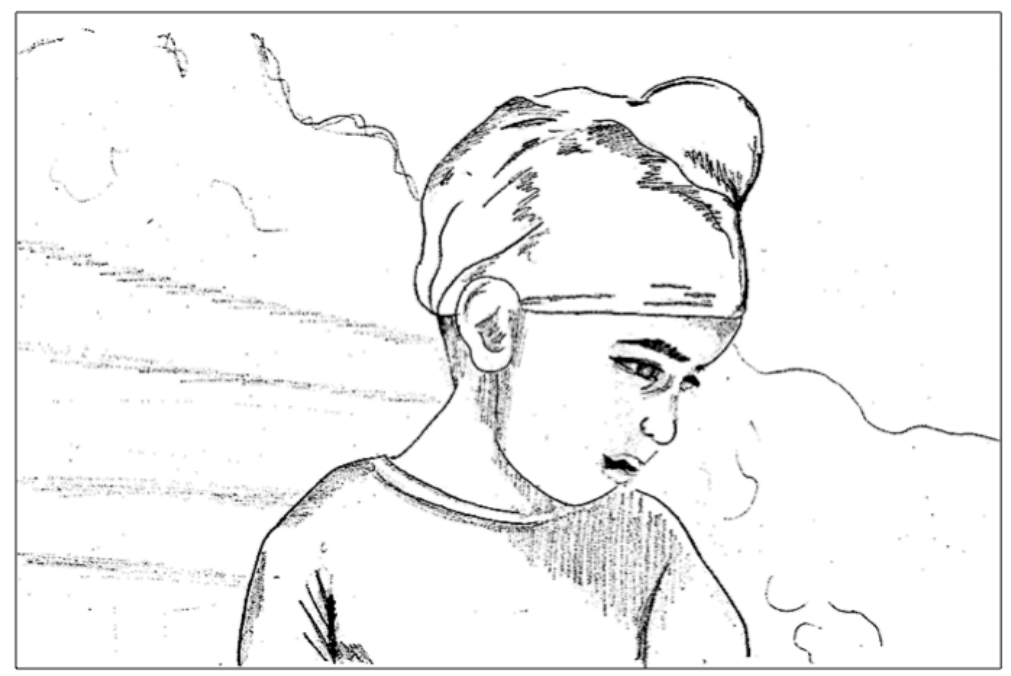

Figure 24.

This content is unavailable

Please consult print version for access

Figure 25.

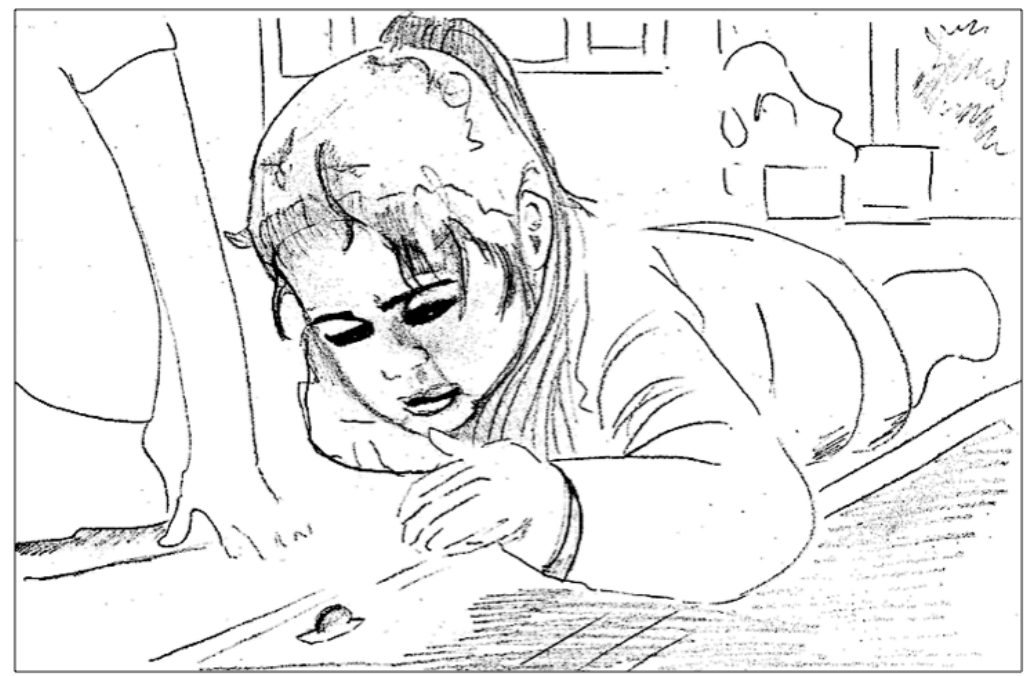

Figure 26. 
We might ask what similarities these depictions display. Perhaps the most obvious of which is that all of these images depict children as agentive/competent individuals. The photographer in each instance has framed the children in such a way that isolates the individual from the wider environment to varying degrees. Through the technological apparatus of the camera the photographer has focused sharply on the child, an effect of which being that the background (to varying degrees) is out of focus. The aesthetic properties of these images draw the eye to the child in focus at the center of the frame. The individual child is thrown into sharp relief through the medium of photography, calling upon us as viewers to relate to these children in particular ways. No adult figures feature in these images. In a sense the individual is separated from the dynamic multiplicities of the social environment. The inter and intra connected and material-relational qualities of being a child are silenced to some extent. Musing over these images in relation to each other allows us to consider the parallels and resonances between visual representations of agentive children within pedagogical documentation and those that operate in a wider social context through advertising and media images of children. In the context of this work Nikolas Rose's (1999) concept of translation is a useful tool for examining the way in which broad government rationalities of an advanced liberal nature might render themselves consonant/link up with a particular practice (or procedure for the conduct of conduct) that operates on a local level within a specific programme of government (such as early childhood centres and other educational institutions).

It is important to note that this kind of exercise is not an attempt to draw definitive links between advertising images of children and those produced through pedagogical documentation. Of course the motivations of those performing the documentation are vastly different in each context and obviously aim to service different ends. What is interesting to me, thinking with Michel Foucault and Nikolas Rose, is the extent to which visual representations of children exceed themselves, bleed beyond the frame and create particular effects that might be understood to service oppressive regimes of truth/selfhood across various programmes of government. What I hope such an exercise is able to 
illuminate is that mediated representations of children are just that, mediated, and alter that which is being represented in significant ways, creating "effects not always intended or even apparent to those who do the representing" (Prout, 2005 , p. 85). In this sense I want to suggest that the practice of photographic image making does not offer a transparent window into children's worlds through which we can lay objective or neutral descriptions concerning children's activities or human nature more generally. Rather, for the purposes of this work (particularly this chapter and the next), I suggest that such a practice mediates particular governmental interests and power relations. In this way photographic images of young children, understood in terms of visual discourse, are (in part and among other forms of representation) productive of particular kinds of educated subjects.

\subsection{Conclusion}

As suggested above Foucault's (2007) notion of governmentality provides a useful conceptual tool through which the dormant meanings within contemporary discourses of childhood can be opened up for debate and critical analysis. If we come to consider government as a force that seeks to shape rather than exclude human agency (Foucault, 2007) then it becomes important for the critical analyst to consider how agency is represented. For the purposes of this thesis the representations in question are visual in nature. In the above section I have brought attention to two seemingly disparate spheres that represent children through visual systems of representation - pedagogical documentation and advertising - as a way of thinking about the resonances/parallels between the visual-discursive construction of the child (as manifest in Te Whāriki) and broader relations of power and the discourses they instantiate (as manifest in advertising images that take young children as their subjects). I have suggested that, through an engagement with the concept of translation, these visualdiscursive statements exceed the local context in which they are produced and service ends that may not always be intended by those doing the representing.

We might understand this 'end' in terms of the production of autonomous, entrepreneurial, individual subjects imbued with the capacity to work upon 
themselves (Fender, 2001). This end can be understood as problematic in the sense that it acts to erode other educational values such as community and interconnectedness (Hsueh \& Tobin, 2003) and naturalizes notions of individualism and entrepreneurialship demanded from a particular economic enterprise (Fender, 2001; Smith, 2011). In this respect Fender (2001) suggests, the end goal (the production of flexible souls) is predetermined and can be perceived through a conceptualization of success defined in reductive and restrictive economic terms. Kelly (2006) articulates this point in the following way:

It is not that 'initiative', 'enterprise', 'responsibility', or 'activity' are not worthwhile human capacities... Rather, it is that within the frame of entrepreneurial Selfhood, as it is imagined at the turn of the second millennium CE, 'initiative', 'enterprise', 'responsibility', and 'activity' are narrowly imagined in relation to the performance of exchange relations in the extended order of capitalist markets of all sorts... And we must all assume an entrepreneurial disposition to this life form. We fail to do so at our own risk (Kelly, 2006, as cited in Smith, 2011, p. 32).

In this respect it could be concluded that the intensive focus on the individual child through the visual medium of photography is related to (and contributes towards) wider governance practices of the late modern neoliberal disciplinary state. 


\section{Chapter 5: DISCIPLINING HUMAN DIFFERENCE: THE CHILD INSCRIBED IN 'PSY' VISUAL DISCOURSE}

\subsection{Introduction}

It is not the slumber of reason that engenders monsters, but vigilant and insomniac rationality (Deleuze \& Guattari, 2009, p. 112).

The central aim of this chapter remains the same as the last: to explore the links/parallels between the visual-discursive construction of the child and broader relations of power. The initial question that formed in the introductory chapter, which acted to loosely orient my analysis, was: what is being produced or constructed through the photographic practices of pedagogical documentation (in this case the Aotearoa-New Zealand early childhood curriculum) that, with some consistency (but not exclusively), frames the child through the medium of digital photography as an isolated individual? In the preceding chapter I explored this question by illuminating the parallels/resonances between the rise of the agentive/competent child and the prioritization of responsibility and selfreliance within what Nikolas Rose (1999) terms advanced liberal approaches to government. It was concluded that the intensive focus on the individual child through the visual medium of photography could be understood in terms of its relationship to, and contribution towards, wider governance practices of the late modern neoliberal disciplinary state. This chapter approaches the same question as the previous chapter but from a slightly different perspective, exploring another aspect of how the photographic practices of pedagogical documentation are entangled in the assemblage of rationalities that construct the young educated subject in particular ways.

The rationalities of interest in this chapter are those of the 'psy' sciences and the (visual) discourse that this regime of truth instantiates. As discussed above a central concern of this work is regarding the unrelenting focus on the individual and the burdensome levels of responsibility this places on the young, ignoring and acting to erode consciousness around the inter/intra connected nature of 
teaching and learning, which includes various bodies and materials beyond the individual 'learning' subject inscribed in dominant individualizing discourses. Bendix Petersen (2016) draws attention to the ways in which mainstream psybased discourses (the intensive focus on the individual as a bounded agent with a fixed identity) coalesces powerfully with the advanced liberal rationalities examined in the previous chapter. As discussed above, under the advanced liberal regime of truth, the child is regarded as a competent, individualized learner, which can be linked to the "free-market orientated society in need of autonomous, entrepreneurial individuals" (Vandenbroeck \& Bouverne-De Bie, 2006, p. 134). In this sense, education under neo/advanced liberalism consists of increasing the value of each individual agent in terms of economy through notions of personal and social capacity and academic competence (Davies \& Bansel, 2007, as cited in Bendix Petersen, 2016).

Peterson and O’Flynn (2007) illuminate how both neoliberalism and psybased discourses presuppose that the individual human agent is imbued with the capacity to work on him or herself to become a more productive version of that self. Bondi (2005) suggests neoliberal governmentality resonates strongly with rationalist enlightenment discourse, and constructs a concept of the human subject as a bounded, autonomous and individualized agent. Becoming a 'learner' under these conditions involves a process of becoming familiar with seeing oneself and others in particular (in this case bounded and individualized) ways (Bendix Petersen, 2016). As discussed above in relation to the work of Biesta $(2007 ; 2009)$ the term learning, as apposed to education, has an individualizing function (much like the term learner, as apposed to child, in the context of early childhood education). In this way "learning centred psy-discourses become a powerful technique of 'governing at a distance'; subjects are governed through the 'learning sciences', which masks it as a politics" (Bendix Petersen, 2016, p. 71).

This chapter is concerned with how this politics operates through particular visual statements present in the revised Te Whāriki (2017a) document. As discussed in the preceding chapters visual politics can be understood in this 
context as a discursive practice that plays a central role in forming our understanding of children/childhood within a particular institutional setting (Nguyen \& Mitchell, 2012). The photographic images subject to analysis in this chapter then are considered as discursive statements that "structure the way a thing is thought, and the way we can act on the basis of that thinking" (Rose, 2001, p. 136). In this way discourse is not merely considered as "groups of signs" but also as "practices forming the objects of which they speak" (Foucault, 1997, as cited in Barad, 1998, p. 103). As was the case with the preceding chapter, this analysis is limited and partial. In this sense I do not intend to convey that the competent/individualized child produced through visual discourse is totalizing or inevitable, there is no claim here that there is a direct or straightforward relationship between discourse and subjectification. As Bendix Petersen (2016) points out, discourse might be best understood as an "invitation to subjectivity" (p. 71). This is so because, in theory, individuals still have the agency to reject or ignore the dominant discourses of neoliberal policies and practices (Patrick, 2013). However, in practice, the degree to which individuals can exercise choice over whether to consent or resist such policies and practices may be restricted by various factors - socio-material, economic and cultural (I would also add biological) for instance (Bendix Petersen, 2016). With this in mind we might consider which discourses are dominant and in what ways these discourses limit other possibilities and available options for individuals to think and act.

The analysis of this chapter is predicated on the assumption that the psysciences generally, and developmental psychology specifically, remain a privileged source of knowledge in the context of early childhood education. In the previous chapter I suggested that particular visual representations of children present in the revised Te Whāriki (2017a) document resonated strongly with broader discourses of the child in which competence and agency was a dominant theme. It was also suggested that these discourses resonated strongly with broader (advanced liberal) rationalities, which demand and are productive of flexible/entrepreneurial subjectivities. In this chapter I consider how the psysciences (specifically developmental psychology) and the visual discourses this body of knowledge instantiates is entangled in the assemblage of rationalities 
that construct the young educated subject at this particular point in history. Bendix Petersen (2016) explains that since the work of Foucault (1977) we have had an understanding that psy-discourses are a central aspect of modern educational environments and that a critical analysis of said discourses is nothing new (see for example Fendler, 2001; De Vos, 2009; Walkerdine, 1993). However,

it remains interesting to trace how psy-disciplinary knowledges and practices operate in specific times, and at specific sites, as the manifestation of psy-changes, as they are confronted by, or coalesce with, other discourses. We must keep asking critical questions about their effects on the ways we think, feel, and act (Bendix Petersen, 2016, p. 71).

In this way I hope to show within the scope of this chapter how the educated subject represented through the visual discourse of the revised Te Whāriki (2017a) document can be understood, at least in part, to be produced by the confluence of competent/agentive discourses and psy-based discourses. In both cases the child is constructed as a bounded individual with the capacity to work on him or herself in the process of becoming a more 'productive' version of that individualized self. Central to this analysis is the idea that dominant (often takenfor-granted) discourses act to foreclose other possible ways of being. In response to this concern the last chapter of this work is devoted to outlining some conceptual resources that might be understood as useful tools for moving beyond the narrow discursive construction of the child as an economic unit, or bounded individual whose end is to adopt an entrepreneurial subjectivity in service of a capitalist market place.

\subsection{The 'psy' complex and the young citizen}

In the previous chapter I have outlined Foucault's (1977; 2007) and Rose's (1999) thinking around government and the new forms it took with the emergence of the modern, liberal state. Foucault (2007) suggested that this mode of exercising power sort to shape, rather than exclude human agency. Thus neo/advanced liberalism is structured on the premise that autonomous 
individuals are willing to choose to exercise responsible self-government. In this way the notion of individual 'freedom' becomes a form of control - sovereignty over the self (Rose, 1999). Central to Foucault's thought, not covered in the last chapter (though implicit in Nikolas Rose's conception of psychotherapeutics), was how what he termed the 'psy'-disciplines - for Foucault this term encapsulated psychiatry, psychoanalysis, psychology and other psychotherapies (Bendix Petersen \& Millei, 2016) - became entangled in these new forms of government. Rose $(1990 ; 1998 ; 1999)$ has elaborated on this idea and suggested that the 'psy' sciences have come to play a key role "in the folds through which we, today, have come to relate to ourselves", and that an "analysis of these psychological 'foldings' goes some way to help us understand how, as inhabitants of this particular spatiotemporal zone, we have been brought to recognize ourselves as subjects of 'freedom'” (Rose, 1998, p. 21).

An investigation into the entanglement of the 'psy' sciences and modern form of government is perhaps most vividly exemplified in Foucault's book Discipline \& Punish: The Birth of the Prison (1977).

In part one of Discipline \& Punish (1977) Foucault offers an account of a public execution that took place in Paris. The year was 1757, and the punishment was inflicted on a man found guilty of attempting to murder King Louis XVth of France. Foucault spares no detail in his account of the torturous acts inflicted on this man, bringing attention to the burning of his flesh with sulphur, the dismembering and drawing-and-quartering of his body. After painting this vivid picture of retributive punishment Foucault goes on to bring attention to the fact that such public displays of violence lessen as we move into the nineteenth century. Foucault informs us that during this historical time period the attention shifts from public displays of bodily punishment to the mechanics of the trail and sentencing processes. The rational process comes to replace the excessive symbolism of the public execution (Jenks, 1996). Foucault argues that this shift is reflective of changing collective attitudes in a new form of society concerned with the appearance of public humanism. It is against this backdrop that overt violence carried out on the physical body is slowly transformed into more subtle 
and psychologically intrusive disciplinary practices that aim to shape the human 'soul', rather than torture/threaten the human body. In short: the governance of the individual shifted from the outside to the inside (Jenks, 1996). Foucault (1977) articulates this shift as follows:

From being an art of unbearable sensations punishment has become an economy of suspended rights. If it is still necessary for the law to reach and manipulate the body of the convict, it will be at a distance, in the proper way, according to strict rules, and with a much 'higher' aim. As a result of this new restraint, a whole army of technicians took over from the executioner, the immediate anatomist of pain: warders, doctors, chaplains, psychologists, psychiatrists, educationalists; by their very presence by the prisoner they sing the praises that the law needs; they reassure it that the body and pain are not ultimate objects of its punitive action (Foucault, 1977, p. 11).

Bendix Petersen and Millei (2016), synthesizing Foucault's thinking in Discipline and Punish (1977), explain that "18 $18^{\text {th }}$ and 19th century Europe was faced with the challenge to govern the population to ensure morality and order, but in ways that also guaranteed freedom of individuals and a free economy" (p.1). These authors explain that, through a Foucauldian lens, the various spheres of expertise (including psy-disciplines, social sciences, statistics and economics) provided a solution to this governmental challenge by constructing bodies of knowledge about individual persons, society and the economy (Foucault, 1988, as cited in Bendix Petersen \& Millei, 2016). Foucault (1997) argues that the emergent psy-disciplines provided pathways for individuals to comprehend and regulate themselves in accordance with particular scientific discourses. These emerging spheres of expertise thus enabled a shift from overt, forceful control to 'the conduct of conduct,' a space of governance in which the individual comes to govern the self through practices of self-formation. Following this line of thought Fendler (2001) suggest that psy-disciplines are 'technologies of the social,' rather that unproblematic spheres of scientific inquiry premised on simple rules and propositions in service of scientific discovery (Bendix Petersen \& Millei, 2016). 
Nikolas Rose $(1990 ; 1999)$ has taken up and elaborated upon Foucault's thinking by analyzing the ways in which educational institutions and practitioners have been central to the dissemination of psy-disciplines knowledge and practices. Through an engagement with Rose's work here I hope to show how photographic image making practices in the context of pedagogical documentation may be regarded as normalizing and individualizing visual discourse that is partly informed by psy-based knowledge(s)/particular scientific regimes of truth. Consider the photographic image of Arnold Gesell in his laboratory below (circa 1920) and the commentary Nikolas Rose offers in response to this particular image. I employ this rather long quote from Rose to set up my discussion concerning how we might understand photographic images of young children as (psy) visual-discursive statements that discipline human difference in particular ways and thus act to produce a particular kind of educated subject in conjunction with and relation to the advanced liberal discourses examined in the previous chapter.

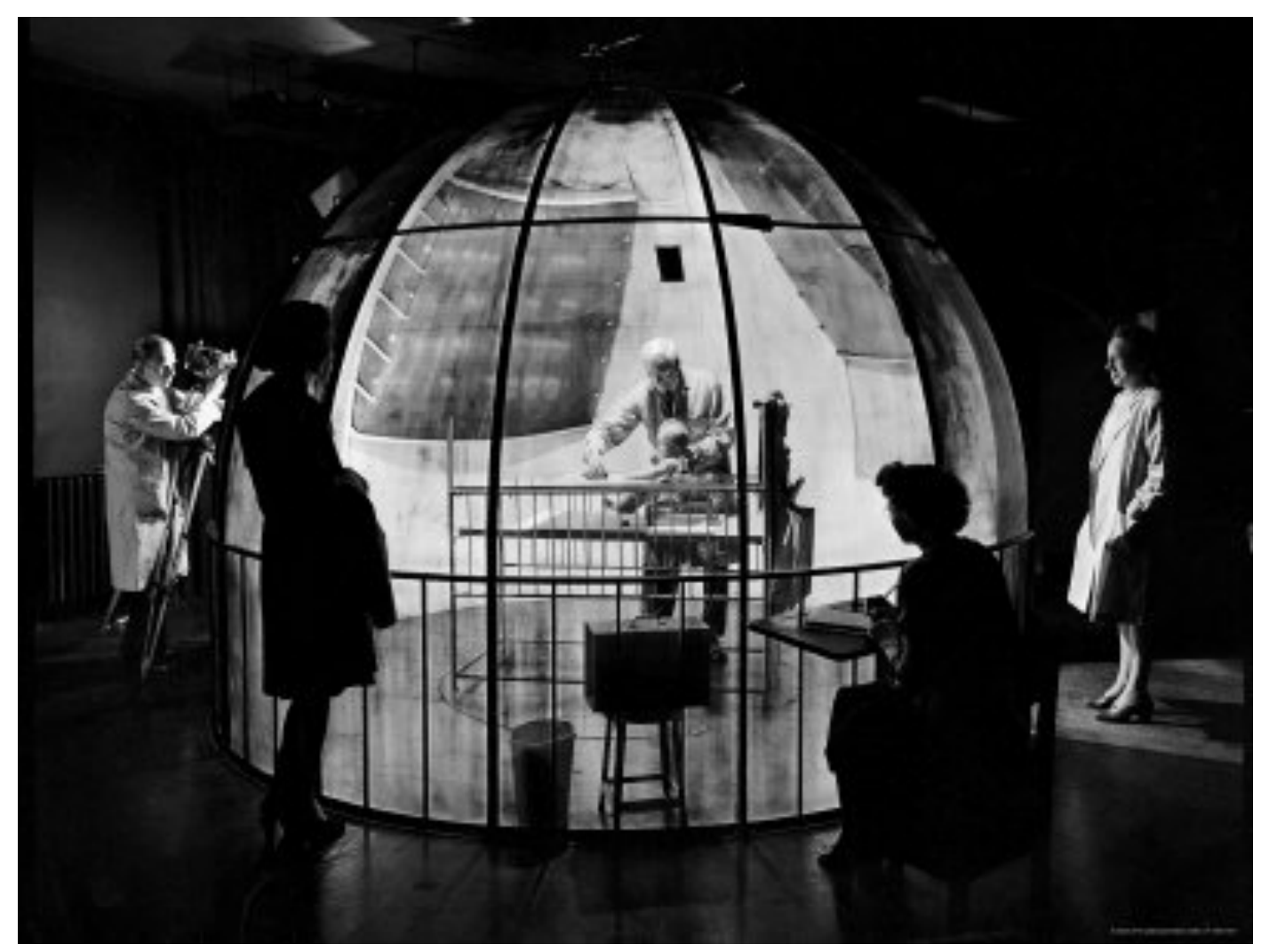

Figure 27. 
The date is probably in the 1920s. The laboratory itself manifests in its design and equipment the characteristics of the gaze that psychologists would, from this moment on, target upon the child. It is a dome brilliantly lit within and designed for one-way vision. Outside, able to see in without being seen themselves, are observers, probably student psychologists. While one merely watches, another writes notes with pencil upon a pad. A third, probably a technician, operates a movie camera. Within the dome is the white-coated scientist. His gaze, like that of the observers in the picture, and our own, is focused upon one particular spot. At the centre of the dome, contained in a kind of playpen, sitting at a table, playing with what appears to be a small brick, is a baby. This is a photograph of Dr Arnold Gesell testing a baby.

We should not be misled by the familiarity of such a scene. It is surely something quite remarkable that this small creature should have become the focus of this complex apparatus. The child is here caught up within a complicated arrangement that will transform it into a visible, observable and analyzable object, within a particular rational scientific discourse (developmental psychology) making a particular kind of claim to truth (pp. 143 - 144).

What I hope to bring attention to within the scope of this chapter is that the child within a contemporary early years setting is still very much caught up within a complex arrangement that, much like the work of Gesell above, transforms that child into a visible, observable and analyzable object. This contemporary arrangement may bear little resemblance to the clinical monstrosity depicted above. However, I would argue that the discourse it instantiates is of equal significance and thus equally worthy of critical engagement. Regardless of paradigmatic shifts in relation to early childhood education since the work of Gesell was carried out the positioning of the child as the central object of surveillance and our (teachers, researchers and policy makers) gaze seems to have remained the same. My contention is that this historically contingent individualizing gaze is a highly significant consideration when reflecting upon and analyzing the visual practices of contemporary curricula and broader policy networks. In this way we can begin to consider how the visual-discursive construction of the child is constituted by both 'psy' and advanced liberal rationalities and the way in which these seemingly disparate 
discourses are entangled. I suggest that the frequency with which children are visually represented as isolated individuals might be understood as illustrative of these two dominant discourses converging at this particular point in history.

Rose (1990) suggests that developmental psychology was made possible by the clinic and early childhood institutions such as nursery schools. These institutions played a key role in constructing this particular scientific discourse because they enabled the controlled observation of a significant number of children. The observation of a number of children the same age, and a number of children of different ages, produced a body of comparable information that allowed psychological experts to construct standards and norms. What came to be understood as a developmental norm was a "standard based upon the average abilities or performances of children of a certain age on a particular task or specified activity" (Rose, 1990, p. 142). In this sense the developmental norm, as produced through the psychological gaze, not only presented a picture of what was normal for children of a certain age, but also opened up a new space in which the normality of any child was assessed in relation to this norm.

Rose $(1990 ; 1998)$ articulates the fact that, for the psychologists (and scientists elsewhere) processes of inscription have various advantages over the subjects of study themselves. As I have mentioned in the previous chapter, stillness and composure may be understood as problematic/inaccurate qualities to assign to the messy, experimental-movement-orientated, ephemeral and everchanging child subject. We can imagine how such 'child-like' preoccupations would cause 'trouble' in a clinical setting informed by positivist logic. As Rose (1990) explains:

Children are difficult to accumulate in large numbers. Large rooms and considerable labour are required to hold them side by side, to pick out common or differentiating features. They change over time... They are unstable material for a science to work on (p. 144). 
Rose (1990) goes on to explain how Gesell solved this problem through employing the technology of photography in his work. In the series of images featured below Gesell analyzed moving images of children and produced a series of still frames that became representative of 'typical' actions of children between the ages of fifteen months and four years. In this way the photographic images below (and others like them) formed "the material of cognitive operations constrained only by the limits of the scientific imagination, operations that would be difficult to manage with the children who were their subjects"(Rose, 1990, p. 144). These 'typical' images of young children could then be used as objects or artifacts to assert/evidence what was not 'typical', 'unusual' or 'abnormal'. These inscriptions are archived as scientific knowledge and disseminated through scientific debate, textbooks, articles and teaching materials (Rose, 1990). Thus such a process of inscription acts to normalize and regulate human subjects, to discipline infinite possibilities, in part, by silencing/freezing the ephemeral, ceaseless flow of being and becoming human. In the words of Deleuze (1994): "Science... relinquishes the infinite in order to gain reference: it lays out a plane of simply undefined coordinates that each time, through the action of partial observers, defines states of affairs, functions, or referential propositions" (p. 197). Here we are confronted with the troubling polemic nature of scientific observation. Rose (1998), drawing on the thinking of Bachelard (1984) puts it this way:

Science... entails the attempt to produce in reality, through observation and experimentation, that which has already been produced in thought. In scientific thought, meditation on the object always takes the form of a project... Scientific observation is always polemical; it either confirms or denies a prior thesis, a preexisting model, an observational protocol. And experimentation is essentially a process by which theories are materialized by technical means... Now phenomena must be selected, filtered, purified, shaped by instruments; indeed it may well be the instruments that produce the phenomena in the first place. And the instruments are nothing but theories materialized (p. 51). 


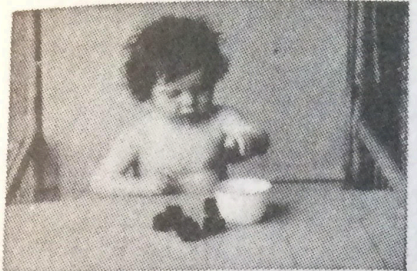

THREE CUBES IN CUP

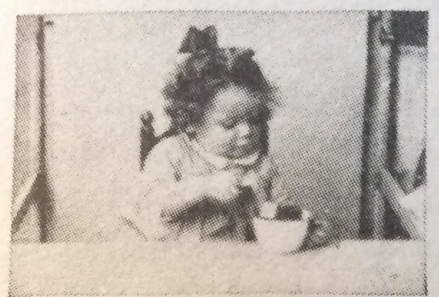

FIILS CUP

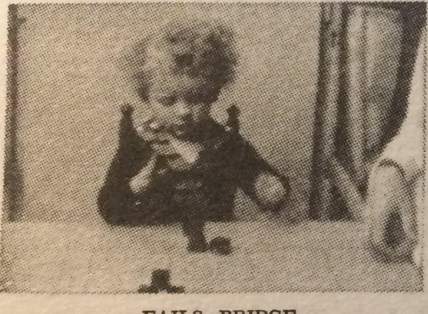

FAILS BRIDGE

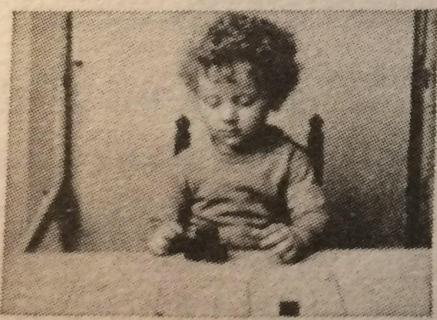

IMITATES BRIDGE

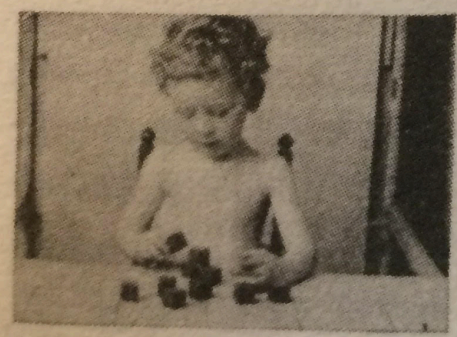

SPONTANEOUS BRIDGE

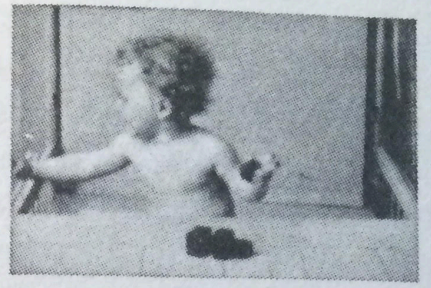

THROWS

FIFTEEN MONTHS

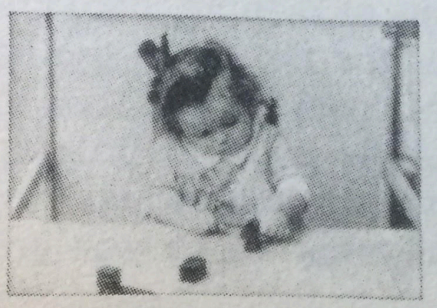

FAILS TRAIN EIGHTEEN MONTHS

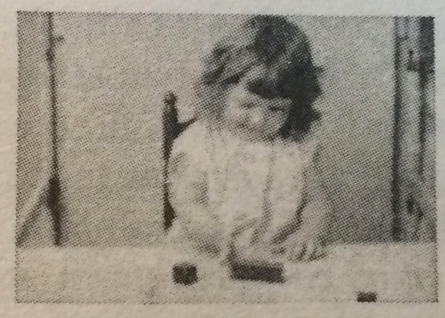

TRAIN WITHOUT CHIMNEY TWO YEARS

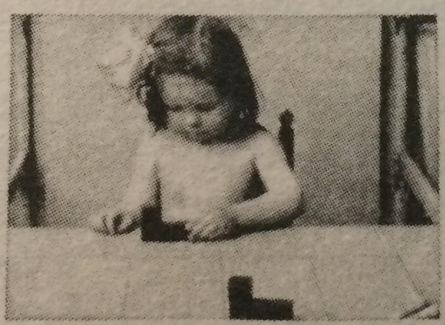

TRAIN WITH CHIMNEY THREE YEARS

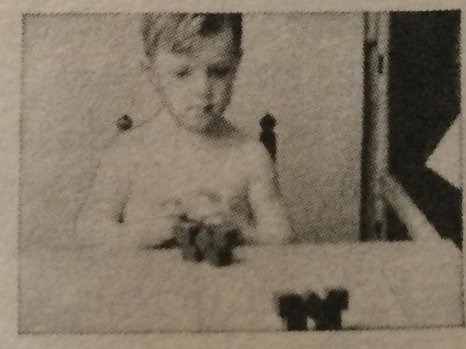

GATE

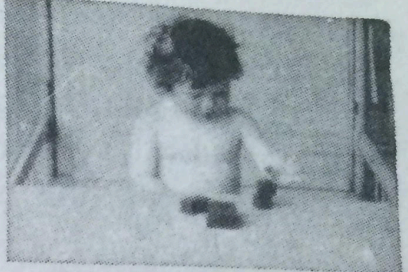

TOWER OF TWO

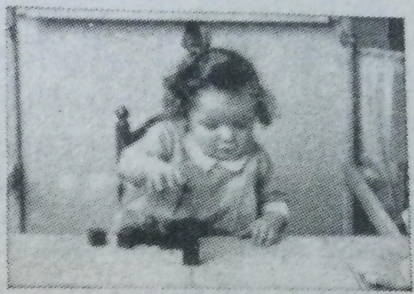

TOWER OF THREE

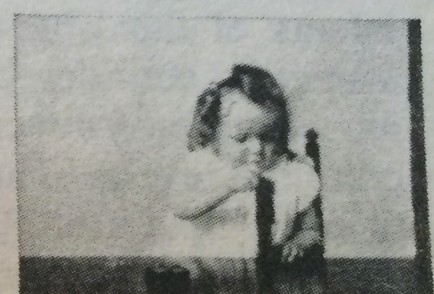

TOWER OF SIX

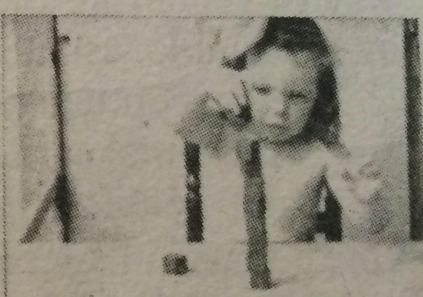

TOWER OF NINE

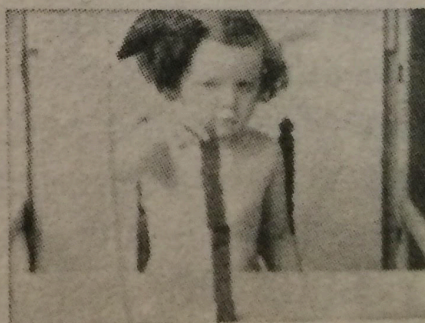

TOWER OF TEN

Figure 28.

As Rose (1990) points out in his analysis of Arnold Gesell's work particular scientific techniques that operate within particular scientific regimes of truth act to discipline human difference in particular ways. Through the discipline of developmental psychology... "Growth and temporality could become principles 
of organization of a psychology of childhood. And normalization and development enabled individual children to be characterized in terms of their position on this axis of time relative to that deemed 'normal' for their age" (Rose, 1990, p. 142). In this regard Rose's analysis of Gesell's work offers us a tangible example of how we can understand a Foucauldian conceptualization of discourse that defines discourse both as groups of signs and practices that form the objects of which they speak. Or again:

Discourses are not merely 'meaning systems', but are embodied within complex technical and practical associations and devices that provide 'places' that human beings must occupy if they are to have the status of subjects of particular sorts, and which immediately position them in certain relations with one another and with the world of which they speak (Foucault, 1972, as cited in Rose, 1998, p. 53).

As I have discussed in the previous chapter a striking feature of a significant number of photographic images utilized in the revised Te Whāriki (2017a) document is that children are frequently depicted as isolated (often partial) individuals, separate from other bodies (both human and non-human) and the wider material environment. This isolation of the individual child produced through the visual medium of photography is reflected in both the framing conventions (the space, materials and bodies that are actually depicted within the confined of the frame) and other techniques that the technological apparatus of the camera allow (what is of most interest to me in this regard is the function of focus and depth of field). The photographic images subject to my analysis feature adult figures - for example teachers, kaiako or parents - relatively rarely. With 'psy' discourse in mind it is also worth bringing attention to the prominence and privileging of the head across the scope of these photographic images (M. Haggerty, personal communication, September 14, 2017). We might consider the repetitive depictions of heads (that part of the body that holds our cognitive capacity most readily associated with 'learning') as a significant psyvisual-discursive thread (see figures below). The clear prioritization of heads (regardless of how many children feature within the image) and the marginalized position of adult figures in these visual statements resonate with 
broader policy research in the Aotearoa-New Zealand context that expresses concerns around the erosion of notions of care and holistic development in contemporary early childhood education policy discourse (Alcock \& Haggerty, 2016). Alcock \& Haggerty (2016) observe the way in which "development and learning' has been replaced with singular 'learning' in the official discourse of MOE publications" (p. 142), which displaces notions of holistic development, where development is understood as "relational, complex, non-linear and as a way of reintegrating living, changing, material bodies with thinking, feeling, social selves" (p. 142). In this way we can begin to consider the ways in which 'learner-centric' or neo/advanced liberal associated discourses and psy-based discourses converge and are produced through both visual and written mediums across the Aotearoa-New Zealand policy landscape.

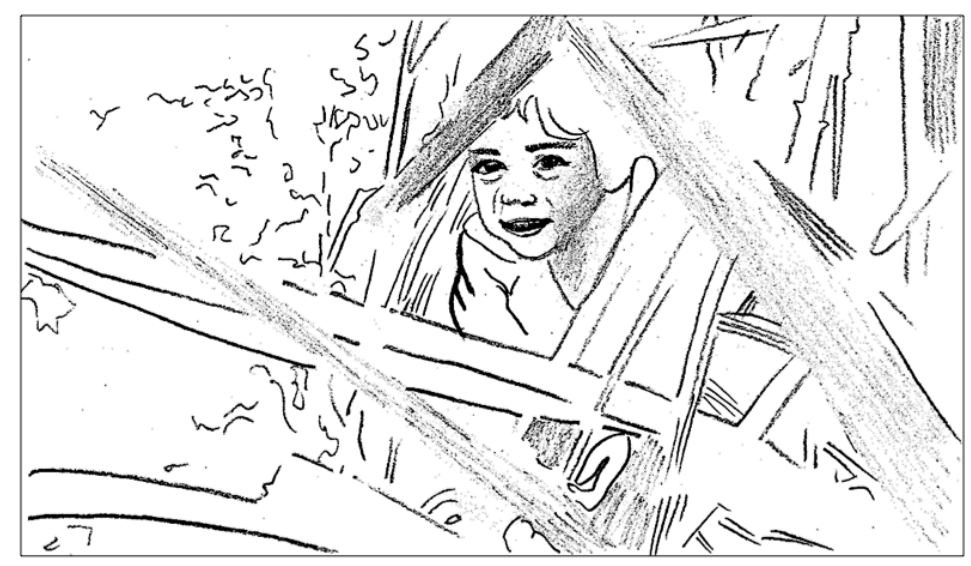

Figure 29.

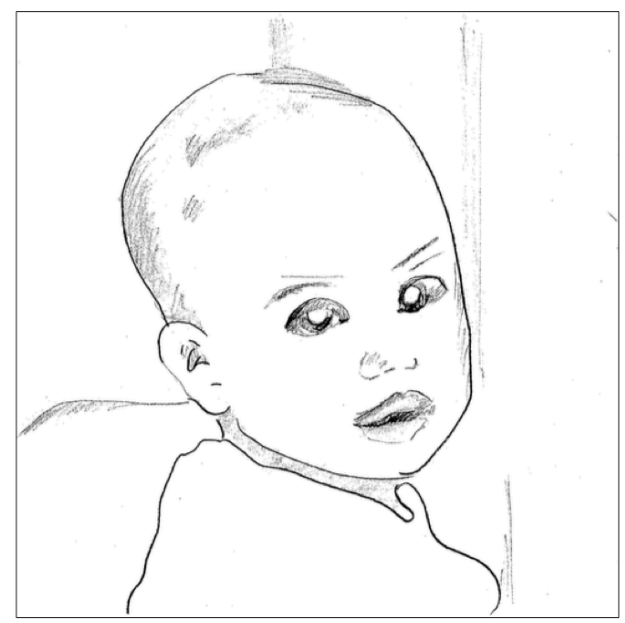

Figure 30. 


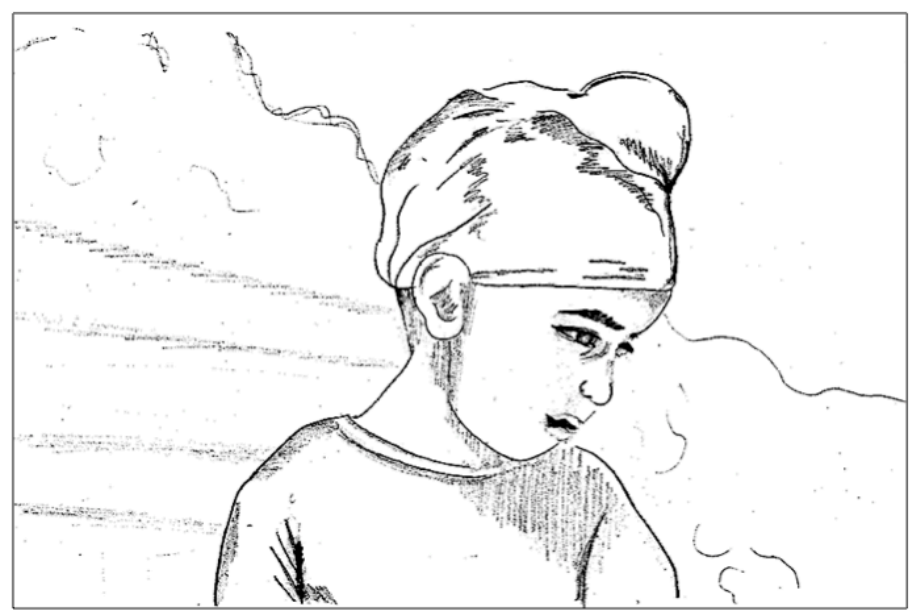

Figure 31.

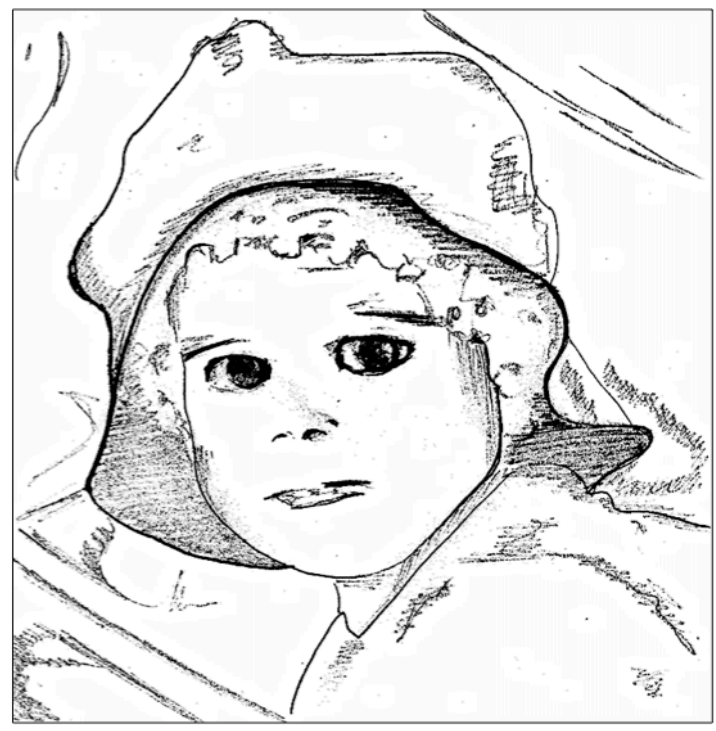

Figure 32.

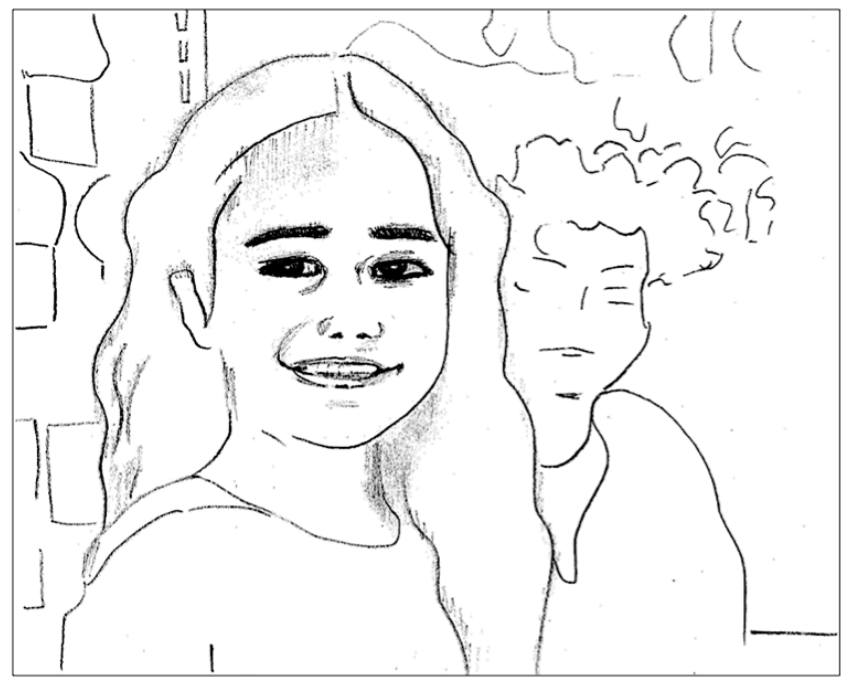

Figure 33. 


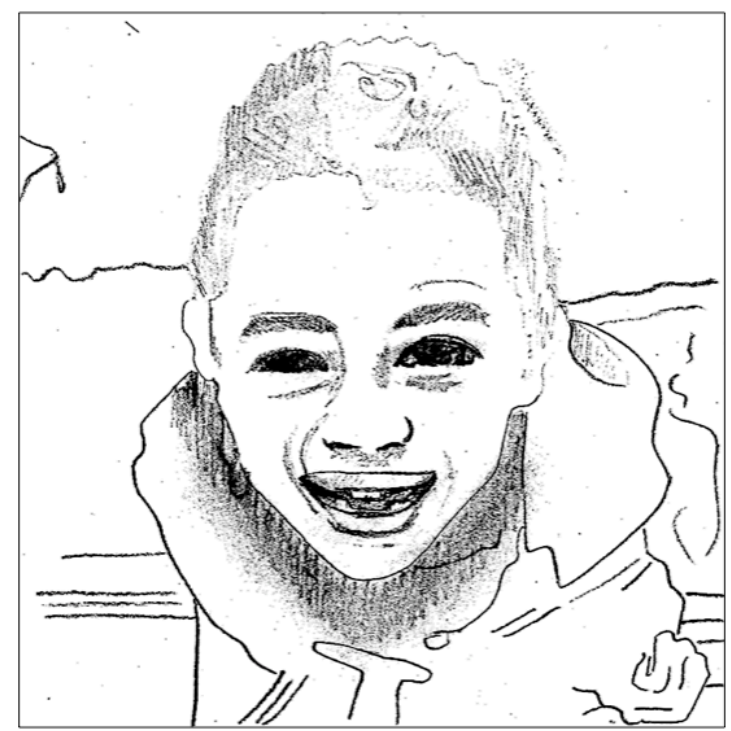

Figure 34.

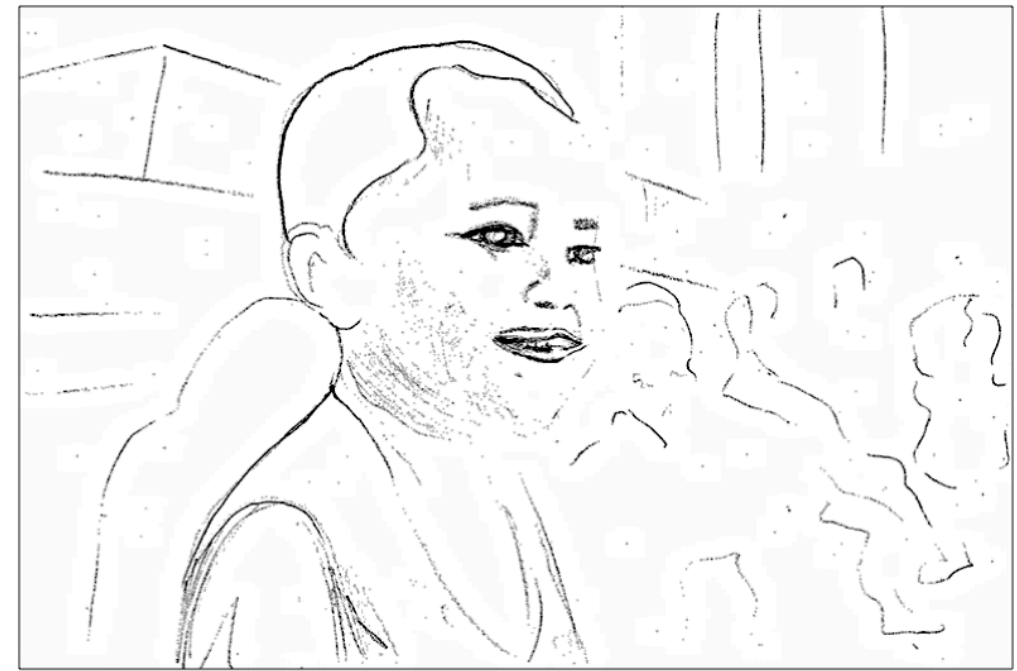

Figure 35.

As I have elaborated on in the previous chapters we can come to understand these repetitive framing and focus conventions intrinsic to the technological capacity of the camera in terms of how they direct our gaze in particular ways. We can also consider how the images present in the revised Te Whāriki (2017a) document are reflective of certain assumptions/subjectivities of those taking the photographs and those responsible for selecting and curating the images within the process of revising the document. In this way we can consider how these images may come to function as visual discourse and constitute a kind of visual politics. An interrogation of the ways in which 'psy'-based knowledge and 
practices might permeate/inform the visual practices and statements featured within revised Te Whāriki (2017a) document is a central aim of this chapter. As discussed above this can be understood as a modest attempt to bring light to the parallels/resonances between the visual-discursive construction of the child and broader relations of power, working towards an understanding of how the educated child subject is constructed at this point in history through dominant contemporary discourses that are entangled in messy ways. Key to a visualdiscourse analysis of 'psy'-based knowledges and practices is the recognition that 'psy'-based discourses often emerge and operate as ethical, liberating, natural and inevitable (Bendix Petersen \& Millei, 2016). In this sense, as Rose (1999) notes in a discussion concerning the spirit in which such an analysis might proceed: "Historical investigations are thus used not for knowing but for cutting, as Foucault says in his essay on Nietzsche: to disturb that which forms the very groundwork of our present, to make the given once more strange and cause wonder at how it came to appear so natural" (p. 58).

Burman (2008) suggests that "as the 'psy' complex comes to exercise an ever greater grip on our lives, we have an ever greater need for critical resources to interrogate and resist its presumptions: (p. viii). In what follows I will draw on the new sociology of childhood literature (specifically work around the being/becoming dichotomy) as one such resource. This move might be best understood in the context of my analysis as a way of exploring how psy-based knowledge and practices may operate in contemporary education institutions, specifically through the photographic images of pedagogical documentation. The theoretical resources I draw on through an engagement with the new sociology of childhood literature can be understood to serve at least two functions here: (1) to problematize certain photographic conventions as exemplified in the revised Te Whāriki (2017a) document, bringing attention to the historically contingent nature of these conventions and how they resonate with the techniques of inscription (Rose, 1998) employed by the discipline of developmental psychology; (2) to illuminate how an attentiveness to particular theoretical constructs might work to destabilize our relationship to photographic image making practices and how we analyze the data produced from such 
practices. Following a similar line to Rose $(1990 ; 1998)$ I suggest that certain photographic inscriptions present in the revised Te Whāriki (2017a) document can, at least in part, be understood as normalizing visual discourse that disciplines human difference in particular ways.

\section{3 'Psy' discourse and the child conceptualized as a human 'becoming'}

A central focus of the new sociology of childhood literature, emergent in the early 1990s, was a robust criticism of developmentalism (Prout \& James, 1997). Coppock (2011) explains that developmental discourses assert that "children can only aspire to achieve the same status as adults as they progress through the life course" (p. 388). In this regard developmental discourse construct children as human becomings (that is to say becoming adults), rather than as human beings (Qvortrup, 1994). According to Prout \& James (1997) there are three predominant themes that reinforce the construction of the 'normal' child within developmentalism: rationality, naturalness and universality. Rationality and competency are recognized as the assurances of adulthood, strengthened by the assumed irrationality and incompetence of childhood. In this sense childhood is constructed as a secondary (inferior) binary in relation to adulthood. This binary creates the conditions through which the incapacity of children is legitimized by asserting their inability to be adult (Coppock, 2011). The themes of naturalness and universality (Prout \& James, 1997) can be understood as potent ideological forces that reflect and produce the 'common-sense' belief that children (given their biological immaturity and their inevitable growth into adulthood) should be understood as humans becoming adult, systematically ignoring the position that children are socially situated beings, participating (in whatever strangled channels) in the socio-cultural, material and political contexts of their lives. While biological immaturity of children may be a fact, how we interpret such immaturity is dependent on various ideologically and discursively informed factors that are by no means 'natural' (Prout, 2005). Thus, the need to criticize that which manifest as natural or taken-for-granted arises. As Coppock (2011) explains: "Developmental discourses of childhood are so embedded in the general consciousness as the inevitable phase that all humans pass through on their journey to adulthood that they have entered the realm of common-sense 
and their taken-for-grantedness makes them almost impenetrable" (p. 388). Here I aim to penetrate the taken-for-granted nature of 'psy'-based knowledge and practices, foregrounding the way in which particular photographic images may be understood as (psy) developmental visual discourse.

Prout (2005) surveys the various perspectives derived from childhood studies that engage with the being/becoming dichotomy. Prout explains that some scholars interested in this area of inquiry have dogmatically insisted upon the distinction between children as beings or becomings in such a way that denies the possibility of both. In contrast to such a position Prout (2005) advocates for a sociology of childhood that deconstructs these dogmatic assertions and recognizes children as both beings and becomings. Key to this shift is the insight that such a sharp distinction makes little sense in contemporary societies in which the life course (of both adults and children) has been reconstituted through such discourses as 'life-long learning' and 'reskilling,' constructed in response to a shifting economic climate that demands a certain kind of malleability (Lee, 2001). Prout explains that these significant shifts in the social landscape of western societies have made "the unfinished character of adult lives as visible as those of children" (Prout, 2005, p. 66). Lee (2001) addresses another problem with foregrounding children as beings 'in and of themselves' by cautioning that such assertions risk perpetuating the myth that children are autonomous, independent entities that some how exist outside of an intricate web of interdependencies. With this perspective in mind Prout (2005) critiques much of the new sociology of childhood literature for reductively basing its intellectual efforts on the idea of children as autonomous, independent beings, and calls for a recognition of both children and adults as "a multiplicity of becomings in which all are incomplete and dependent" (p. 67). Considering the photographic inscriptions below, what strikes me as problematic is the way in which such visual-discursive statements communicate/endorse/produce this reductive independent conceptualization/construction of the young educated subject, systematically ignoring the various interdependencies (whether these be human, non- human, material) that constitute what it is to be a human being throughout the course of our lives. 


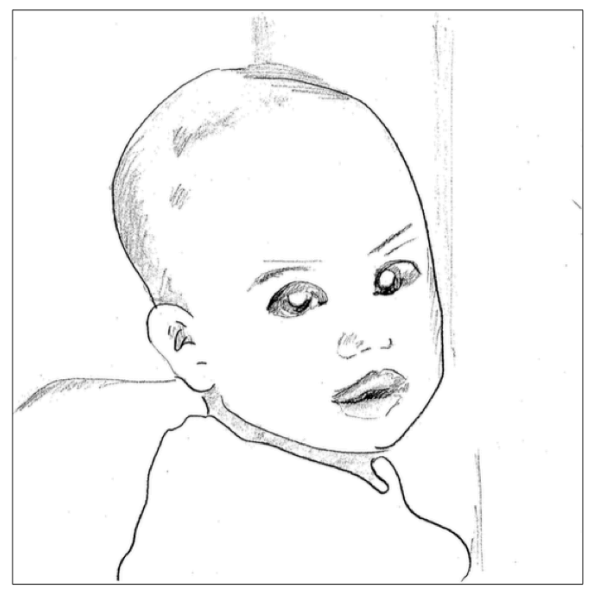

\section{Infants}

Figure 36.

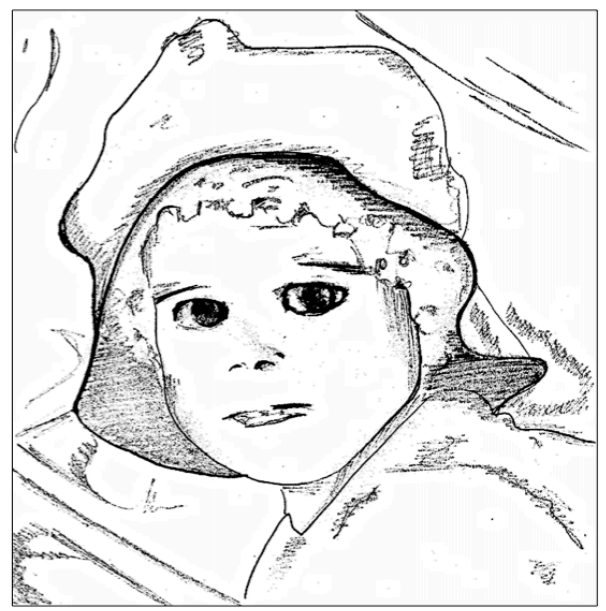

\section{Toddlers}

Figure 37.

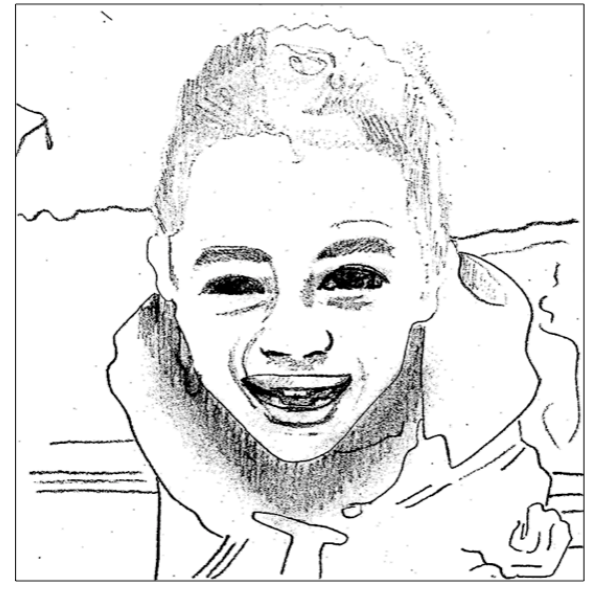

Young children

Figure 38. 
The above photographic inscriptions are repeated throughout the revised Te Whāriki (2017a) document, featuring within each of the five strands of the curriculum framework. They appear after a table that outlines goals, learning outcomes, and evidence of learning and development under the heading examples of practices that promote these learning outcomes. Each of the three photographic images are annotated with a linguistic marker - Infants, Toddlers, Young Children. To the right of the annotated images there are bullet pointed examples of practices that promote the learning outcomes of the particular strand in which they feature. With these observations in mind we might ask in what ways these images (repeatedly employed throughout the document as 'visual markers') operate as 'psy' visual discourse.

Perhaps most obviously there is a reduction of the child to an individual (or to be more accurate a part of an individual - a head). As noted above these images come with a distinct linguistic marker - infants, toddlers, young children - and resonate strongly with the 'psy' inscription techniques employed by Arnold Gesell outlined above. Through such techniques of inscription the child becomes the object of psychological discourse. These techniques "do not simply manufacture and manipulate, but... more fundamentally, order being, frame it, produce it, make it thinkable as a certain mode of existence that must be addressed in a particular way" (Rose, 1998, p. 54). Indeed, these images, understood to be objects of psychological discourse, are addressed in very particular ways, annotated by bullet-pointed examples of specific practices that promote the learning outcomes of the particular strand in which they feature. Significantly, this kind of photographic inscription images the children removed from the inter/intra relations of the social world in which they are situated. These images function in conjunction with the textual annotations to assert three normative categories (infant, toddler and young child). My contention is that such categorical visual statements act to discipline human difference in a particular way that resonates strongly with both the 'psy'-based discourses explored above and individualizing discourses produced by advanced liberal rationalities explored in chapter four. In Rose's (1990) analysis of Gesell's photographic work depicted earlier he explains how these images formed "the 
material of cognitive operations constrained only by the limits of the scientific imagination, operations that would be difficult to manage with the children who were their subjects" (p. 144). With this insight in mind we might come to understand how these photographic images, repeatedly employed throughout the revised Te Whāriki (2017a) document in relation to specific teaching practices, systematically categorize children to manage/inform particular pedagogical practices that operate to discipline and homogenize human difference in particular ways and legitimize social regulation in relation to the 'common-sense' assumptions of developmental norms.

\subsection{Conclusion}

Within the scope of this chapter I have aimed to shed some light on the ways in which 'psy'-based discourses, in conjunction with and relation to the competent child/advanced liberal discourses discussed in chapter four, can be understood to discipline human difference in particular ways and thus construct a particular kind of educated subject at this point in history. I have, more specifically, tried to show how particular photographic techniques/visual practices as manifest in the revised Te Whāriki (2017a) document can be understood as visual-discursive statements that, in part, attain their (taken-for-granted) authority to speak for the other by relying on some fundamental assumptions, which are partly informed by the individualizing metaphysics of the 'psy'-sciences (specifically developmental psychology). In this way I have continued to explore the links or resonances between the visual-discursive construction of the child and broader relations of power.

The analysis of this chapter has not intended to be in any way totalizing or concerned with claiming a direct relationship between visual-discursive practices and modes of subjectification. In other words, this analysis is not based on a new form of self-evidence (the child is this or that, inevitably reduced and produced by these particular discourses). Rather, this analysis is based "on the transgression of existing self-evidence in order to show that other subjectpositions are possible; subject-positions that, in a sense, are located outside of existing and predominant discourses and, in a sense, cannot be captured or 
articulated within them" (Biesta, 2008, p. 202-203). In this respect I conclude that both 'psy'-based and advanced liberal discourses are productive (though not in a totalizing way) of a particular kind of educated subject, and that the photographic image making practices of pedagogical documentation are implicated/entangled in the assemblage of rationalities that inform these diffuse discursive practices in significant ways. I suggest that these dominant discourses act to foreclose other ways of thinking and being in a contemporary early education setting and thus call for an exploration of possible subject-positions that are potentially asphyxiated by these dominant individualizing discourses. It is in response to this call that the following chapter takes form. 


\subsection{Introduction}

In the final chapter of this work I will outline some theoretical positions produced through the work of Bruno Latour (1993; 1996; 2005), Karen Barad (1998; 2003; 2007) and Gilles Deleuze/Fèlix Guattari (1987/1988) respectively that might be understood as useful tools or 'travel-guides' for the exploration of subject-positions beyond those foregrounded and critiqued thus far. Latour (2005) in the introductory pages of his book Reassembling the Social: An Introduction to Actor-Network-Theory explains that his work "resembles a travel guide through a terrain that is at once completely banal - it's nothing but the social world we are used to - and completely exotic - we will have to learn how to slow down at each step" (p. 17). Latour (2005) prefers the term travel guide over the "pompous" Greek derivative 'methodology' in that such an approach "cannot be confused with the territory on which it simply overlays" (p. 17):

A guide can be put to use as well as forgotten, placed in a backpack, stained with grease and coffee, scribbled all over, its pages torn apart to light a fire under a barbeque. In brief, it offers suggestions rather than imposing itself on the reader (Latour, 2005, p. 17).

In this respect the final chapter of my work might be considered as serving a 'where to from here' or 'direction for future research' function that at once problematizes and moves beyond the narrow discursive construction of the child as an economic unit, or bounded individual. My work, so far, has been preoccupied with an examination of the subjectivities produced through the dominant contemporary discourses of the child and the ways in which particular visual representations of young children resonate with these discourses. I have been concerned with the government of subjectivity and the way in which visual representations operate in this (post) modern governmental space. I have expressed concern around the foreclosure of subject-positions that may dwell outside of these dominant discourses and thus feel it necessary to put forward an alternative image of subjectivity to those foregrounded and critiqued throughout 
my analysis. For this task I first briefly turn to the philosophy of Gilles Deleuze and Fèlix Guattari (1987/1988).

\subsection{The plural subject}

Nikolas Rose (1998) suggests that Gilles Deleuze and Fèlix Guattari have proposed one of the most radical and insightful alternatives to the established image of subjectivity as coherent and individualized across time and space. Consider the following passage from Deleuze and Guattari (1988):

\footnotetext{
You are a longitude and a latitude, a set of speeds and slownesses between unformed particles, a set of nonsubjectified affects. You have the individuality of a day, a season, a year, a life (regardless of its duration) - a climate, a wind, a fog, a swarm, a pack (regardless of its singularity). Or at least you can have it, you can reach it (p. 162).
}

Following the philosophy of Deleuze and Guattari (1988) we (as subjects and human beings more generally) are much more plural than we think or have been led/encouraged to believe through the various forms of discipline and control that have governed our being/becoming throughout history. We are in actuality, according to Deleuze and Guattari, nonsubjectified in all sorts of interesting ways. Furthermore, we can inhabit these nonsubjectified forms of existence through action upon ourselves. These nonsubjectified forms are conceptualized under the term "haeccities” (Deleuze \& Guattari 1988, as cited in Rose, 1998, p. 170). Haeccites stand for

modes of individualization that are not those of a substance, a person, a thing, or a subject but of a cloud, a winter, an hour, a date - relations of movement and rest between molecules or particles, capacities to affect and be affected (Deleuze \& Guattari, 1988, as cited in Rose, 1998, p. 170).

In contrast to this nonsubjectified plane of existence is another plane (a plane that I have hoped to bring attention to/critique in this work), which is one of organization, stratification and territorialization (Rose, 1998). Deleuze and Guattari (1988) suggest that if we do not relate to ourselves on the 
nonsubjectified plane, a plane of movements, flows, perpetual decomposition and composition, it is because we are so concretely located on the other plane of organization and stratification. The plane of organization and stratification is complex and sophisticated, it is an assemblage of "parts, forces, movements, affects of other humans, animals, objects, spaces and places" (Rose, 1998, p. 171) that subjectify the human being. Here subjectivity is understood as the effects of being-assembled-together (Rose, 1998). Within the scope of this thesis I have foregrounded particular assemblages of rationalities and suggested that the photographic practices of pedagogical documentation are entangled in these rationalities, constructing a particular kind of educated subject, in part, through visual discourse. Considering the philosophy of Deleuze and Guattari (1988) here, specifically their thinking around the 'subject', brings to the fore the contingent nature of contemporary constructions of subjectivities whilst offering us another image of the subject to work with. Reading Deleuze and Guattari's philosophy in relation to the concerns of this thesis I do wonder why we must name and inscribe children's subjectivities/identities with such fervor within the context of policy literature, and to what end? It is the contention in the context of this closing chapter that the multiplicity of the Deleuzio-Guattarian subject is obscured by predominant discourses that collectively serve individualizing ends (fixing the identity of children in particular ways), assemblages constructed on the plane of organization that are always "trying to plug the lines of flight, stop or interrupt the movements of deterritorialization, weigh them down, restratify them, reconstitute forms and subjects in a dimension of depth" (Deleuze \& Guattari, 1988, p. 270).

It is important to foreground here that the Deleuzio-Guattarian subject is not void of stratified elements - the nonsubjectified/deterritorialized plane is not positioned dichotomously in relation to the plane of organization and stratification within Deleuze and Guattari's philosophy. These authors are aware that philosophizing about modes of individuation premised on proliferation/multiplicity will not save us and that we cannot escape subjectivity entirely (nor would it be desirable to do so). In the words of Deleuze and Guattari (1987): 
You have to keep enough of the organism for it to reform each dawn; and you have to keep small supplies of significance and subjectification, if only to turn them against their own systems when the circumstances demand it, when things, persons, even situations, force you to; and you have to keep small rations of subjectivity in sufficient quantity to enable you to respond to the dominant reality (p. 160).

As St. Pierre (2004) illustrates, this articulation around contesting processes of subjectification is in resonance with Michel Foucault's response to questions of the subject, which involves "refusing the reality of what we are and, as a consequence, the life such a subject compels" (p. 292). In this sense the destratified subject of Deleuze and Guattari's thought is a "trajectory or tendency rather than a fixed state or final position" (Grosz, 1993, p. 175). Thus this is not about advocating for the termination or complete destabilization of identity. Rather, Deleuze and Guattari (1987) are concerned with micro-destratifications that function in such a way as to make the body/subject responsive to transformations or possible becomings. Here the 'individual' is thought of in terms of what they might become, rather than what they are currently 'identified' as. This strikes me as a hopeful ontological preoccupation within an educational context that seems so at ease with normalizing and regulatory techniques of categorization, techniques that we might consider, through a Deleuzio-Guattarian lens, as unethical habits, complacent practices that train us to be unworthy of what happens to us within the nuanced and textured events and encounters of the education environment (see methods chapter, section 2.2 for Deleuze and Guattari's ethical stance).

Returning to the photographic practices of pedagogical documentation we can consider the images below (as presented in the revised Te Whāriki (2017a) document) in terms of how they plug up or interrupt the movements of deterritorialization: 


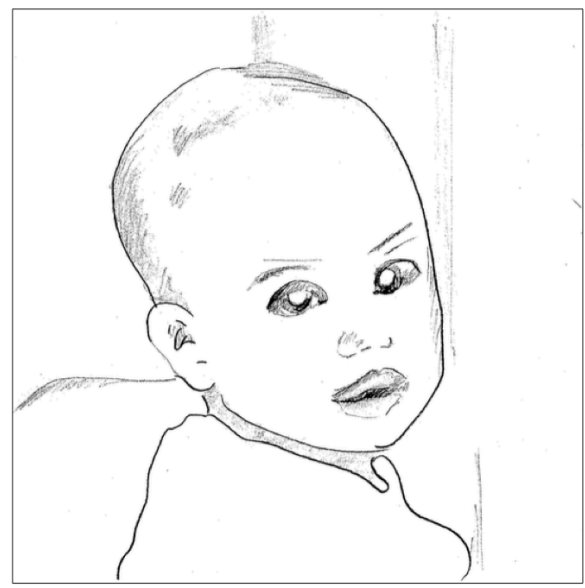

\section{Infants}

Figure 39.

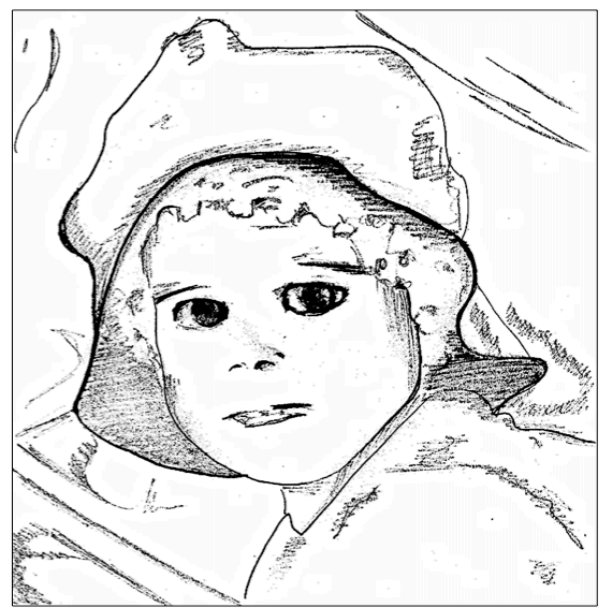

\section{Toddlers}

Figure 40.

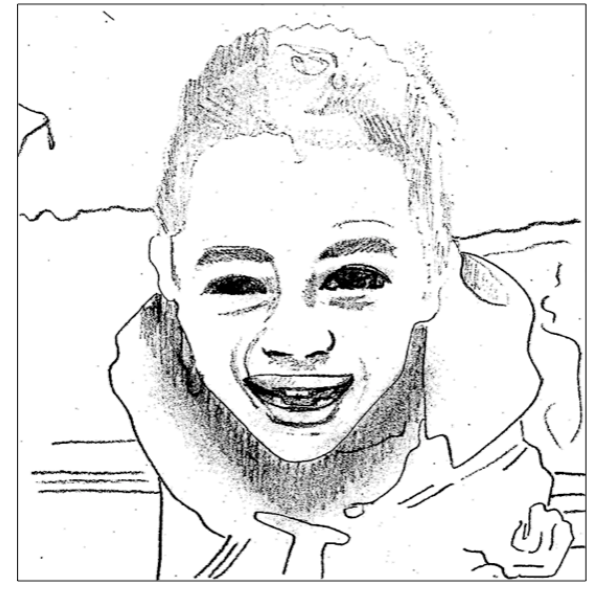

Young children

Figure 41. 
Perhaps it will be of use to briefly reiterate what was foregrounded in the previous chapter concerning the repetitive use and positioning of this particular photographic convention within the document, Te Whāriki (2017a). The above photographic inscriptions are repeated throughout the revised Te Whāriki (2017a) document, featuring within each of the five strands of the curriculum framework. They appear after a table that outlines goals, learning outcomes, and evidence of learning and development under the heading examples of practices that promote these learning outcomes. Each of the three photographic images are annotated with a linguistic marker - Infants, Toddlers, Young Children. To the right of the annotated images there are bullet pointed examples of practices that promote the learning outcomes of the particular strand in which they feature.

Considering these photographic conventions on the nonsubjectified plane offered by Deleuze and Guattari (1988) renders them troublingly reductive, hopelessly lacking in their ability to convey the ever-changing assemblages of parts, forces, movements, objects, spaces and places that constitute (and endlessly reconstitute) the human subject. With this subject-position in mind these images might be understood as the materialization of the psychologists gaze. The psychologist, the educationalist, two of Foucault's modern anatomists of pain (see p. 97-98 above), blocking the flows of movement and ceaselessly (re)constituting the ephemeral subject in the dimension of depth rather than width (see methods chapter, section 2.3 for clarification around the epistemological/ontological situated distinction between depth and width).

This conceptualization of the subject presented by Deleuze and Guattari (1988) resonates with Prout's (2005) call (in the context of childhood studies) for a recognition of both children and adults as "a multiplicity of becomings in which all are incomplete and dependent" (p. 67). This subject-position might also be understood as a critical resource that interrogates and resists the presumptions of the 'psy' complex (Burman, 2008) and its concurrent discourses (Rose, 1990; 1998). In a similar way this conceptualization of the subject challenges the individualizing function of neo/advanced liberal rationalities and 
illuminates the contingent nature of the (visual) discourses that these rationalities instantiate. Thinking, or "cutting" (Rose, 1999, p. 58) with Deleuze and Guattari (1988) the given does indeed feel strange, and one does wonder about how it has come to appear so natural. In relation to the photographic practices of pedagogical documentation the Deleuzian subject-position, to my mind at least, calls into question the fundamental philosophical assumptions that inform our (teachers, researchers and policy makers) work with visual representations of young children and challenges the prevalent (anthropocentric) visual politic of our time.

From this position we might ask how to proceed with this image of the plural, heterogeneous subject in a theoretical sense. How can research, specifically in the field of education, do justice to this subject-position that necessitates the deconstruction of stratified boundaries and embraces messiness and ambiguity in the process of constructing knowledge? I suggest that both actor-network theory (ANT) and agential realism can be understood as useful theoretical tools for confronting such questions. In what follows I will briefly outline the core of these theoretical positions and gesture towards how they might offer insight into and augment the concerns and aims foregrounded in this thesis.

\subsection{Actor-network theory}

ANT is a form of relational materialism (Prout, 2005) that extends the word 'actor' to include non-human and non-individual entities (Latour, 1996). Latour (1996) explains that the use of the word network derives from the work of Diderot who used the term to describe matter and bodies in such a way that avoided the Cartesian divide between matter and spirit. In this sense ANT reconstitutes what we come to think of as an actor and challenges the "individualized, rational and binary representational logics on which the Cartesian knowing subject and his knowledge-making practices rest" (Taylor, 2016). In the words of Latour (1996): 
ANT is a change of metaphors to describe essences: instead of surfaces one gets filaments... More precisely it is a change of topology. Instead of thinking in terms of surfaces - two dimensions - or spheres - three dimensions - one is asked to think in terms of nodes that have as many dimensions as they have connections... ANT claims that modern societies cannot be described without recognizing them as having a fibrous, thread-like, wiry, stringy, ropy, capillary character that is never captured by the notions of levels, layers, territories, spheres, categories, structures, systems (p. 370).

Latour $(1993 ; 1996 ; 2005)$ insists that an actor can be understood in both human (such as adult/child) and non-human (such as organisms, artifacts and technologies) forms. Furthermore, all of these forms or entities should be treated as "hybrids of culture and nature produced through networks of connection and disconnection" (Prout, 2005, p. 71). Latour (1993) terms the hybrid nature between humans and the rest of the material world 'quasi-objects' and 'quasisubjects', "where the boundary between the human and the non-human is shifting, negotiated and empirical" (Prout, 2005, p. 70). In this regard, no single 'actor' totally determines the assemblage that results from their combination.

Prout (2005) suggests that employing the metaphor of 'networks' in relation to the sociology of childhood may be useful in the sense that it constructs an image of the child as a "collection of different, sometimes competing and sometimes conflicting, heterogeneous orderings" (p. 71). Following the logic of ANT we might come to consider the ways in which new forms of childhood emerge when new sets of network connections (for instance between children and various technologies such a cameras, television and the internet) are established (Prout, 2005). With the insights from ANT in mind Prout (2005) suggests that a key question becomes: "what makes up the network that produces a particular form of childhood" (p. 72)? In relation to my concerns around the photographic practices of pedagogical documentation ANT presents an interesting pathway for future research. ANT opens up a space to think about the photographic practices of pedagogical documentation beyond an investigation of the visual discourses this particular technology produces (as I have attempted to do within the scope of this work). ANT is not concerned with 
whether a network is a "representation or a thing, a part of society or a part of discourse or a part of nature, but what moves and how this movement is recorded" (Latour, 1996, p. 378). In this respect Latour (1996) describes ANT as a network-tracing activity through which an 'actor's' definition of "the world outlines, traces, delineates, describes, files, lists, records, marks or tags a trajectory called a network" (p. 378). In this way we might begin to think of the photographic practices of pedagogical documentation and the apparatus of the camera as material-discursive entanglements that are productive of (and part of) the phenomena produced; and in which various 'actors' /'agents' (human and non-human) enact local "cuts" that produce "objects of particular knowledge practices within the particular phenomena produced" (Barad, 2003, p. 819). In this sense human and non-human bodies can be considered as forces that are continually exchanging properties with each other (Hultman \& Lenz Taguchi, 2010), and are perhaps best understood in terms of this relational continuity rather than oppositional, bounded or discrete units (Grosz, 2005). Following this line of thought Barad (2007) argues that neither discourse nor the human subject can be taken as privileged starting points for analysis. Karen Barad's $(1998 ; 2003 ; 2007)$ theoretical framework agential realism offers further insight into this way of thinking about photographic practices of pedagogical documentation as material-discursive phenomena.

\subsection{Agential Realism}

Agential realism is a theory developed by Barad $(1998 ; 2003 ; 2007)$ to explain her view that matter and meaning are "iteratively reconfigured by a whole range of participating agencies in each and every moment in the ongoing reconstitution and mattering of the world" (Taylor, 2016, pp. 8-9). Barad conceptualizes ontology as

A material entanglement of human, non-human and other-than-human bodies, all of which emerge as co-constitutive agents, that is, as dynamic co-producers of the social. The 'agential' refers to a rethinking of (human) will and intentionality, which recasts agency as a material enactment, no matter who or what is doing the acting; whereas 'realism' does not refer to representations of an independent reality but to 
the real consequences, interventions, creative possibilities, and responsibilities of intra-acting within and as part of the world (Barad, 2007). Agential realism, therefore, erases any of the usual (man-made/human) boundaries between nature and the cultural, which is why Barad speaks of the naturalcultural (Taylor, 2016, p. 9).

Barad's (2007) notion of Intra-activity is to be distinguished from the notion of Inter-activity that is commonly employed in the social sciences to explain social phenomena. Inter-activity assumes that the relationship between two or more persons or entities is fundamentally defined by said entities inherent separateness from each other. The notion Intra-activity is employed by Barad (2007) in relation to the discipline of physics and to a particular understanding of the relationship between any organism and matter (human or non-human), which is defined not by clear and inherent boundaries but by states of "intraactivity of higher or lesser intensity or speed" (Hultman \& Lenz Taguchi, 2010, p. 530). Here we see an interesting resonance with Barad's (2007) notion of intraactivity and Deleuze and Guattari's (1988) conception of 'individualization' that does not refer to a particular, bounded thing or subject, but to "relations of movement and rest between molecules or particles, capacities to affect and be affected" (Deleuze \& Guattari, 1988, as cited in Rose, 1998, p. 170) on the 'nonsubjectified' plane of existence. In this respect both Barad (2007) and Deleuze and Guattari (1988) recast and de-centre the human subject, activating a 'flatter' ontology that "reworks will, intention and causality, seeing them not as the properties of individual bodies but as post-personal events in an emerging confederation" (Taylor, 2016, p. 3).

In this sense the field of social relations social scientists concern themselves with might be better understood as horizontal rather than vertical, perceived in terms of width rather than depth (Hultman \& Lenz Taguchi, 2010). This resonates with Foucault's resistance to what he termed in the Order of Things the "metaphysics of 'depths'” (Foucault, 1970, p. 245). For Foucault this resistance manifested in a presentation (empirical performance) of an aesthetics of depthlessness, suggesting that "everything appears at the surface, at the level of 
human activity" (St. Pierre, 2013, p. 649). Here we can gain a sense around how fields of social relations, understood through the lens of New Empiricism/relational materialism, might be usefully approached through a rhizomatic cartography or tracing and mapping methodology (see methods section, $2.3 \& 2.4)$.

What implications does this have in relation to my concerns regarding the photographic practices of pedagogical documentation? One clear implication would be regarding the way in which the relational materialist perspectives outlined above might inform how we analyze visual representations of young children within the framework of educational practices. What interests me here is how an engagement with a relational materialist perspective resists the dominant discourses of the child critiqued within the scope of this thesis and foregrounds an alternative subject-position that resides outside of these predominant discourses and which cannot be articulated within them.

Hultman and Lenz Taguchi (2010) employ the thinking of both Deleuze and Barad in what they describe as a post-humanist analysis of photographic images of children in Swedish preschools. Working with the understanding of human and non-human actors outlined above as "post-personal events in an emerging confederation" (Taylor, 2016, p. 3), Hultman and Lenz Taguchi (2010) consider the following photographic image of a child in a sand-pit and extrapolate on what it means to think horizontally rather than vertically when analyzing such an image: 


\section{This content is unavailable}

Please consult the print version for access

\section{Figure 42.}

The girl and the sand have no agency of their own. Rather, what is understood as 'agency' in a relational materialist approach is a quality that emerges in-between different bodies involved in mutual engagements and relations: muscles lifting the arm and hand which slowly opens up and lets go of the sand, which by force of gravity falls with specific speed into the bucket, where it lands - one grain upon the other with force causing it to roll over and down and simultaneously constructing a hill of sand in the middle of the bucket (Hultman \& Lenz Taguchi, 2010, p. 530).

\subsection{Conclusion}

When we adopt this 'flatter' ontology through the theoretical framework of relational materialism in our work with photographic images the 'subject' of our gaze is spread out horizontally and our anthropocentric inclinations to categorize the human subject as a bounded individual or discrete unit becomes clearly problematic. Within the scope of this thesis I have critiqued dominant contemporary discourses of the child (proposed to be entangled with each other) and suggested that these discursive constructions collectively service 
individualizing and normalizing ends. In chapter four I explored the resonances between the visual-discursive construction of the child and broader relations of power, concluding that the intensive focus on the individual child through the visual medium of photography is related to (and contributes towards) wider governance practices of the late modern neoliberal disciplinary state. In Chapter five I focused on the rationalities of the 'psy' sciences and, more specifically, the (visual) 'psy'-based discourses that this regime of truth instantiates. It was concluded that 'psy'-based visual-discourses, in conjunction with and relation to the competent child/advanced liberal discourses discussed in chapter four, can be understood to discipline human difference in particular ways and thus construct a particular kind of educated subject at this point in history. In this final chapter of my work I have aimed to outline an alternative image of subjectivity that does away with linear coherence and the prevalent inclination to individualize children across time and space. I have done so through considering Deleuze and Guattari's (1988) conceptualization of subjectivity, which prioritizes plurality and heterogeneity over organization and stratification. I have also outlined two theoretical frameworks - actor-network theory and agential realism - which I suggest might be understood as useful tools for future research concerned with tracing the heterogeneous modes of becomings of both children and adults in the context of early childhood education.

\subsection{Final thoughts: towards the ethical task of re-imagining being} In part, the New Empirical/relational materialist perspectives explored above can be understood in terms of how they turn away from the privileging of epistemology (knowing) towards an invigoration of ontological considerations (being) in the context of qualitative science. Foucault (1970) deftly brought attention to the contingency of knowledge(s) in the human sciences in his archeological and genealogical analyses that focused on numerous systems of thought across different historical periods of time. In this work Foucault observed and examined how each period had "created an "order of things" that cohered for a time until it did not" (St. Pierre, 2013, p. 646). In short, Foucault explained that "different cultural codes produce systems of thought that enable 
different ontologies and epistemologies" (St. Pierre, 2013, p. 646). St. Pierre (2013) explains how the various "posts" (e.g. postmodern, poststructural, postFordist, posthuman, post- emancipatory, postfoundational, postcolonial, postsubjective, and so on)" (p. 646-647) provided a range of analytic tools that all functioned to critique the epistemological and ontological order of things in the Enlightenment derived humanist perspectives that have historical been privileged across the humanities and social sciences. The rhizomatic epistemology of Deleuze and Guattari (1987) and Foucault's (1991b) methodological notion of 'eventualization' explored in the methods chapter of this thesis are illustrative of this active interrogation of the order of humanist thought. Spivak (1993) observes how this intellectual activism formed in postWorld War II France as scholars started to acknowledge that their intellectual practices were

not merely a disinterested pursuit of knowledge, but productive in the making of human beings. It was because of this that they did not accept unexamined human experience as the source of meaning and the making of meaning as an unproblematic thing (as cited in St. Pierre, 2013, pp. 647-648).

An element of what this assemblage of critical projects revealed was that, in western thought, epistemology undermines ontology. Within this critical trajectory Descartes' cogito (I think, therefore I am) is often foregrounded as the origin story behind the ontological and epistemological assumptions of the positivist human sciences (Jackson, 2013; St. Pierre, 2011; 2012; 2013), articulated as a kind of wound left on the western consciousness, which has significant implications for the way we think of knowledge and being as researchers in this historical moment. As St. Pierre (2013) notes: "it will be difficult for those of us who call ourselves researchers to escape the centuriesold knowledge-making machines his [Descartes] fiction has spawned" (p. 654). Foucault (1997) notes this privileging of epistemology (and in a sense the collapse of ontology into epistemology) in Descartes' work: 
Reading Descartes, it is remarkable to find in the Mediations this same spiritual concern with the attainment of a mode of being where doubt was no longer possible, and where one could finally know... But by thus defining the mode of being to which philosophy gives access, one realizes that this mode of being is defined entirely in terms of knowledge, and that philosophy in turn is defined in terms of the knowing [connaissant] subject, or of what qualifies the subject as such (as cited in St Pierre, 2013, p. 648).

In light of revealing Descartes' fiction the emergent intellectual project of New Empiricism is laboring for a wider socio-political recognition of ontology (being) within our institutionalized and disciplined knowledge making practices. This project is not about asserting a new fiction in the hope of gaining the totalizing traction of self-evidence. Rather, it is about freeing life from the barracks self-evidence has built. It is a deeply political and ethical empirical direction that has an intense curiosity for, and hope in, the possible world(s) we might come to inhabit. In this way, as Barad (2007) suggests, ethics, epistemology and ontology might best be understood as inseparable modes of thought. Barad (2007) calls for

an appreciation of the intertwining of ethics, knowing and being - since each intraaction matters, since the possibilities for what the world may become call out in the pause that precedes each breath before a moment comes into being and the world is remade again, because the becoming of the world is a deeply ethical matter (as cited in Kuby, 2017, p. 17).

This 'ethico-onto-epistemology' is essential for a "theory of change" that aims to move beyond "the capture of a narrow scientism and reduction to an instrumentalism that meets the demands of audit culture" (Lather, 2013, p. 640643). As Lather (2013) observes "what appears to be amassing is a widespread recognition that to do less than a kind of performing forward, an enactment of the "after" of neo-liberalism, is to court not just a narrowed science but a narrowed future" (p. 643). 
In this sense, if I were to propose a future trajectory for the qualitative study of the photographic practices of pedagogical documentation it would be located on this New Empirical plane, and function in such a way that worked towards an indeterminable opening up of heterogeneous subjectivities through an engagement with visual data. The potential of this New Empirical mode moves the researcher away from the trap of representational meaning-making that supposedly provides knowledge about human activity towards a showing of what we do in the world through "an interplay of human and non-human agency" (Jackson, 2013, p. 747). Such a mode of empiricism would implicate the researcher in an intra-active (Barad, 2007) relationship with the data, embracing a material-discursive entanglement that held the potential to create new and vital realities, knowledge(s) and relationships within a specific locality.

As discussed in chapter 1 (section 1.2) this thesis formed in response to a growing feeling of unease in relation to my personal experience of photographic practices as a student and teacher in the context of early childhood education. An ethic of resistance took shape around this experience and informed the trajectory of this work, which aimed to deconstruct/problematize the assumptions and unacknowledged relations of power pertaining to the photographic practices of pedagogical documentation. Within the scope of this thesis I have suggested that an entanglement of both neoliberal and 'psy' rationalities are constitutive of particular visual-discursive practices, which mutually serve individualizing/identity fixing/normalizing ends and construct particular subjectivities at this point in history. The predominant (visual) discourses illuminated in this work and the subjectivities they are productive of are perceived to be problematic on the grounds that they place burdensome levels of responsibility on the young citizen and act to erode other educational values such as collective responsibility and community. I have further suggested that these predominant discourses are problematic in the sense that they act to foreclose other ways of thinking and being in educational settings to the effect of limiting other possible subject-positions (thought or unthought) that both child and teacher might come to inhabit within these spaces. 
This experimental empirical exercise has consisted of exploring the resonances between the visual-discursive construction of the child and broader relations of power. I have suggested that the intensive focus on the individual child through the visual medium of photography can be understood in terms of its relationship to, and contribution towards, wider governance practices of the late modern neoliberal disciplinary state. I have further suggested that the advanced/neo liberal rationalities and the individualizing/normalizing discourses they instantiate coalesce powerfully with those of the 'psy' sciences, which can be observed in particular photographic techniques present in the revised Te Whāriki (2017a) document.

In this sense I conclude that the entanglement of both 'psy'-based and neoliberal associated discourses are productive of a particular kind of educated subject, and that the photographic image making practices of pedagogical documentation are implicated in the assemblage of rationalities that inform these diffuse discursive practices in significant ways. This empirical exercise has illuminated the limits predominant (visual) discourses impose on the child subject and disturbed the taken-for-granted through a practical critique that has taken the form of possible transgression (Biesta, 2008). In this respect I call for the proliferation of empirical exercises concerned with the exploration of possible subject-positions (thought or unthought) that are potentially asphyxiated by the predominant normalizing discourses critiqued in this work. Such research would be premised on a conceptualization of thought as a process of transformation and change and hold the potential to enact an 'after' of the realities produced through the entangled rationalities of neoliberalism and the psychological sciences. 


\section{Bibliography}

Ahl, H. (2008). Motivation theory as power in disguise. In A. Fejes, \& K. Nicoll (Eds.), Foucault and lifelong learning: Governing the subject (pp. 151-164). London: Routledge.

Ailwood, J. (2005). Genealogies of Governmentality: Producing and Managing Young Children and Their Education. Australian Educational Researcher, 31(3), 19-34. https://doi.org/10.1007/BF03249526

Alasuutari, M., \& Karila, K. (2010). Framing the Picture of the Child. Children \& Society, 24(2), 100-111. https://doi.org/10.1111/j.1099-0860.2008.00209.x

Aries, P. (1962). Centuries of childhood. London: Cape.

Bachelard, G. (1984). The new scientific spirit. Boston: Beacon Press.

Ball, S. J. (1994). Education reform: a critical and post structural approach. Philadelphia: Open University Press.

Ball, S. J. (2003). The teacher's soul and the terrors of performativity. Journal of Education Policy, 18(2), 215-228. https://doi.org/10.1080/0268093022000043065

Ball, S. J. (2013). Global Education Inc: New Policy Networks and the Neoliberal Imaginary New York: Routledge.

Barad, K. (1998). Getting real: Technoscientific practices and the materialization of reality. Differences, 10(2), 87-128.

Barad, K. (2003). Posthumanist Performativity: Toward an Understanding of How Matter Comes to Matter. Signs, 28(3), 801-831. https://doi.org/10.1086/345321 
Barad, K. M. (2007). Meeting the universe halfway: quantum physics and the entanglement of matter and meaning. Durham: Duke University Press.

Barthes, R. (1977). Rhetoric of the Image. New York: Hill and Wang. Retrieved from http://huma1970a.blog.yorku.ca/files/2010/04/Barthes_Rhetoric-of-theImage.pdf

Barthes, R. (1981). Camera Lucida: reflections on photography. New York: Hill and Wang.

Barthes, R. (1982). A Barthes reader. New York: Hill and Wang.

Barthes, R. (1993). Mythologies. London: Vintage.

Baudrillard, J. (1988). Selected writings. Cambridge: Polity.

Bendix Petersen, E., Millei, Z., \& SpringerLink. (2016). Interrupting the psy-disciplines in education. London: Macmillan.

Bendix Petersen, E., \& Millei, Z. (2016). An Introduction. In E. Bendix Petersen, \& Z. Millei (Eds.), Interrupting the psy-disciplines in education (pp. 1-13). London: Macmillan.

Bendix Petersen, E. (2016). Becoming a 'learner' in the Australian primary school: An (auto)ethnographic exploration. In E. Bendix Petersen, \& Z. Millei (Eds.), Interrupting the psy-disciplines in education (pp. 59-74). London: Macmillan.

Benjamin, W. (2008). The work of art in the age of its technological reproducibility, and other writings on media. Cambridge, Mass: Harvard University Press.

Berger, J. (2008). Ways of Seeing. UK: Penguin.

Biesta, G. (2007). Why “What Works” Won't Work: Evidence-Based Practice and the Democratic Deficit in Educational Research. Educational Theory, 57(1), 1-22. https://doi.org/10.1111/j.1741-5446.2006.00241.x 
Biesta, G. (2008). Encountering Foucault in lifelong learning. In A. Fejes, \& K. Nicoll (Eds.), Foucault and lifelong learning: Governing the subject (pp. 193-206). London: Routledge.

Biesta, G. (2009). Good education in an age of measurement: on the need to reconnect with the question of purpose in education. Educational Assessment, Evaluation and Accountability (formerly: Journal of Personnel Evaluation in Education), 21(1), 33-46. https://doi.org/10.1007/s11092-008-9064-9

Bondi, L. (2005). Working the Spaces of Neoliberal Subjectivity: Psychotherapeutic Technologies, Professionalisation and Counselling. Antipode, 37(3), 497-514. https://doi.org/10.1111/j.0066-4812.2005.00508.x

Burchell, G., Gordon, C., \& Miller, P. M. (1991). The Foucault effect: studies in governmental nationality: with two lectures by and an interview with Michel Foucault. London: Harvester Wheatsheaf.

Burke, P. (2001). Eyewitnessing: the uses of images as historical evidence. Ithaca, N.Y: Cornell University Press.

Burman, E. (1997). Psychology: Market, Metaphor and Metamorphosis. Culture \& Psychology, 3(2), 143-152. https://doi.org/10.1177/1354067X9700300203

Burman, E. (2008). Deconstructing developmental psychology. London: Routledge.

Callon, M. (1986). Some elements of a sociology of translation: Domestication of the scallops and the fishermen of St Brieuc Bay. In J. Law (Eds.), Power, action \& belief: A new sociology of knowledge (pp. 196-233). London: Routledge \& Kegan Paul.

Cannella, G. S. (1997). Deconstructing early childhood education: social justice and revolution. New York: Peter Lang.

Clarke, A. E. (2005). Situational analysis: grounded theory after the postmodern turn. London: Sage Publications. Retrieved from 
http://methods.sagepub.com/book/situational-analysis

Colebrook, C. (2010). Deleuze and the meaning of life. New York: Continuum. Retrieved from http://ebookcentral.proquest.com/lib/vuw/detail.action?docID=495346

Colebrook, C. (2014). Death of the PostHuman: Essays on Extinction. Ann Arbor: Open Humanities Press. Retrieved from http://oapen.org/download?type=document $\&$ docid $=502353$

Cook, D. T. (2004). The commodification of childhood: the children's clothing industry and the rise of the child consumer. Durham: Duke University Press.

Coppock, V. (2011). Liberating the Mind or Governing the Soul? Psychotherapeutic Education, Children's Rights and the Disciplinary State. Education Inquiry, 2(3), 385-399. https://doi.org/10.3402/edui.v2i3.21990

Craw, J. (2005). Mixed-up childhood. Auckland, N.Z: Auckland Art Gallery.

Craw, J., \& Leonard, R. (2005). Inventing Childhood. In J. Craw, \& R. Leonard (Eds.), Mixed-up childhood (pp. 127-168). Auckland, N.Z: Auckland Art Gallery.

Dahlberg, G. (2005). Ethics and politics in early childhood education. New York: RoutledgeFalmer.

Dahlberg, G. (2006). Beyond quality in early childhood education and care languages of evaluation. New York: Routledge. Retrieved from http://helicon.vuw.ac.nz/login?url=http://www.VUW.eblib.com/EBLWeb/patro n/?target=patron\&extendedid=P_285984_0\&

Davies, B., \& Bansel, P. (2007). Neoliberalism and education. International Journal of Qualitative Studies in Education, 20(3), 247-259. https://doi.org/10.1080/09518390701281751

De Vos, J. (2009). Now that you know, how do you feel? The milgram experiment and psychologization. Annual review of Critical Psychology, 7, 223-246. Retrieved from https://biblio.ugent.be/publication/807086 
Dean, M. (2010). Governmentality: power and rule in modern society. London: SAGE.

Dean, M. (2014). Rethinking neoliberalism. Journal of Sociology, 50(2), 150-163. https://doi.org/10.1177/1440783312442256

Deleuze, G., \& Guattari, F. (1987). A thousand plateaus: capitalism and schizophrenia Minneapolis: University of Minnesota Press. Retrieved from http://helicon.vuw.ac.nz/login?url=http://www.VUW.eblib.com/EBLWeb/patro $\underline{n} /$ ?target=patron\&extendedid=P_310185_0

Deleuze, G., \& Guattari, F. (1988). A thousand plateaus: capitalism and schizophrenia London: Athlone.

Deleuze, G. (1990). The logic of sense. London: Athlone.

Deleuze, G. (1994). Difference and repetition. New York: Columbia University Press.

Deleuze, G., \& Guattari, F. (1994). What is philosophy? New York: Columbia University Press.

Deleuze, G. (1995). Negotiations. New York: Columbia University Press.

Deleuze, G., \& Guattari, F. (2009). Anti-Oedipus: capitalism and schizophrenia. New York: Penguin.

Education Review Office. (n.d). Part 2: Outcomes for children in early childhood education. Retrieved from http://www.ero.govt.nz/publications/he-pou-tataki-how-ero-reviews-earlychildhood-services/part-2-outcomes-for-children-in-early-childhoodeducation/

Evans, J., \& Hall, S. (1999). Visual culture: the reader. London: Sage.

Fejes, A., \& Nicoll, K. (2008). Foucault and lifelong learning: governing the subject. New York: Routledge. 
Fendler, L. (2001). Educating flexible souls: The construction of subjectivity through developmentality and interaction. In K. Hultqvist, \& G. Dahlberg (Eds.), Governing the child in the new millennium (pp. 119-142). London: RoutledgeFalmer.

Foucault, M. (1970). The order of things: an archaeology of the human sciences. London: Tavistock.

Foucault, M. (1972). The archaeology of knowledge. London: Tavistock.

Foucault, M. (1977). Discipline and punish: the birth of the prison. New York: Pantheon Books.

Foucault, M. (1982). The Subject and Power. Critical Inquiry, 8(4), 777-795. https://doi.org/10.1086/448181

Foucault, M. (1983). This is not a pipe. Berkeley: University of California Press.

Foucault, M. (1990). The history of sexuality. London: Penguin.

Foucault, M. (1991a). Governmentality. In G. Burchell, C. Gordon, \& P. Miller (Eds), The Foucault effect (pp. 87-104). Chicago: University of Chicago press.

Foucault, M. (1991b). Questions of method. In G. Burchell, C. Gordon, \& P. Miller (Eds.), The Foucault effect (pp. 73-86). Chicago: University of Chicago press.

Foucault, M. (1997). Ethics: subjectivity and truth. New York: New Press.

Foucault, M. (2007). Security, territory, population: lectures at the Collège de France, 1977-1978. New York: Macmillan.

Foucault, M., Martin, L., H, Gutman., \& Hutton, P. (1988). Technologies of the self: a seminar with Michel Foucault. Amherst: University of Massachusetts Press.

Graham, L. J. (2007). (Re)Visioning the Centre: Education reform and the "ideal" citizen 
of the future. Educational Philosophy and Theory, 39(2), 197-215.

https://doi.org/10.1111/j.1469-5812.2007.00306.x

Green, N. (1990). The spectacle of nature: landscape and bourgeois culture in nineteenth century France. New York: St Martin's Press.

Grosz, E. (1993). A thousand tiny sexes: Feminism and rhizomatics. Topoi, 12(2), 167179. https://doi.org/10.1007/BF00821854

Grosz, E. A. (2005). Time travels: feminism, nature, power. N.S.W: Allen \& Unwin.

Haggerty, M., \& Alcock, S. (2016). The changing roles of early childhood care and education in Aotearoa New Zealand: A shifting policy landscape. Global Studies of Childhood, 6(1), 136-146. https://doi.org/10.1177/2043610615625164

Haggerty, M., \& Loveridge, J. (2017). Strengthening early childhood and school sector continuities in producing the lifelong learner in Aotearoa New Zealand. Journal of Education Policy, 1-18. https://doi.org/10.1080/02680939.2017.1410576

Haraway, D. J. (1991). Simians, cyborgs, and women: the reinvention of nature. New York: Routledge.

Hsueh, Y., \& Tobin, J. (2003). Chinese Early Childhood Educators' Perspectives. Journal of Early Childhood Research, 1(1), 73-94.

https://doi.org/10.1177/1476718X030011004

Hultman, K., \& Lenz Taguchi, H. (2010). Challenging anthropocentric analysis of visual data: a relational materialist methodological approach to educational research. International Journal of Qualitative Studies in Education, 23(5), 525-542. https://doi.org/10.1080/09518398.2010.500628

Jackson, A. Y. (2013). Posthumanist data analysis of mangling practices. International Journal of Qualitative Studies in Education, 26(6), 741-748. https://doi.org/10.1080/09518398.2013.788762

James, A., \& Prout, A. (1997a). Constructing and reconstructing childhood: contemporary 
issues in the sociological study of childhood. Washington, D.C: Falmer Press.

James, A., \& Prout, A. (1997b). Constructing and reconstructing childhood: contemporary issues in the sociological study of childhood. Washington, D.C: Falmer Press.

Jay, M. (1993). Downcast Eyes: The Denigration of Vision in Twentieth-Century French Thought. London: University of California Press.

Jay, M. (2008). That visual turn: the advent of visual culture. In M. Smith (Eds.), Visual Culture Studies (pp. 182-188). London: SAGE.

Jenks, C. (1995). Visual Culture. London: Routledge.

Jenks, C. (1996). Childhood. London: Routledge.

Kampmann, J. (2004). Societalization of childhood: New opportunities? New demands? In H. Brembeck, B. Johansson, \& J. Kampmann (Eds.), Beyond the competent child: Exploring contemporary childhoods in the Nordic welfare societies (pp. 127-152). Roskilde: Roskilde University press.

Kelly, P. (2006). The Entrepreneurial Self and "Youth at-risk": Exploring the Horizons of Identity in the Twenty-first Century. Journal of Youth Studies, 9(1), 17-32. https://doi.org/10.1080/13676260500523606

Kind, S. (2013). Lively Entanglements: The Doings, Movements and Enactments of Photography. Global Studies of Childhood, 3(4), 427-441. https://doi.org/10.2304/gsch.2013.3.4.427

Kuby, C. R. (2017). Why a Paradigm Shift of "More than Human Ontologies" Is Needed: Putting to Work Poststructural and Posthuman Theories in Writers' Studio. International Journal of Qualitative Studies in Education (QSE), 30(9), 877-896. https://doi.org/10.1080/09518398.2017.1336803

Lather, P. (2013). Methodology-21: what do we do in the afterward? International Journal of Qualitative Studies in Education, 26(6), 634-645. https://doi.org/10.1080/09518398.2013.788753 
Lather, P., \& St. Pierre, E. A. (2013). Post-qualitative research. International Journal of Qualitative Studies in Education, 26(6), 629-633. https://doi.org/10.1080/09518398.2013.788752

Latour, B. (1983). Give me a laboratory and I will raise the world. In K. Knorr-Centina, \& M. Mulkay (Eds.), Science observed: Perspectives on the social study of science (pp. 141-170). London: Sage.

Latour, B. (1986). Visualization and cognition. Knowledge and Society, 6(1), 1-40.

Latour, B. (1987). Science in action: how to follow scientists and engineers through society. Cambridge, Mass: Harvard University Press.

Latour, B. (1993). We have never been modern. Cambridge, Mass: Harvard University Press.

Latour, B. (1996). On actor-network theory. A few clarifications. Soziale Welt, 47(4), 369-381.

Latour, B. (2002). What is iconoclash? Or is there a world beyond the image wars? In B. Latour, \& P. Weibel (Eds.), Iconoclash (pp. 16-42). London: MIT Press.

Latour, B. (2005). Reassembling the social: an introduction to actor-network-theory. New York: Oxford University Press.

Leander, K., \& Boldt, G. (2013). Rereading “A Pedagogy of Multiliteracies." Journal of Literacy Research, 45(1), 22-46. https://doi.org/10.1177/1086296X12468587

Lee, N. (2001). Childhood and society: growing up in an age of uncertainty. Buckingham: Open University Press.

Lenz Taguchi, H. (2013). “Becoming molecular girl”: transforming subjectivities in collaborative doctoral research studies as micro-politics in the academy. International Journal of Qualitative Studies in Education, 26(9), 1101-1116. https://doi.org/10.1080/09518398.2013.816886 
Lenz Taguchi, H. (2016). “The Concept as Method.” Cultural Studies $\leftrightarrow$ Critical Methodologies, 16(2), 213-223. https://doi.org/10.1177/1532708616634726

Lenz-Taguchi, H. (2010). Going beyond the theory/practice divide in early childhood education: introducing an intra-active pedagogy. New York: Routledge.

Lenz-Taguchi, Hillevi, H. (2009). An "Ethics of Resistance" Challenges Taken-for-Granted Ideas in Swedish Early Childhood Education. International Journal of Educational Research, 47(5), 270-282. https://doi.org/10.1016/j.ijer.2008.12.006

Liljestrand, J., \& Hammarberg, A. (2017). The social construction of the competent, selfgoverned child in documentation: Panels in the Swedish preschool. Contemporary Issues in Early Childhood, 18(1), 39-54. https://doi.org/10.1177/1463949117692270

Maclure, M. (2013). The Wonder of Data. Cultural Studies $\leftrightarrow$ Critical Methodologies, 13(4), 228-232. https://doi.org/10.1177/1532708613487863

Martin, A. D., \& Kamberelis, G. (2013). Mapping not tracing: qualitative educational research with political teeth. International Journal of Qualitative Studies in Education, 26(6), 668-679. https://doi.org/10.1080/09518398.2013.788756

Massumi, B. (2002). Parables for the virtual: movement, affect, sensation. Durham, NC: Duke University Press.

Ministry of Education (2017a). Te Whāriki: He Whāriki mātauranga mō ngā mokopuna o Aotearoa/Early childhood curriculum. Wellington, New Zealand: Mātauranga House.

Ministry of Education (2017b). Update of Te Whāriki: Report on the engagement process. Wellington, New Zealand: Mātauranga House.

Mirzoeff, N. (1999). An introduction to visual culture. New York: Routledge.

Mirzoeff, N. (2002). The Visual Culture Reader. New York: Routledge. 
Mirzoeff, N. (2009). An introduction to visual culture. New York: Routledge.

Nail, T. (2017). What is an Assemblage? SubStance, 46(1), 21-37. https://doi.org/10.3368/ss.46.1.21

Navab, A. D. (2008). Re-Picturing Photography: A Language in the Making. Journal of Aesthetic Education, 35(1), 69-84.

New Zealand Ministry of Social Development. (n.d). United Nations Convention on the Rights of the Child (UNCROC). Retrieved from https://www.msd.govt.nz/about-msd-and-our-work/publicationsresources/monitoring/uncroc/

Nguyen, X. T., \& Mitchell, C. (2017). On the Use of Visual Methodologies in Educational Policy Research. South African Journal of Education, 32(4), 479-493. https://doi.org/10.15700/saje.v32n4a654

Patrick, F. (2013). Neoliberalism, the Knowledge Economy, and the Learner: Challenging the Inevitability of the Commodified Self as an Outcome of Education. ISRN Education, 2013, 1-8. https://doi.org/10.1155/2013/108705

Petersen, E. B., \& O’Flynn, G. (2008). Neoliberal Technologies of Subject Formation: A Case Study of the Duke of Edinburgh's Award Scheme. Critical Studies in Education, 48(2), 197-211. https://doi.org/10.1080/17508480701494234

Pink, S. (2006). The future of visual anthropology: engaging the senses. New York: Routledge.

Pinney, C. (2004). Photos of the gods: the printed image and political struggle in India. London: Reaktion.

Potter, J. (1996). Discourse analysis and constructionist approaches: theoretical background. In J. T. E. Richardson (Eds), Handbook of Qualitative Methods for psychology and the social sciences (pp. 125-140). Leicester: British Psychological Society. 
Prout, A. (2005). The future of childhood. New York: Routledge.

Qvortrup, J. (1994). Childhood matters: An introduction. In J. Qvortrup, M. Burby, G. Syritta, \& H. Winterberg (Eds.), Childhood matters: Social theory, practice and politics (pp. 1-25). Aldershot: Avebury.

Rose, G. (2001). Visual methodologies: an introduction to the interpretation of visual materials. London: Sage.

Rose, G. (2012). The question of method: practice, reflexivity and critique in visual culture studies. In I. Heywood \& B. Sandywell (Eds.), The Handbook of Visual Culture (pp. 542-558). London: Berg. Retrieved from http://www.bloomsbury.com/uk/the-handbook-of-visual-culture9781847885739/

Rose, G. (2014). On the relation between "visual research methods" and contemporary visual culture. Sociological Review, 62(1), 24-46. https://doi.org/10.1111/1467954X.12109

Rose, N., \& Miller, P. (2010). Political power beyond the State: problematics of government. British Journal of Sociology, 61(1), 271-303. https://doi.org/10.1111/j.1468-4446.2009.01247.x

Rose, N. S. (1990). Governing the soul: the shaping of the private self. New York: Routledge.

Rose, N. S. (1998). Inventing our selves: psychology, power, and personhood. New York: Cambridge University Press.

Rose, N. S. (1999). Powers of freedom: reframing political thought. New York: Cambridge University Press. Retrieved from http://ebookcentral.proquest.com/lib/vuw/detail.action?docID=201623

Rose, N. S. (2007). Politics of life itself: biomedicine, power, and subjectivity in the twentyfirst century. Princeton: Princeton University Press. Retrieved from 
http://ebookcentral.proquest.com/lib/vuw/detail.action?docID=483582

Rouse, J. (1996). Engaging Science: How to Understand Its Practices Philosophically. New York: Cornell University Press.

Rousseau, J. (1911). Emile, or, on Education. Hanover, New Hampshire: Dartmouth College Press.

Saari, A., \& Harni, E. (2016). Positive Education as Translation and Conquest of Schooling. In B. Peterson, \& Z. Millei (Eds.), Interrupting the Psy-Disciplines in Education (pp. 93-110). UK: Palgrave Macmillan. Retrieved from http://link.springer.com/chapter/10.1057/978-1-137-51305-2_6

Smith, K. (2012). Producing Governable Subjects: Images of Childhood Old and New. Childhood: A Global Journal of Child Research, 19(1), 24-37. https://doi.org/10.1177/0907568211401434

Smith, M. (2008). Visual culture studies. London: SAGE. Retrieved from http://sk.sagepub.com/books/visual-culture-studies

Sontag, S. (1978). Susan Sontag on photography. London: Allen Lane.

Spinoza, B. (1982). The ethics and selected letters. Indianapolis: Hackett Publishing.

Spivak, G. C. (1993). Outside in the teaching machine. New York: Routledge.

St. Pierre, E. A. (2004). Deleuzian Concepts for Education: The subject undone. Educational Philosophy and Theory, 36(3), 283-296. https://doi.org/10.1111/j.1469-5812.2004.00068.x

St. Pierre, E. A. (2011). Refusing human being in humanist qualitative inquiry. In N. K. Denzin \& M. D. Giardina (Eds.), Qualitative inquiry and the global crises (pp. 4055). Walnut Creek, CA: Left Coast Press.

St. Pierre, E. A. (2012). Another Postmodern Report on Knowledge: Positivism and Its Others. International Journal of Leadership in Education, 15(4), 483-503. 
https://doi.org/10.1080/13603124.2012.696710

St. Pierre, E. A. (2013). The posts continue: becoming. International Journal of Qualitative Studies in Education, 26(6), 646-657.

https://doi.org/10.1080/09518398.2013.788754

Steeves, C. (2012). (De/Re)-constructing teachers and their work: a discourse analysis of British Columbia's 21st-century policy agenda (Masters thesis, University of British Columbia). Retrieved from https://open.library.ubc.ca/cIRcle/collections/ubctheses/24/items/1.0073420

Sturken, M., \& Cartwright, L. (2001). Practices of looking: an introduction to visual culture New York: Oxford University Press.

Sturken, M., \& Cartwright, L. (2009). Practices of looking: an introduction to visual culture New York: Oxford University Press.

Tagg, J. (2009). The disciplinary frame: photographic truths and the capture of meaning. University of Minnesota Press. Retrieved from http://helicon.vuw.ac.nz/login?url=http://www.jstor.org/stable/10.5749/j.cttt v1qh\&sid=0CLC:WCDS

Taylor, C. A. (2017). Rethinking the empirical in higher education: post-qualitative inquiry as a less comfortable social science. International Journal of Research \& Method in Education, 40(3), 311-324. https://doi.org/10.1080/1743727X.2016.1256984

Tobin, J. (1995). The Irony of Self-Expression. American Journal of Education, 103(3), 233-258. https://doi.org/10.1086/444101

Tobin, J., Wu, D., \& Davidson, D. (1989). Preschool in three cultures: Japan, China, and the United States. New Haven: Yale University Press.

Tobin, J., Karasawa, M., \& Hsueh, Y. (2004). Komatsudani Then and Now: Continuity and Change in a Japanese Preschool. Contemporary Issues in Early Childhood, 5(2), 128-144. https://doi.org/10.2304/ciec.2004.5.2.2 
Tonkiss, F. (1998). Analysing discourse. In C. Seale (Eds.), Researching Society and Culture (pp. 245-260). London: Sage.

Vandenbroeck, M., \& Bie, M. B. (2006). Children's Agency and Educational Norms: A Tensed Negotiation. Childhood: A Global Journal of Child Research, 13(1), 127143. https://doi.org/10.1177/0907568206059977

Walkerdine, V. (1993). Beyond Developmentalism? Theory \& Psychology, 3(4), 451-469. https://doi.org/10.1177/0959354393034004 